\title{
Recent Updates to the MELCOR 1.8.2 Code for ITER Applications
}

\author{
Brad J. Merrill
}

May 2007

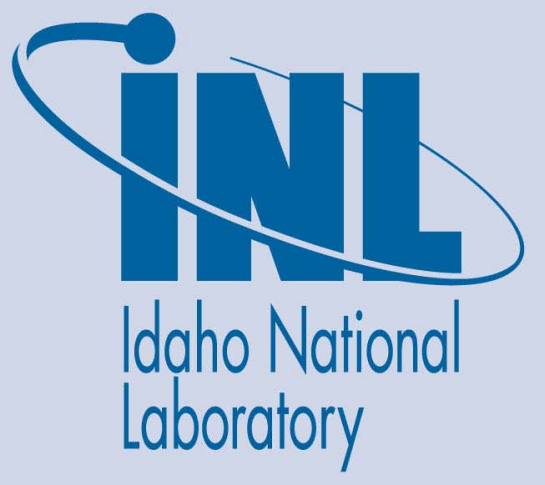

The INL is a U.S. Department of Energy National Laboratory operated by Battelle Energy Alliance 
INL/EXT-07-12493

Rev. 1

\title{
Recent Updates to the MELCOR 1.8.2 Code for ITER Applications
}

\author{
Brad J. Merrill \\ May 2007 \\ Idaho National Laboratory \\ Idaho Falls, Idaho 83415 \\ Prepared for the \\ U.S. Department of Energy \\ Office of Science Education and Technical Information \\ Under DOE Idaho Operations Office \\ Contract DE-AC07-05ID14517
}


Recent Updates to the MELCOR 1.8.2 Code for ITER Applications

INL/EXT-07-12493

April 2007

Approved by

Be al Menial
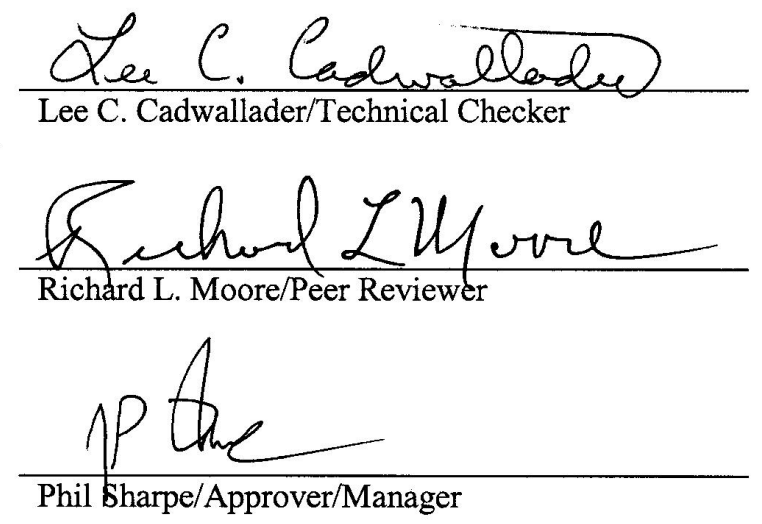

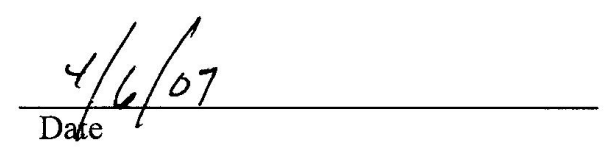

$\frac{4-6-2007}{\text { Date }}$

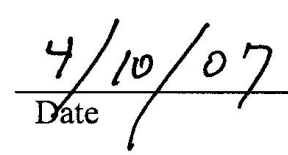

$\frac{4 / 6107}{\text { Date }}$ 


\section{ABSTRACT}

This report documents recent changes made to the MELCOR 1.8.2 computer code for application to the International Thermonuclear Experimental Reactor (ITER), as required by ITER Task Agreement ITA 81-18. There are four areas of change documented by this report. The first area is the addition to this code of a model for transporting HTO. The second area is the updating of the material oxidation correlations to match those specified in the ITER Safety Analysis Data List (SADL). The third area replaces a modification to an aerosol transport subroutine that specified the nominal aerosol density internally with one that now allows the user to specify this density through user input. The fourth area corrected an error that existed in an air condensation subroutine of previous versions of this modified MELCOR code. The appendices of this report contain FORTRAN listings of the coding for these modifications. 



\section{CONTENTS}

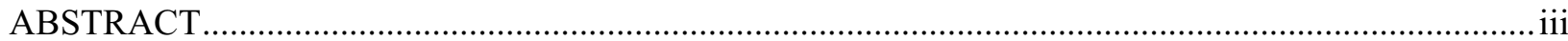

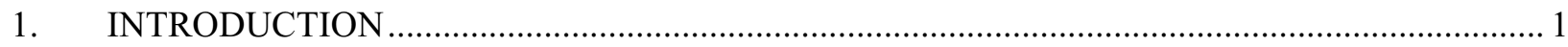

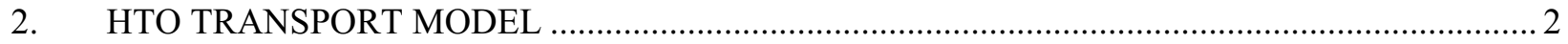

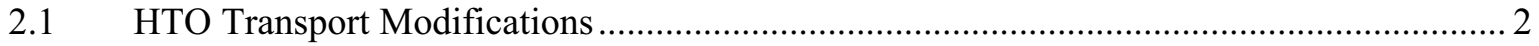

2.2 HTO Transport Modification Test Problems................................................................ 3

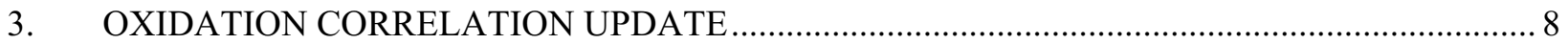

4. CORRECTIONS TO THE AEROSOL TRANSPORT SUBROUTINE RN1RN4 ….................... 11

5. CORRECTIONS TO THE AIR CONDENSATION SUBROUTINES ..................................... 12

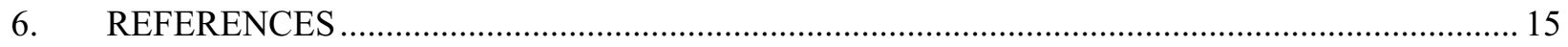

Appendix A- Code Listing of changes to MELCOR for HTO Transport Model .................................... 16

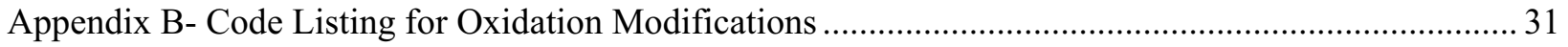

Appendix C- Code Listing for Aerosol Transport Modifications ....................................................... 50

Appendix D- Code Listing for Air Condensation Model Modifications ….............................................. 54

\section{FIGURES}

1. HTO pool and atmosphere masses for HTO transport test problem one …........................................ 4

2. HTO pool and atmosphere masses for HTO transport test problem two...................................... 5

3. HTO pool and atmosphere masses for HTO transport test problem three................................ 6

4. Total HTO pool and atmosphere masses for HTO transport test problem three ......................... 7

\section{TABLES}

1. Comparison of condensation model enthalpy change with values from Reference 10 for oxygen ........ 14

2. Comparison of condensation model enthalpy change with values from Reference 10 for nitrogen....... 14 


\section{Recent Updates to the MELCOR 1.8.2 Code for ITER Applications}

\section{INTRODUCTION}

This report documents recent changes made to the MELCOR 1.8.2 computer code ${ }^{1}$ for application to the International Thermonuclear Experimental Reactor (ITER), as required by ITER Task Agreement ITA $81-18 .^{2}$ There are four areas of change documented by this report. The first area is the addition to this code of a model for transporting tritiated water (HTO). The second area is the updating of the material oxidation correlations to match those specified in the latest version of the ITER Safety Analysis Data List (SADL). ${ }^{3}$ The third area replaces a modification to an aerosol transport subroutine that specified the nominal aerosol density internally with one that now allows the user to specify this density through user input. The fourth area corrected an error that existed in an air condensation subroutine of previous versions of this modified MELCOR code. The sections which follow describe these changes in more detail. 


\section{HTO TRANSPORT MODEL}

A simple transport model for tritiated water (HTO) was added to a modified version the MELCOR 1.8.2 code for use in ITER safety analyses. ${ }^{4}$ The new version of MELCOR 1.8.2 was used for the ITERFEAT Generic Site Safety Report (GSSR) ${ }^{5}$ analyses, but this particular feature was until now undocumented. This HTO transport model allows MELCOR to track tritium releases from components inside of the ITER vacuum vessel (VV) to the environment during accident conditions. A conservative assumption that has been adopted by ITER regarding tritium is that unless otherwise justified, any tritium gas mobilized will be immediately oxidized and be released in the oxide form (HTO), which is much more radiotoxic than the elemental tritium gas $\left(\mathrm{T}_{2}\right){ }^{6}$ Once HTO is released into the atmosphere of a given enclosure, HTO will act like water by condensing on cooler surfaces such as a water pool or a building wall, evaporating from a hot water pool or wall, and moving between enclosures as a flowing gas. The following sub-sections of this report present the equations and assumptions on which this model is based, and present the results of three test problems that demonstrate that the model is working properly. Finally, because the intent of this report is to document modifications made to the MELCOR -1.8.2 code, Appendix A contains a FORTRAN listing of the changes made to MELCOR 1.8.2 for this HTO transport model.

\subsection{HTO Transport Modifications}

This HTO transport model accounts for HTO transport as a result of mass movement between volumes of a MELCOR model and between the pool and atmosphere of a given MELCOR volume by the mechanism of bulk boiling, bulk condensation, and surface condensation. To minimize the effort of implementing this model in MELCOR, the aerosol mass transport equations solved by MELCOR were adapted for use by this HTO transport model. As this version of MELCOR now operates, the first fifteen material classes remain the standard MELCOR classes, but if there are more than fifteen material classes, that is, the user has defined additional material classes, and if the highest material class is designated HTO, then the HTO transport model is activated. For the HTO material class, the aerosol agglomeration and deposition processes are bypassed since HTO is a gas or liquid and not aerosol. The resulting conservation of mass equations that constitute this HTO transport model can be written as follows:

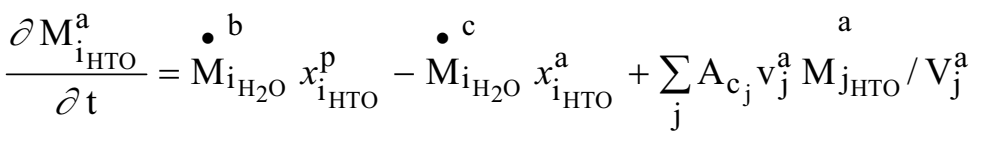

$$
\begin{aligned}
& \text { a } \\
& -\sum_{\mathrm{i}} \mathrm{A}_{\mathrm{c}_{\mathrm{i}}} \mathrm{v}_{\mathrm{i}}^{\mathrm{a}} \mathrm{M}_{\mathrm{i}_{\mathrm{HTO}}} / \mathrm{V}_{\mathrm{i}}^{\mathrm{a}}-\sum_{1} \mathrm{~A}_{\mathrm{s}_{1}} \Gamma_{1_{\mathrm{H}_{2} \mathrm{O}}}^{\mathrm{c}} x_{\mathrm{i}_{\text {HTO }}}^{\mathrm{a}}
\end{aligned}
$$

for the atmosphere of the "ith" control volume, where

$$
\begin{aligned}
& \mathrm{M}_{\mathrm{i}_{\text {нто }}} \text { is the mass of HTO in the atmosphere }(\mathrm{kg}) \\
& \text {. b } \\
& \dot{\mathrm{M}}_{\mathrm{i}_{2} \mathrm{O}} \text { is the bulk pool } \mathrm{H}_{2} \mathrm{O} \text { boiling rate }(\mathrm{kg} / \mathrm{s}) \\
& x_{\mathrm{i}_{\text {нто }}}^{\mathrm{p}} \quad \text { is the HTO to } \mathrm{H}_{2} \mathrm{O} \text { mass ratio in the pool } \\
& \dot{\mathrm{M}}_{\mathrm{i}_{\mathrm{H}_{2} \mathrm{O}}} \text { is the bulk atmosphere } \mathrm{H}_{2} \mathrm{O} \text { condensation rate }(\mathrm{kg} / \mathrm{s}) \\
& x_{\mathrm{i}_{\text {нто }}}^{\mathrm{a}} \text { is the } \mathrm{HTO} \text { to } \mathrm{H}_{2} \mathrm{O} \text { mass ratio in the atmosphere }
\end{aligned}
$$


$A_{c_{i, j}}$ are cross-sectional flow areas of flow paths between volumes $i, j\left(\mathrm{~m}^{2}\right)$

$\mathrm{v}_{\mathrm{i}, \mathrm{j}}^{\mathrm{a}} \quad$ are atmosphere flow velocities of flow paths between volumes $\mathrm{i}, \mathrm{j}(\mathrm{m} / \mathrm{s})$

$\mathrm{V}_{\mathrm{i}, \mathrm{j}}^{\mathrm{a}} \quad$ are atmosphere volumes in control volumes $\mathrm{i}, \mathrm{j}\left(\mathrm{m}^{3}\right)$

$A_{s_{1}} \quad$ is the surface area of the "lth" heat structure $\left(\mathrm{m}^{2}\right)$

$\Gamma_{1_{\mathrm{H}_{2} \mathrm{O}}}^{\mathrm{c}}$ is the $\mathrm{H}_{2} \mathrm{O}$ condensation flux on the "lth" heat structure $\left(\mathrm{kg} / \mathrm{m}^{2}-\mathrm{s}\right)$

and, as:

$$
\begin{array}{r}
\frac{\partial M_{i_{H T O}}^{p}=-M_{i_{H_{2} O} O} x_{i_{H T O}}^{p}}{\partial t}+\dot{M}_{i_{H_{2} O} O}^{c} x_{i_{H T O}^{a}}^{a}+\sum_{j} A_{c_{j}} v_{j}^{p} M_{j_{H T O}}^{p} / V_{j}^{p} \\
-\sum_{i} A_{c_{i}} v_{i}^{p} M_{i_{H T O}}^{p} / V_{i}^{p}+\sum_{l} A_{s_{l}} \Gamma_{l_{H_{2} O}}^{c} x_{i_{H T O}}^{a}
\end{array}
$$

for the pool of the "ith" control volume, where

$$
\begin{array}{ll}
\mathrm{M}_{\mathrm{i}_{\text {нто }}}^{\mathrm{p}} & \text { is the mass of HTO in the pool }(\mathrm{kg}) \\
\mathrm{V}_{\mathrm{i}, \mathrm{j}}^{\mathrm{p}} & \text { are pool flow velocities of flow paths between volumes } \mathrm{i}, \mathrm{j}(\mathrm{m} / \mathrm{s}) \\
\mathrm{V}_{\mathrm{i}, \mathrm{j}}^{\mathrm{p}} & \text { are pool volumes in control volumes } \mathrm{i}, \mathrm{j}\left(\mathrm{m}^{3}\right) .
\end{array}
$$

As is the case with all of the MELCOR aerosol material classes, this HTO transport model tracks the mass in all of the user defined aerosol bins, even though an aerosol size distribution has no meaning for the HTO material class. The input for this model is the standard MELCOR user input for a user defined material class. However, film retention of HTO is not considered by this model.

\subsection{HTO Transport Modification Test Problems}

Three problems were developed to test the operation of this HTO transport model. The first problem is a single control volume that contains water. Within the water pool of this control volume resides one kilogram of HTO. Energy inputs to the pool and atmosphere of this control volume are defined so that the pool boils dry, and then the atmosphere re-condensed within an arbitrary time span of 1000 seconds. This problem tests the movement of HTO between the liquid and vapor phases of water due to direct energy inputs into the water. Figure 1 contains the pool and atmosphere HTO masses for this test problem. As can be seen, total mass is being conserved, and the time histories of these quantities appear as a conjugate pair.

The second test problem adds a heat structure to the control volume of the first test problem. The boundary condition for the back of this heat structure is defined to boil the pool dry, and then re-condense the atmosphere within an arbitrary time span of 1000 seconds. This problem tests the movement of HTO between phases due to heat transfer driven mass transport processes. Figure 2 contains the pool and atmosphere HTO masses for this test problem. As can be seen, total mass is being conserved, and the time histories of these quantities appear as a conjugate pair.

The final test problem is a two control volume problem, where in the first control volume a pool energy source is used to boil off the liquid, and in the second control volume an atmosphere energy sink is used to re-condense this vapor. These control volumes are connected by a single flow path. This test 
problem checks the transport of the HTO between control volumes. Figure 3 contains the pool and atmosphere HTO masses for volumes 1 and 2. The pool mass in volume 1 boils off in 250 seconds, the atmosphere HTO masses rise to about $0.5 \mathrm{~kg}$ as flow between volumes distributes the vaporized HTO, and then the pool HTO mass in volume 2 approaches $1.0 \mathrm{~kg}$ as the atmosphere in volume 2 re-condenses following 750 seconds. The total HTO mass in the atmosphere and pool appear in Figure 4. The trends in this figure are similar to the previous test problems. Based on the results of these test problems, the HTO transport model is working as intended.

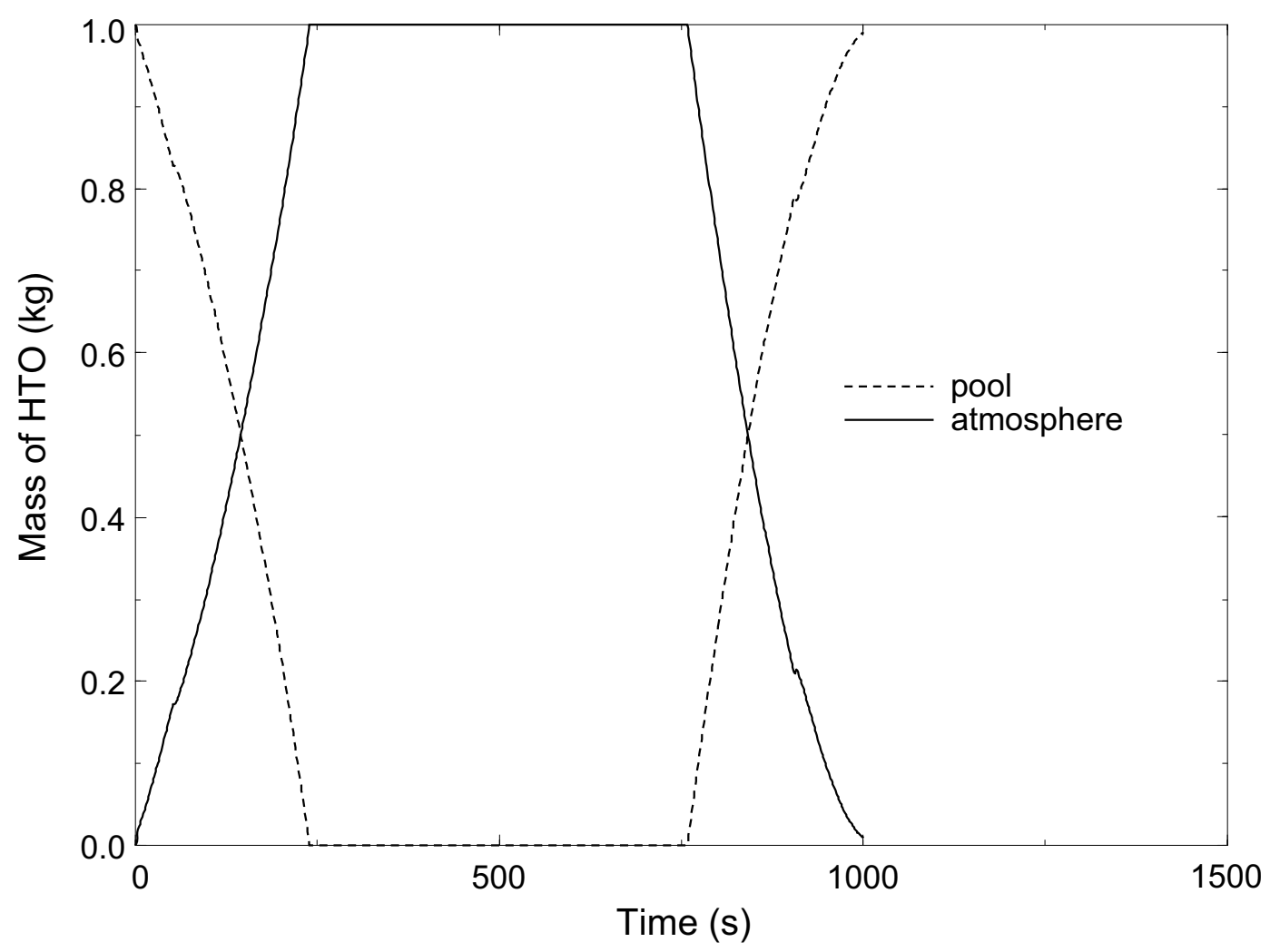

Figure 1. HTO pool and atmosphere masses for HTO transport test problem one. 


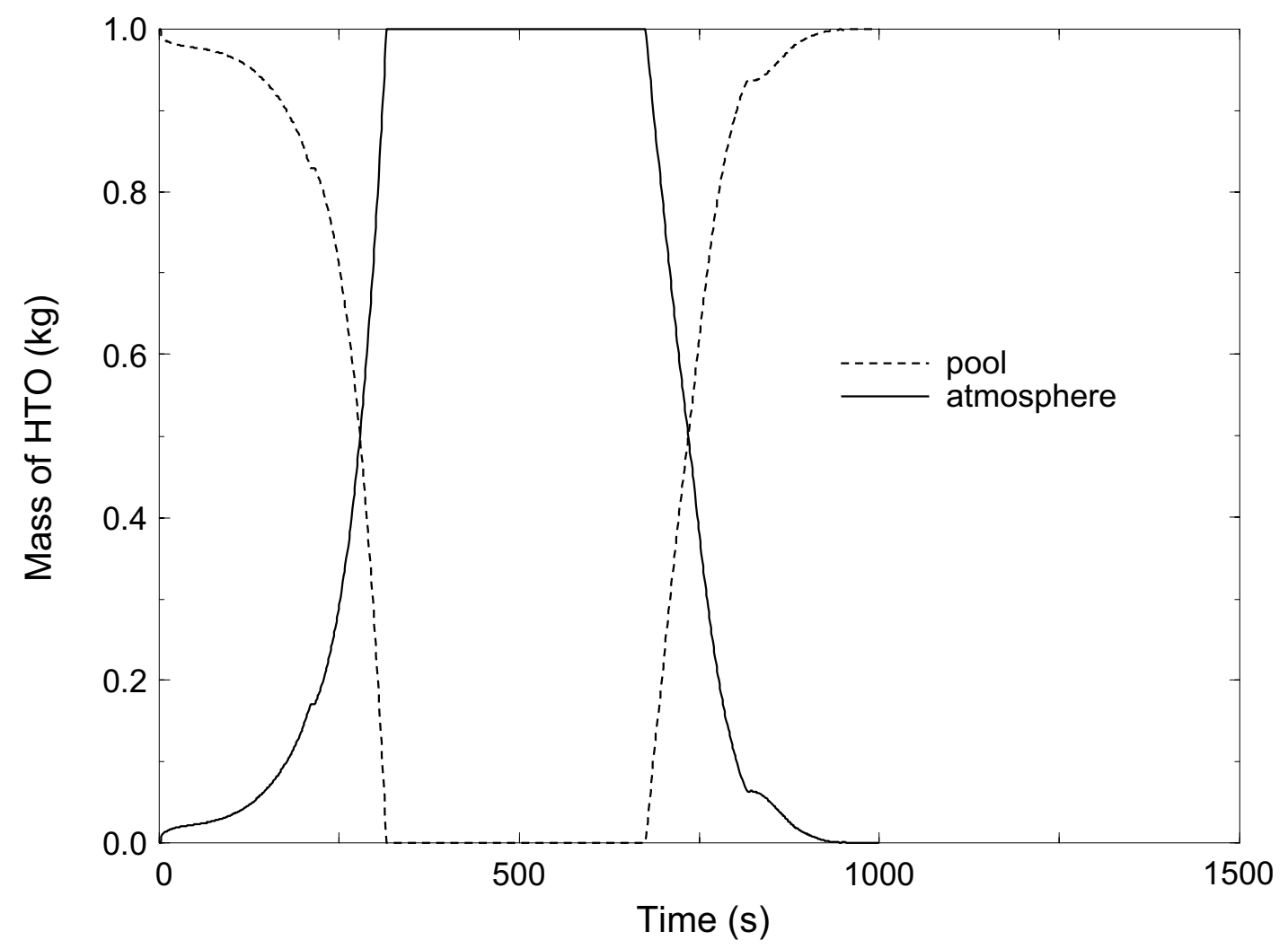

Figure 2. HTO pool and atmosphere masses for HTO transport test problem two. 


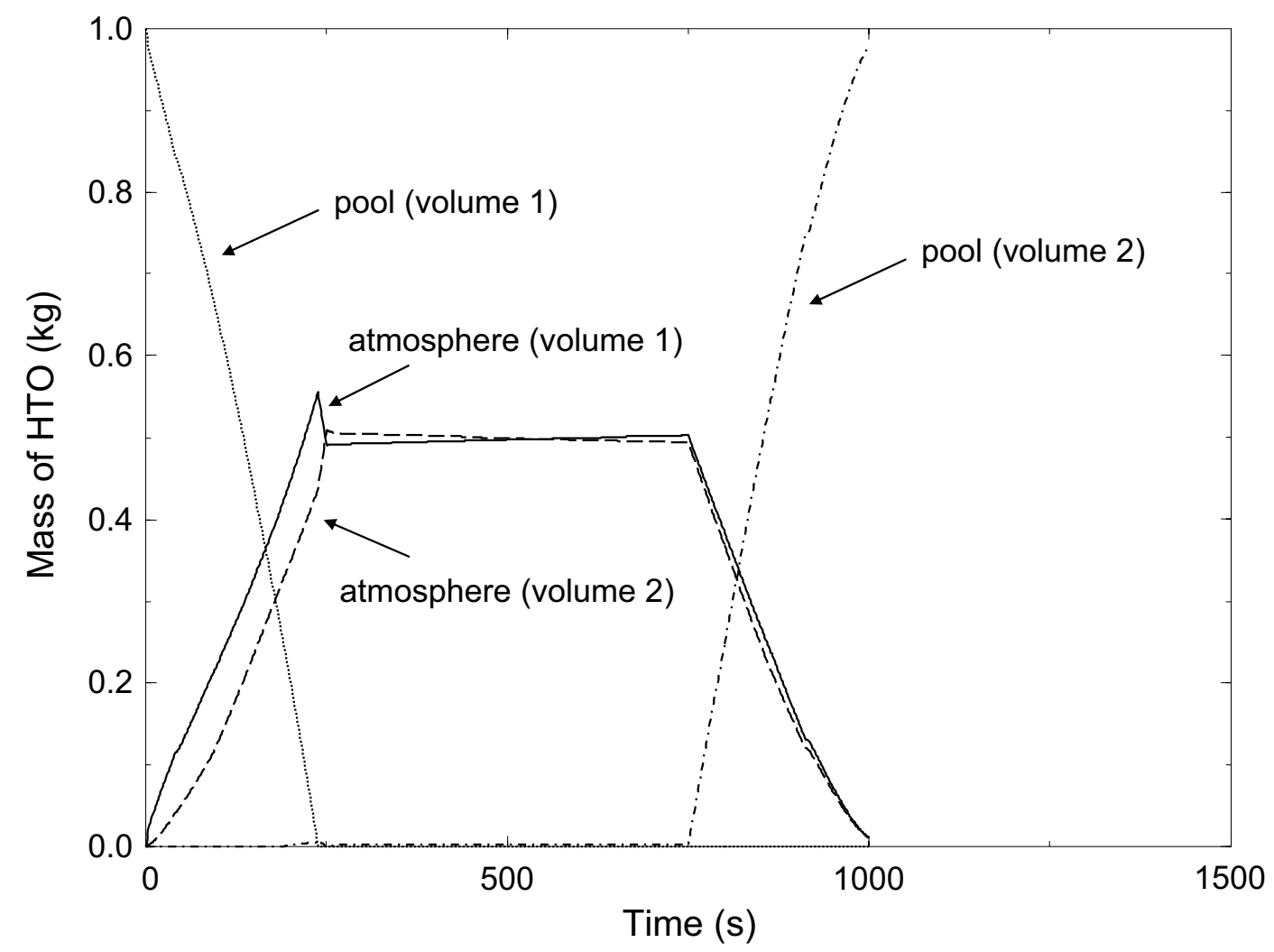

Figure 3. HTO pool and atmosphere masses for HTO transport test problem three. 


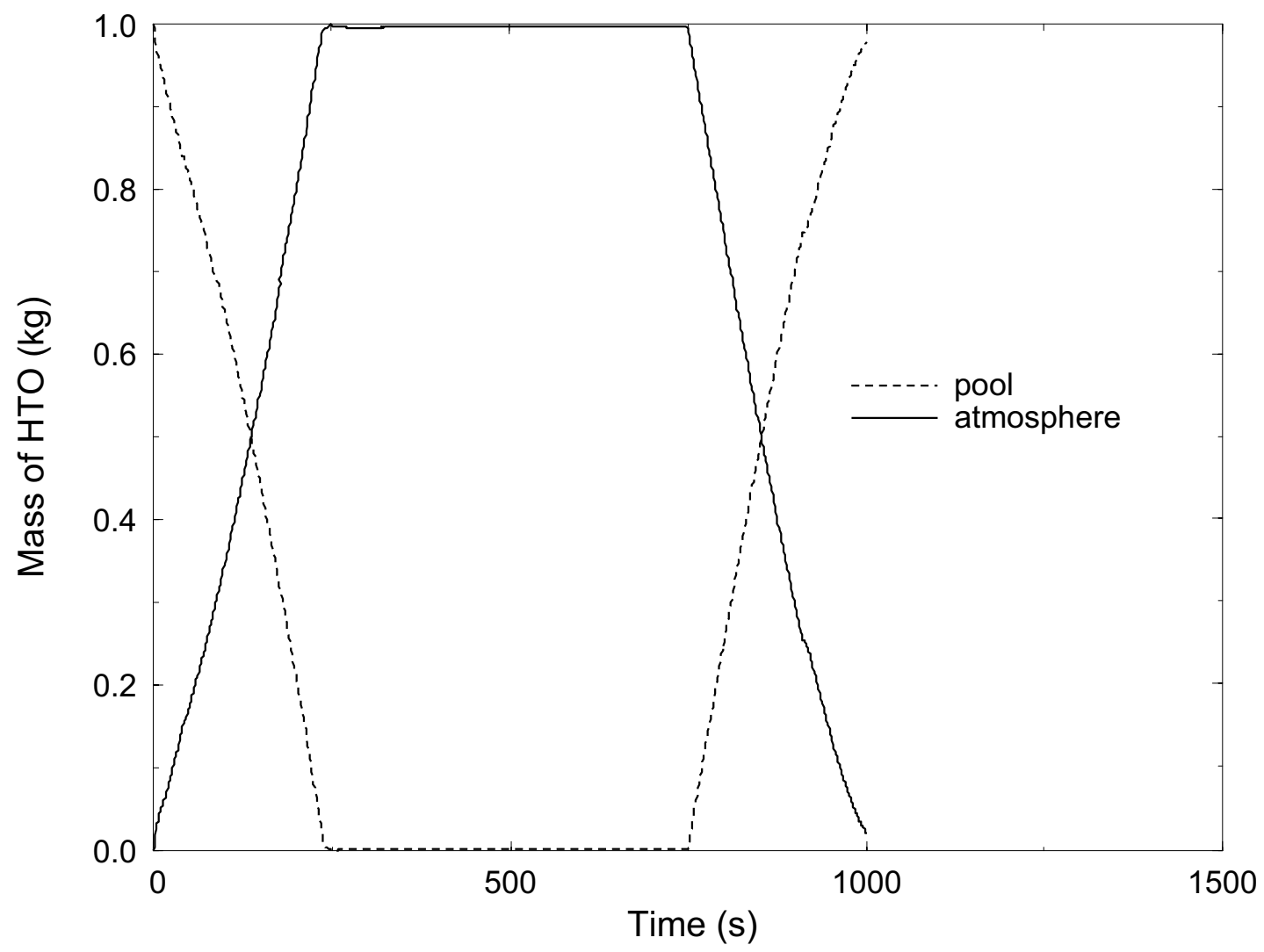

Figure 4. Total HTO pool and atmosphere masses for HTO transport test problem three. 


\section{OXIDATION CORRELATION UPDATE}

The version of MELCOR 1.8.2 used for the ITER-FEAT GSSR ${ }^{5}$ contained oxidation correlations for beryllium, graphite (carbon), and tungsten for steam only and not air. The beryllium correlations in this version of the code did not contain the latest beryllium oxidation rate equations identified in SADL$2000 .^{2}$ The changes documented in this section update these correlations and add those for air.

In the previous version of this code, ${ }^{7}$ FORTRAN coding was added to the MELCOR subroutine HSRUN2 that modified the thickness of a given heat structure at the surface if the material on that surface was either beryllium, graphite, or tungsten and the heat structure surface was exposed to steam. This model assumes that as the material oxidizes it will thin, that is the growth of an oxide film was not accounted for by this model. This thinning was accomplished in the code by changing the heat structure node positions, conduction factors and volumes used by the heat conduction equation solution of the MELCOR code as presented in Reference 8. The FORTRAN coding for these factors was copied from MELCOR subroutine HSGEOM. As the calculation proceeds, this thinning process continues until either all of the surface material on a heat structure or all of the steam in the attached control volume are consumed, and then this FORTRAN coding terminates the oxidation reaction at this heat structure surface. The oxidation correlations for the reactions were contained in a separate subroutine.

In this updated version of MELCOR 1.8.2, the oxidation FORTRAN coding described above was extracted from subroutine HSRUN2 and placed in two separate subroutines, called OXIDIZW for reactions involving steam and OXIDIZA for reactions involving air. These subroutines automatically actuate if steam or oxygen are present in the atmosphere of the control volume associated with a heat structure surface that contains materials designated by the user as either: Beryllium, Carbon, CFC, or tungsten. These new changes have the advantage of restoring subroutine HSRUN2 to near its original state, making the oxidation modifications more transparent to the quality assurance (QA) process when compared against the original version of this subroutine, while requiring the user to only specify the appropriate material name in the heat structure input to actuate this oxidation model. The new subroutines perform the same function as the FORTRAN coding removed from HSRUN2 described above. As before, the reaction rate equations were placed in two additional subroutines, the first containing reactions for beryllium, carbon, $\mathrm{CFC}$ and tungsten in water called OXIRATW and the second containing reaction rate equations for beryllium, carbon, CFC and tungsten in air called OXIRATA. A listing of these subroutines and the latest changes made to HSRUN2 appear in Appendix B.

The oxidation rate equations for beryllium in steam contained in OXIRATW as taken from $\mathrm{SADL}^{3}$ and converted to $\mathrm{kg}-\mathrm{Be} / \mathrm{m}^{2}$-s, are:

$$
\begin{aligned}
& \mathrm{R}_{\mathrm{Be}-\mathrm{H}_{2} \mathrm{O}}=\mathrm{sP}_{\mathrm{M}}\left(0.1205 \times \mathrm{e}^{-13,465 / \mathrm{T}}\right) \quad \mathrm{T}<773 \mathrm{~K} \\
& \mathrm{R}_{\mathrm{Be}-\mathrm{H}_{2} \mathrm{O}}=\mathrm{sP}_{\mathrm{M}}\left(4.378 \times 10^{15} \times \mathrm{e}^{-42,933 / \mathrm{T}}\right) \quad 773 \mathrm{~K} \leq \mathrm{T} \leq 873 \mathrm{~K} \\
& \mathrm{R}_{1}=49.398 \times \mathrm{e}^{-12,500 / \mathrm{T}} \\
& \mathrm{R}_{2}=2.571 \times 10^{7} \times \mathrm{e}^{-28,789 / \mathrm{T}} \quad \mathrm{T}<1133 \mathrm{~K} \\
& \mathrm{R}_{2}=35.357 \times \mathrm{e}^{-13,387 / \mathrm{T}} \quad \mathrm{T} \geq 1133 \mathrm{~K} \\
& \begin{array}{ll}
\mathrm{R}_{\mathrm{Be}-\mathrm{H}_{2} \mathrm{o}}=\mathrm{sP}_{\mathrm{M}} \sqrt{\mathrm{R}_{1} \mathrm{R}_{2}} \quad \mathrm{~T}>873 \mathrm{~K}
\end{array}
\end{aligned}
$$


where, $\mathrm{s}$ is a safety factor, set equal to two for design basis accidents (DBA) and to one for beyond design basis accidents (BDBA), and $\mathrm{P}_{\mathrm{m}}$ is a scaling factor for steam pressure defined as

$$
\mathrm{P}_{\mathrm{M}}=\left(\mathrm{P}_{\mathrm{H}_{2} \mathrm{O}} / \mathrm{P}_{\mathrm{o}}\right)^{0.9}
$$

where $\mathrm{P}_{\mathrm{H} 2 \mathrm{O}}$ is the transient steam pressure and $\mathrm{P}_{\mathrm{o}}$ is the steam pressure during the reaction tests from which Equations 3-5 were derived $\left(\mathrm{P}_{\mathrm{o}}=0.86 \times 10^{5} \mathrm{~Pa}\right)$.

The oxidation rate equations for carbon or CFC in steam contained in OXIRATW as taken from $\mathrm{SADL}^{3}$ and converted to $\mathrm{kg}-\mathrm{C} / \mathrm{m}^{2}-\mathrm{s}$, are:

$$
\begin{array}{ll}
\mathrm{R}_{\mathrm{C}-\mathrm{H}_{2} \mathrm{O}}=\mathrm{sP}_{\mathrm{M}}\left(8.571 \times 10^{7} \times \mathrm{e}^{-70,800 / \mathrm{RT}}\right) & \mathrm{T}<1470 \mathrm{~K} \\
\mathrm{R}_{\mathrm{C}-\mathrm{H}_{2} \mathrm{O}}=\mathrm{sP}_{\mathrm{M}}\left(5.196 \times \mathrm{e}^{-22,500 / \mathrm{RT}}\right) & \mathrm{T} \geq 1470 \mathrm{~K}
\end{array}
$$

where, $\mathrm{R}$ is the universal gas constant equal to $1.98 \mathrm{kcal} / \mathrm{kg}-\mathrm{mole}-\mathrm{K}$, the safety factor, $\mathrm{s}$, is set equal to two for DBA and to one for BDBA, and $\mathrm{P}_{\mathrm{m}}$ is a scaling factor for steam pressure defined as

$$
\mathrm{P}_{\mathrm{M}}=\left(\mathrm{P}_{\mathrm{H}_{2} \mathrm{O}} / \mathrm{P}_{\mathrm{O}}\right)
$$

and where $\mathrm{P}_{\mathrm{o}}=0.86 \times 10^{5} \mathrm{~Pa}$.

Finally, the oxidation rate equations for tungsten in steam contained in OXIRATW as taken from $\mathrm{SADL}^{3}$ and converted to $\mathrm{kg}-\mathrm{W} / \mathrm{m}^{2}-\mathrm{s}$, is:

$$
\mathrm{R}_{\mathrm{W}-\mathrm{H}_{2} \mathrm{O}}=\mathrm{SP}_{\mathrm{M}}\left(41.238 \times \mathrm{e}^{-33,106 / \mathrm{RT}}\right) \quad \mathrm{T}<1470 \mathrm{~K}
$$

where, the $\mathrm{s}$ is a safety factor is set equal to two for DBA and to one for BDBA, and $\mathrm{P}_{\mathrm{m}}$ is a scaling factor for steam pressure defined as

$$
\mathrm{P}_{\mathrm{M}}=\left(\mathrm{P}_{\mathrm{H}_{2} \mathrm{O}} / \mathrm{P}_{\mathrm{O}}\right)^{0.78}
$$

and where $\mathrm{P}_{\mathrm{o}}=0.84 \times 10^{5} \mathrm{~Pa}$.

The oxidation rate equations for beryllium in air contained in OXIRATA as taken from SADL ${ }^{3}$ and converted to $\mathrm{kg}-\mathrm{Be} / \mathrm{m}^{2}-\mathrm{s}$, are:

$$
\begin{array}{ll}
\mathrm{R}_{\mathrm{Be}-\mathrm{O}_{2}}=\mathrm{sP}_{\mathrm{M}}\left(4.833 \times 10^{5} \times \mathrm{e}^{-26,200 / \mathrm{T}}\right) & \mathrm{T}<1073 \mathrm{~K} \\
\mathrm{R}_{\mathrm{Be}-\mathrm{O}_{2}}=\mathrm{sP}_{\mathrm{M}}\left(34.83 \times \mathrm{e}^{-15,900 / \mathrm{T}}\right) & \mathrm{T} \geq 1073 \mathrm{~K}
\end{array}
$$

where, $\mathrm{s}$ is a safety factor, set equal to five for design DBA and to one for BDBA, and $\mathrm{P}_{\mathrm{m}}$ is a scaling factor for oxygen pressure defined as 


$$
\mathrm{P}_{\mathrm{M}}=\left(\mathrm{P}_{\mathrm{O}_{2}} / \mathrm{P}_{\mathrm{o}}\right)
$$

where $\mathrm{P}_{\mathrm{O} 2}$ is the transient oxygen pressure and $\mathrm{P}_{\mathrm{o}}$ is the oxygen pressure during the reaction tests upon which the above equations were derived $\left(\mathrm{P}_{\mathrm{o}}=0.181 \times 10^{5} \mathrm{~Pa}\right)$.

The oxidation rate equations for carbon in air contained in OXIRATA as taken from $\mathrm{SADL}^{3}$ and converted to $\mathrm{kg}-\mathrm{C} / \mathrm{m}^{2}-\mathrm{s}$, are:

$$
\begin{array}{ll}
\mathrm{R}_{\mathrm{C}-\mathrm{O}_{2}}=\mathrm{sP}_{\mathrm{M}}\left(0.2472 \times \mathrm{e}^{-5710 / \mathrm{T}}\right) & \mathrm{T}<1273 \mathrm{~K} \\
\mathrm{R}_{\mathrm{C}-\mathrm{O}_{2}}=\mathrm{s} \mathrm{P}_{\mathrm{M}}\left(1.56 \times 10^{-2} \times \mathrm{e}^{-2260 / \mathrm{T}}\right) & \mathrm{T} \geq 1273 \mathrm{~K}
\end{array}
$$

and for CFC taken from Reference 9 are

$$
\begin{array}{lr}
\mathrm{R}_{\mathrm{C}-\mathrm{O}_{2}}=\mathrm{SP}_{\mathrm{M}}\left(1.4754 \times 10^{7} \times \mathrm{e}^{-26,128 / \mathrm{T}}\right) & \mathrm{T}<983 \mathrm{~K} \\
\mathrm{R}_{\mathrm{C}-\mathrm{O} 2}=\mathrm{SP}_{\mathrm{M}}\left(3.6308 \times 10^{1} \times \mathrm{e}^{-13,475 / \mathrm{T}}\right) & 983 \mathrm{~K} \geq \mathrm{T} \geq 1448 \mathrm{~K} \\
\mathrm{R}_{\mathrm{C}-\mathrm{O}_{2}=}=\mathrm{SP}_{\mathrm{M}}\left(1.56 \times 10^{-2} \times \mathrm{e}^{-2260 / \mathrm{T}}\right) & \mathrm{T}>1448 \mathrm{~K}
\end{array}
$$

where, the safety factor, $\mathrm{s}$, is set equal to two for DBA and to one for BDBA, and $\mathrm{P}_{\mathrm{m}}$ is a scaling factor for oxygen pressure defined as

$$
\mathrm{P}_{\mathrm{M}}=\left(\mathrm{P}_{\mathrm{O}_{2}} / \mathrm{P}_{\mathrm{o}}\right)
$$

and where $\mathrm{P}_{\mathrm{o}}=0.181 \times 10^{5} \mathrm{~Pa}$.

Finally, the oxidation rate equations for tungsten in air contained in OXIRATA as taken from $\mathrm{SADL}^{3}$ and converted to $\mathrm{kg}-\mathrm{W} / \mathrm{m}^{2}$-s, are:

$$
\begin{array}{ll}
\mathrm{R}_{\mathrm{W}-\mathrm{O}_{2}}=\mathrm{SP}_{\mathrm{M}}\left(1.62 \times 10^{6} \times \mathrm{e}^{-24,000 / \mathrm{T}}\right) & \mathrm{T}<973 \mathrm{~K} \\
\mathrm{R}_{\mathrm{W}-\mathrm{O}_{2}}=\mathrm{sP}_{\mathrm{M}}\left(7.448 \times \mathrm{e}^{-12,170 / \mathrm{T}}\right) & \mathrm{T} \geq 973 \mathrm{~K}
\end{array}
$$

where, the $\mathrm{s}$ is a safety factor is set equal to two for DBA and to one for BDBA, and $\mathrm{P}_{\mathrm{m}}$ is a scaling factor for oxygen pressure defined as

$$
\mathrm{P}_{\mathrm{M}}=\left(\mathrm{P}_{\mathrm{O}_{2}} / \mathrm{P}_{\mathrm{o}}\right)^{0.5}
$$

and where $\mathrm{P}_{\mathrm{o}}=0.181 \times 10^{5} \mathrm{~Pa}$. 


\section{CORRECTIONS TO THE AEROSOL TRANSPORT SUBROUTINE RN1RN4}

Two changes were made to the MELCOR aerosol transport subroutine RN1RN4. The first change modified an aerosol density feature in this subroutine that had previously been specified internally, ${ }^{10}$ so as to allow the user to specify this density through user input. The original change was to the user input variable "rhonom" in the MELCOR aerosol transport input. During loss-of-coolant accidents (LOCA) analyses in ITER it was noticed that over a significant period of the transient that the aerosol mass was dominated by water droplets or fog. Often as the accident progressed, the atmosphere would dry out leaving only the aerosol particulate of interest, which is tungsten in the case of ITER. Because aerosol density greatly affects the settling rate of aerosols, and because MELCOR only allowed the user to specify a single aerosol density (rhonom), the subroutine RN1RN4 was changed internally to give a homogenous density based on water droplet and tungsten aerosol masses. Unfortunately, this change did not allow the user to specify an aerosol density other than for tungsten.

The first modification uses the input value of rhonom to calculate the homogenous or nominal aerosol density as follows:

$$
\rho_{\text {nom }}=\mathrm{x}_{\mathrm{H}_{2} \mathrm{O} \text { droplets }} \times \rho_{\mathrm{H}_{2} \mathrm{O}}+\left(1-\mathrm{x}_{\mathrm{H}_{2} \mathrm{O} \text { droplets }}\right) \rho_{\text {nom }}^{\text {user input }}
$$

where the mass fraction of water droplets $\left(\mathrm{x}_{\mathrm{H} 2 \mathrm{O}}\right)$ in the atmosphere of a given control volume is defined as:

$$
\mathrm{x}_{\mathrm{H}_{2} \mathrm{O} \text { droplets }}=\frac{\sum_{i=1}^{n \text { nins }} m_{14, i}}{\sum_{\mathrm{l}=1}^{\text {nclass }} \sum_{\mathrm{i}=1}^{\text {nbins }} \mathrm{m}_{1, \mathrm{i}}}
$$

The nomenclature "nclass" and "nbin" represents the number of aerosol material classes (class 14 is reserved by MELCOR for water droplets) and number of aerosol mass bins specified by the user for a given problem.

The second modification introduced a logical variable into RN1RN4 called "STDMEL" that switches the coding in this subroutine, upon compilation, back to its' original function. That is, switches back to the assumption that only air, at standard pressure, exists in the atmosphere of all control volumes for calculating the aerosol transport coefficients during accident analyses. This change was made to allow for comparisons against the original version of MELCOR 1.8.2 code. The FORTRAN listing of these changes appears in Appendix C. 


\section{CORRECTIONS TO THE AIR CONDENSATION SUBROUTINES}

One of the modifications made to the MELCOR 1.8.2 code for application to fusion reactors was the addition of an air condensation model. ${ }^{11}$ The reason for adding this model was to assess the impact of air entering the cryostat during accident analyses. Because the ITER magnets are at cryogenic temperatures, any air entering the cryostat would condense and freeze onto the surface of these magnets. The result would be to slow the pressurization event that ensues during air ingress accidents in the cryostat. Upon reexamination of this model, during the process of pedigreeing a version of the MELCOR 1.8.2 for ITER, it was discovered that the polynomial equations used by this model to calculate the nitrogen and oxygen saturated liquid enthalpy had different reference energies than the non-condensable equations used by the MELCOR 1.8.2 code to calculate the nitrogen and oxygen vapor enthalpy. The result was an incorrect estimate of the energy change by this model during condensation of these two gases. The affected equation of this model, restated here, is as follows:

$$
\mathrm{q}=\Gamma_{\mathrm{c}}^{\mathrm{O}_{2}}\left(\mathrm{~h}_{\mathrm{v}}-\mathrm{h}_{1_{\mathrm{sat}}}\right)_{\mathrm{O}_{2}}+\Gamma_{\mathrm{c}}^{\mathrm{N}} 2\left(\mathrm{~h}_{\mathrm{v}}-\mathrm{h}_{1_{\text {sat }}}\right)_{\mathrm{N}_{2}}
$$

where,

$\Gamma_{\mathrm{c}} \quad=$ condensation mass flux $\left(\mathrm{kg} / \mathrm{m}^{2}-\mathrm{s}\right)$

$\mathrm{h}_{\mathrm{v}} \quad=$ vapor enthalpy $(\mathrm{J} / \mathrm{kg})$

$\mathrm{h}_{1} \quad=$ liquid enthalpy $(\mathrm{J} / \mathrm{kg})$

$\mathrm{O}_{2}, \mathrm{~N}_{2}=$ represent oxygen and nitrogen

and sat $=$ saturated state

To remedy this inconsistency, the following equations were adopted in place of Equation 26:

$$
\mathrm{q}=\Gamma_{\mathrm{c}}^{\mathrm{O}_{2}} \mathrm{~h}_{\mathrm{v}, \mathrm{O}_{2}}+\Gamma_{\mathrm{c}}^{\mathrm{N}} \mathrm{h}_{\mathrm{v}, \mathrm{l}_{2}}
$$

with

$$
\mathrm{h}_{\mathrm{v}, 1}=\mathrm{c}_{\mathrm{p}_{\mathrm{v}}}\left(\mathrm{T}_{\mathrm{v}}-\mathrm{T}_{1}\right)+\mathrm{h}_{\mathrm{fg}} \text { sat }
$$

where the vapor specific heat capacity, $\mathrm{c}_{\mathrm{p}}(\mathrm{J} / \mathrm{kg}-\mathrm{K})$, for oxygen and nitrogen are the ideal values for these gases as presented in Reference 12, which are $916.9 \mathrm{~J} / \mathrm{kg}-\mathrm{K}$ and $1038.3 \mathrm{~J} / \mathrm{kg}-\mathrm{K}$, respectively, and the heat of vaporization, $\mathrm{h}_{\mathrm{fg}}(\mathrm{J} / \mathrm{kg})$ is calculated from Clapeyorn's Equation as follows:

$$
\mathrm{h}_{\mathrm{fg}}=\left.\mathrm{T}\left(\frac{1}{\rho_{\mathrm{v}}}-\frac{1}{\rho_{\mathrm{f}}}\right) \frac{\mathrm{dp}}{\mathrm{dT}}\right|_{\text {sat }}
$$

where

$$
\begin{array}{ll}
\mathrm{T} & =\text { saturation temperature/heat structure surface temperature }(\mathrm{K}) \\
\rho_{\mathrm{v}} & =\text { vapor density }\left(\mathrm{kg} / \mathrm{m}^{3}\right) \\
\rho_{\mathrm{f}} & =\text { saturated liquid density }\left(\mathrm{kg} / \mathrm{m}^{3}\right) \\
\left.\frac{\mathrm{dp}}{\mathrm{dT}}\right|_{\text {sat }} & =\text { derivative of the pressure with respect to temperature at saturation }(\mathrm{Pa} / \mathrm{K})
\end{array}
$$

The derivative of saturation pressure with respect to temperature was found by numerically differentiating the saturation pressure polynomials presented in Reference 13 for oxygen or nitrogen. The gas density is defined from the ideal gas law as follows:

$$
\rho_{\mathrm{v}}=\frac{\mathrm{RT}}{\mathrm{p}}
$$


where $R$ is the Gas Constant $(\mathrm{J} / \mathrm{kg}-\mathrm{K})$ for that gas, $\mathrm{T}$ is the gas temperature $(\mathrm{K})$, and $\mathrm{p}$ is the gas pressure $(\mathrm{Pa})$. The remaining parameter that needs to be defined is the saturated liquid density which was evaluated from the polynomials presented in Reference 13, which take the following form:

$$
\rho_{\mathrm{f}}=\sum_{\mathrm{i}=1}^{6} \mathrm{D}_{\mathrm{i}}\left(1-\frac{\mathrm{T}}{\mathrm{T}_{\mathrm{c}}}\right)^{(\mathrm{i}-1) / 3}
$$

where the polynomial coefficients, $D_{i}$, and critical temperatures, $T_{c}(K)$, are also given in Reference 13 .

To verify that the energy change predicted by this model approximates that predicted by a more complete Equation of State (EOS), property values were selected at a pressure of $5.0 \times 10^{5} \mathrm{~Pa}$ and temperatures that appear in Reference 13 and compared to that predicted made by this model. The results appear in Tables 1 and 2. As can be seen, the comparison is very good.

Most of the modifications for the air condensation model have been made to MELCOR subroutines HSRUN2, HSTRAN, and HSENST. These modifications are listed in Appendix D, along with the condensation subroutines that have been added to the code. The changes to subroutines HSRUN2, HSTRAN, and HSENST are different from those described in Reference 11, and were implemented in order to return subroutine HSRUN2 closer to its' original state for ease in QA checking and new condensation subroutines have been developed to correct the energy error described above. A final change for this model relative to that described in Reference 10 has to do with the calculation of the binary gaseous diffusion coefficients. Reference 10 developed a subroutine call DABMIX. It was later discovered that the MELCOR code performed the same operations as DABMIX, so the standard MELCOR treatment was adopted by removing subroutine DABMIX and replacing the diffusion coefficient correlation in MELCOR subroutine MPVIS with that of Wilke and Lee (note Equation 21 of Reference 10). 
Table 1. Comparison of condensation model enthalpy change with values from Reference 10 for oxygen

\begin{tabular}{|c|c|c|c|c|c|c|c|c|}
\hline \multirow[b]{3}{*}{$\mathrm{T}_{\text {liq }}(\mathrm{K})$} & \multicolumn{8}{|c|}{$\mathrm{T}_{\mathrm{v}}(\mathrm{K})$} \\
\hline & \multicolumn{2}{|c|}{$\begin{array}{l}\text { Saturation } \\
\mathrm{h}_{l, \mathrm{v}}(\mathrm{kJ} / \mathrm{kg})\end{array}$} & \multicolumn{2}{|c|}{$\begin{array}{c}200 \\
\mathrm{~h}_{l, \mathrm{v}}(\mathrm{kJ} / \mathrm{kg})\end{array}$} & \multicolumn{2}{|c|}{$\begin{array}{c}300 \\
\mathrm{~h}_{l, \mathrm{v}}(\mathrm{kJ} / \mathrm{kg})\end{array}$} & \multicolumn{2}{|c|}{$\begin{array}{c}400 \\
\mathrm{~h}_{l, \mathrm{v}}(\mathrm{kJ} / \mathrm{kg})\end{array}$} \\
\hline & Model & Ref. 7 & Model & Ref. 7 & Model & Ref. 7 & Model & Ref. 7 \\
\hline 60 & 238.26 & 238.26 & 366.63 & 363.12 & 458.32 & 455.76 & 550.01 & 549.21 \\
\hline 70 & 230.50 & 230.50 & 349.70 & 346.47 & 441.39 & 439.11 & 533.08 & 532.56 \\
\hline 80 & 222.30 & 222.30 & 332.33 & 329.79 & 424.02 & 422.43 & 515.71 & 515.88 \\
\hline 90 & 213.23 & 213.23 & 314.09 & 312.99 & 405.78 & 405.63 & 497.45 & 498.78 \\
\hline
\end{tabular}

Table 2. Comparison of condensation model enthalpy change with values from Reference 10 for nitrogen

\begin{tabular}{|c|c|c|c|c|c|c|c|c|}
\hline \multirow{3}{*}{$\begin{array}{c}\mathrm{T}_{\text {liq }} \\
(\mathrm{K})\end{array}$} & \multicolumn{9}{|c|}{$\begin{array}{c}\text { Saturation } \\
\mathrm{h}_{l, \mathrm{v}}(\mathrm{kJ} / \mathrm{kg})\end{array}$} & \multicolumn{2}{c|}{$\begin{array}{c}200(\mathrm{~K}) \\
\mathrm{h}_{l, \mathrm{v}}(\mathrm{kJ} / \mathrm{kg})\end{array}$} & \multicolumn{2}{c|}{$\begin{array}{c}300(\mathrm{~K}) \\
\mathrm{h}_{l, \mathrm{v}}(\mathrm{kJ} / \mathrm{kg})\end{array}$} & \multicolumn{2}{|c|}{$\begin{array}{c}400(\mathrm{~K}) \\
\mathrm{h}_{l, \mathrm{v}}(\mathrm{kJ} / \mathrm{kg})\end{array}$} \\
\cline { 2 - 9 } & Model & Ref. 7 & Model & Ref. 7 & Model & Ref. 7 & Model & Ref. 7 \\
\hline 63.15 & 214.83 & 214.83 & 360.19 & 355.05 & 464.02 & 460.25 & 567.85 & 564.89 \\
\hline 70 & 203.14 & 208.14 & 338.12 & 342.04 & 441.95 & 447.24 & 545.78 & 551.88 \\
\hline 80 & 195.65 & 195.65 & 320.25 & 321.55 & 424.08 & 426.75 & 527.91 & 531.39 \\
\hline 90 & 180.64 & 180.64 & 294.85 & 300.62 & 398.68 & 405.82 & 502.51 & 510.39 \\
\hline
\end{tabular}




\section{REFERENCES}

1. R. O. Gauntt, et al., MELCOR Computer Code Manuals Vol. 2: Reference Manuals Version 1.8.5, NUREG/CR-6119, Vol.2, Rev. 2, SAND2000-2417/2, Sandia National Laboratories, Albuquerque, NM, May 2000.

2. N. Taylor, "Support and Assistance for MELCOR Quality Assurance and Safety Analysis," ITER Task Agreement ITA 81-18, Task No. C81TD30FU, IDM No ITER-D-259EJK, February, 2007.

3. ITER, "Safety Analysis Data List," G 81 RI 10 03-08-08 W 0.1, Version: 4.0.3 SADL, September 26, (2003)

4. B. J. Merrill, R. L. Moore, S. T. Polkinghorne, D. A. Petti, Modifications to the MELCOR code for application in fusion accident analyses, Fus. Eng. Des. 51-52 (2000) 555-563.

5. "Generic Site Safety Report, Volume VII: Analysis of Reference Events," ITER Report, G 84 RI 6 R0.2, July (2004).

6. N. Taylor, H-W. Bartels, C. Gordon, T. Honda, "Accident Analysis Guidelines 4, Draft Version 4.1.2," ITER Report IDM Number: ITER_D_24TDZ8 v. 1.2, January (2007), p. 13.

7. B. J. Merrill, "Initial Modifications to the MELCOR Code," US ITER Participant Team Report, ITER/US/95/TE/SA-18, June 30 (1995), pp. 22-29.

8. R. O. Gauntt, et al., MELCOR Computer Code Manuals Vol. 2: Reference Manuals Version 1.8.5, NUREG/CR-6119, Vol. 2, Rev. 2, SAND 2000-2417/2, Sandia National Laboratories, Albuquerque, NM, May 2000, pages HS-RM-11-14.

9. Theron Marshall, et al., "SOMBRERO LOVA Analysis Using CFC NB31 Oxidation Data," Fusion Science and Technology, Vol. 45, No. 4, June (2004), p. 592-596.

10. B. J. Merrill, D. L. Hagrman, "MELCOR Aerosol Transport Module Modification for NSSR-1," Idaho National Engineering Laboratory Report, INEL-96/0081, March (1996).

11. B. J. Merrill, "Initial Modifications to the MELCOR Code," US ITER Participant Team Report, ITER/US/95/TE/SA-18, June 30 (1995), pp. 16-21.

12. G. J. Van Wylen, R. E. Sonntag, Fundamentals of Classical Thermodynamics, John Wiley and Sons, Inc., New York, New York, August (1968), p. 600.

13. W. C. Reynolds, Thermodynamic Properties in SI, Department of Mechanical Engineering, Stanford University, Stanford, CA, (1979), p. 119. 


\section{Appendix A}

Code Listing of Changes to MELCOR for HTO Transport Model 


\section{CHANGES TO SUBROUTINE CVHRN3}

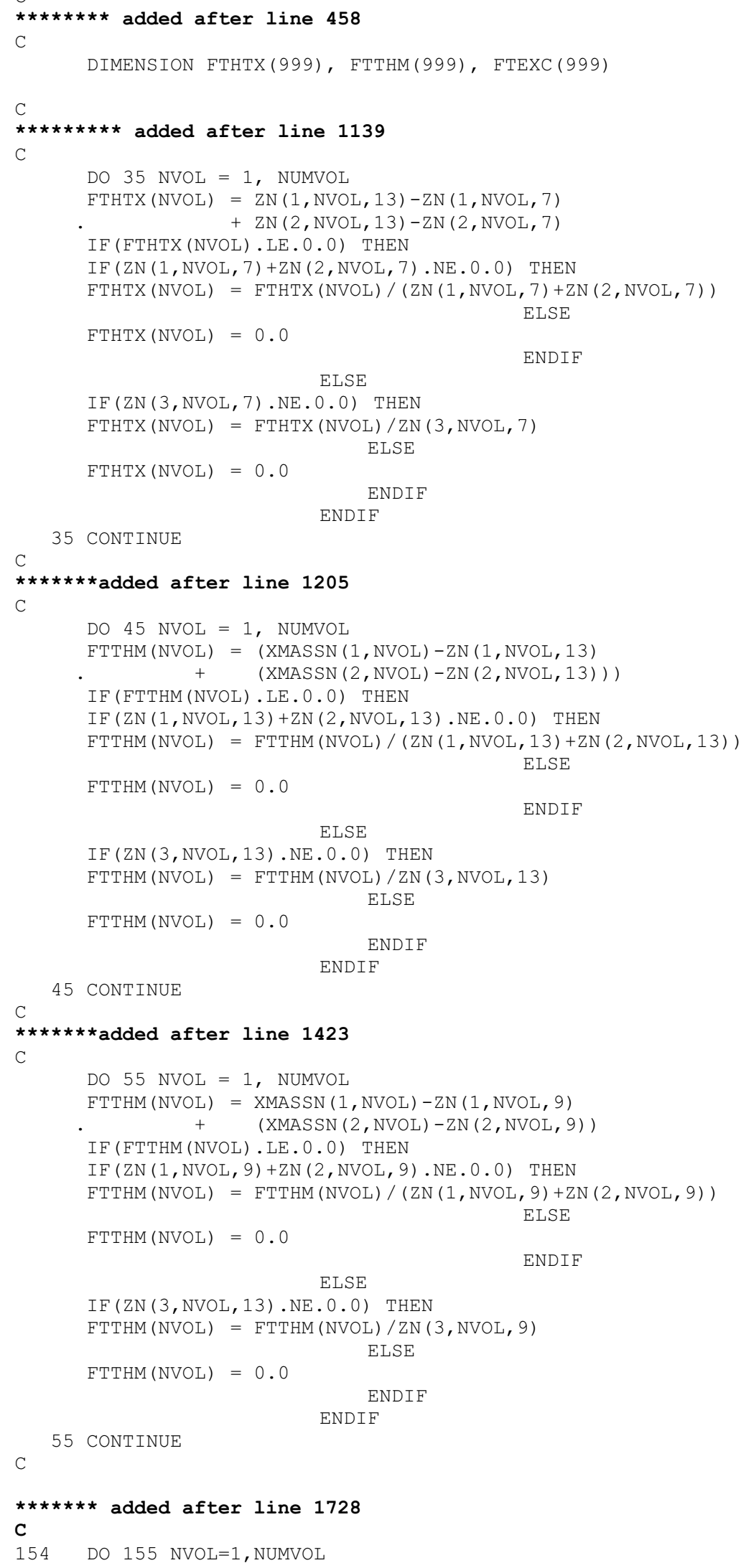




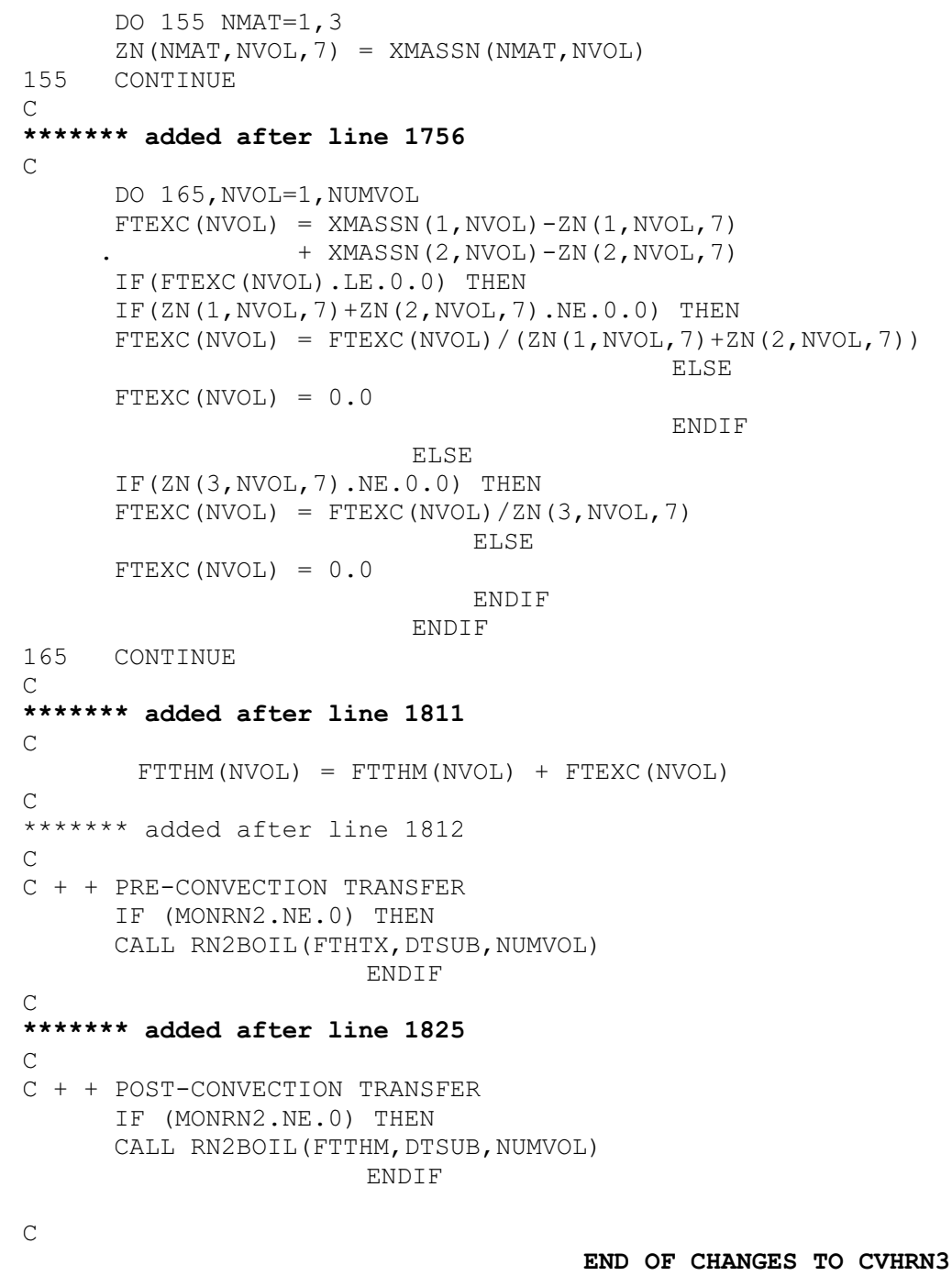


CHANGES MADE TO RN1DBC

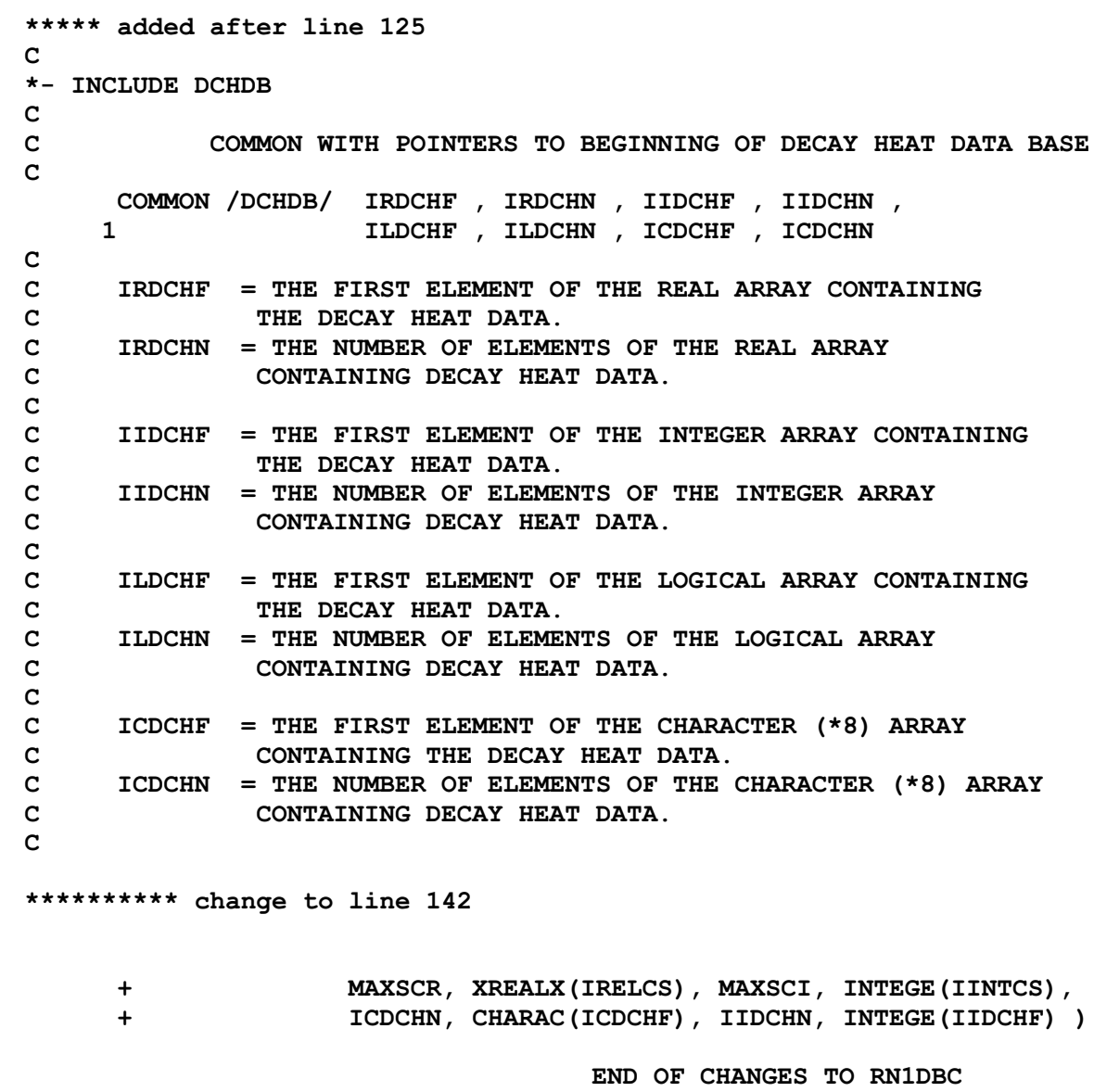


CHANGES MADE TO RN1DBD

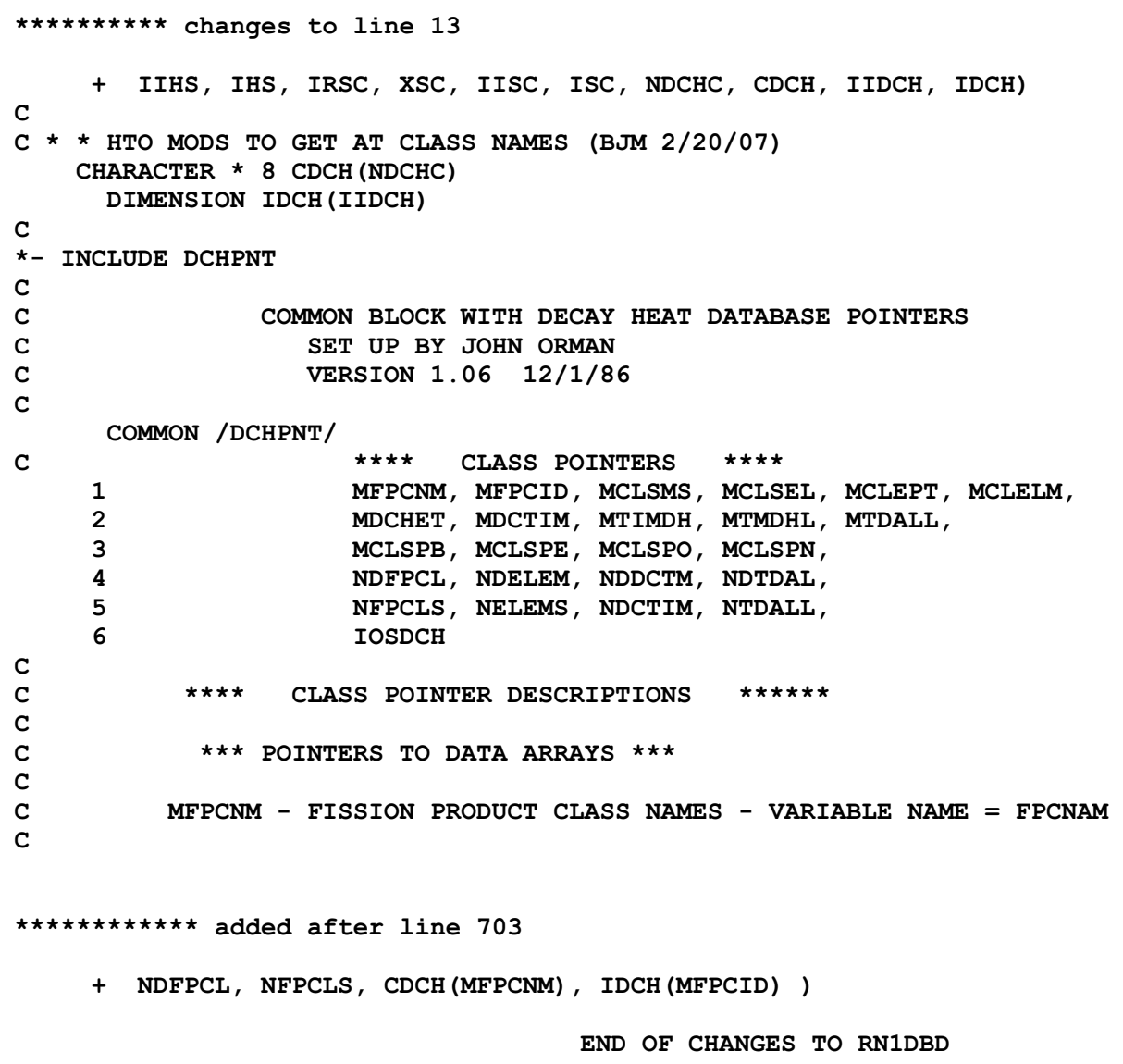


CHANGES TO SUBROUTINE RN1RN4

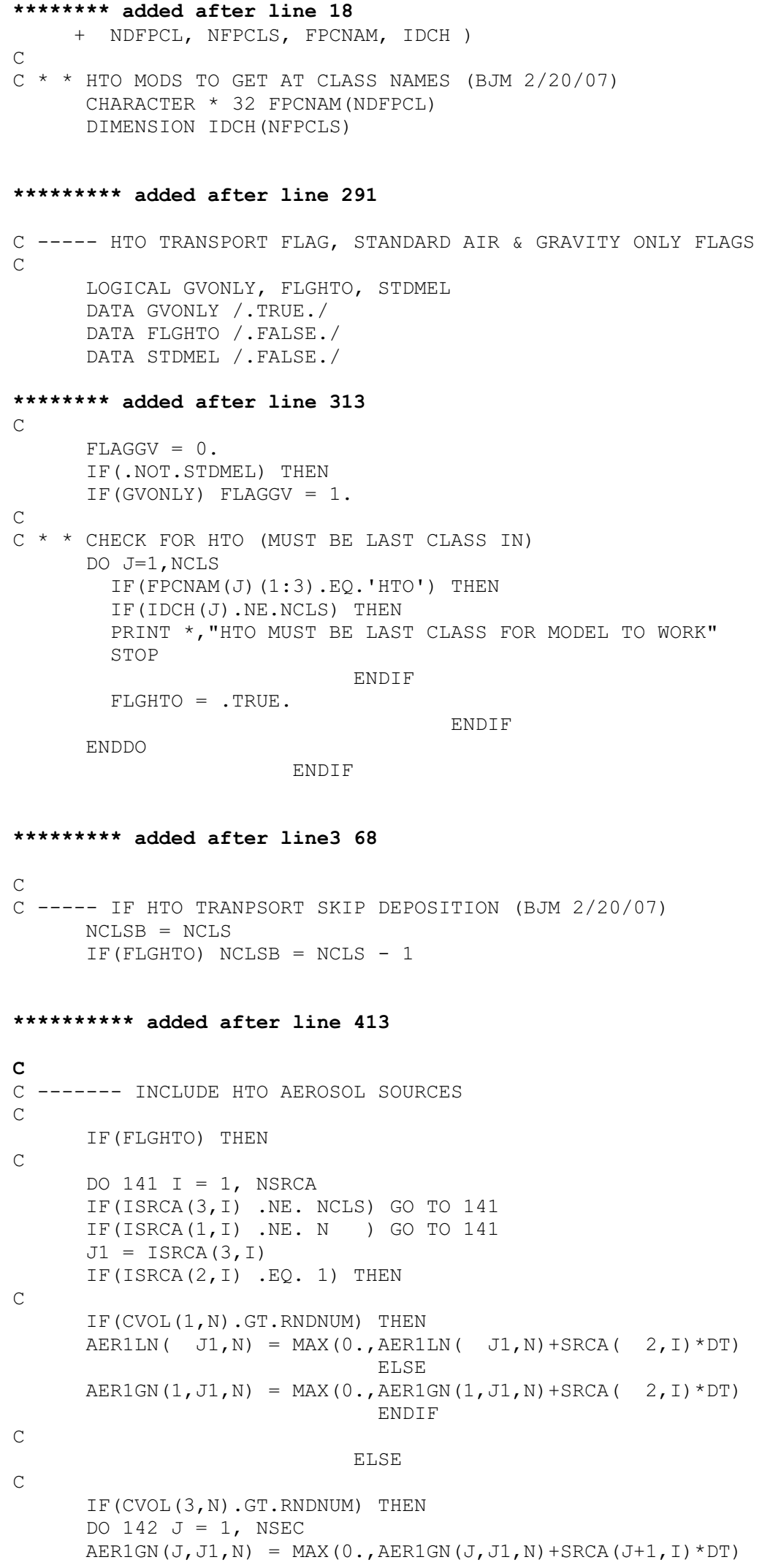




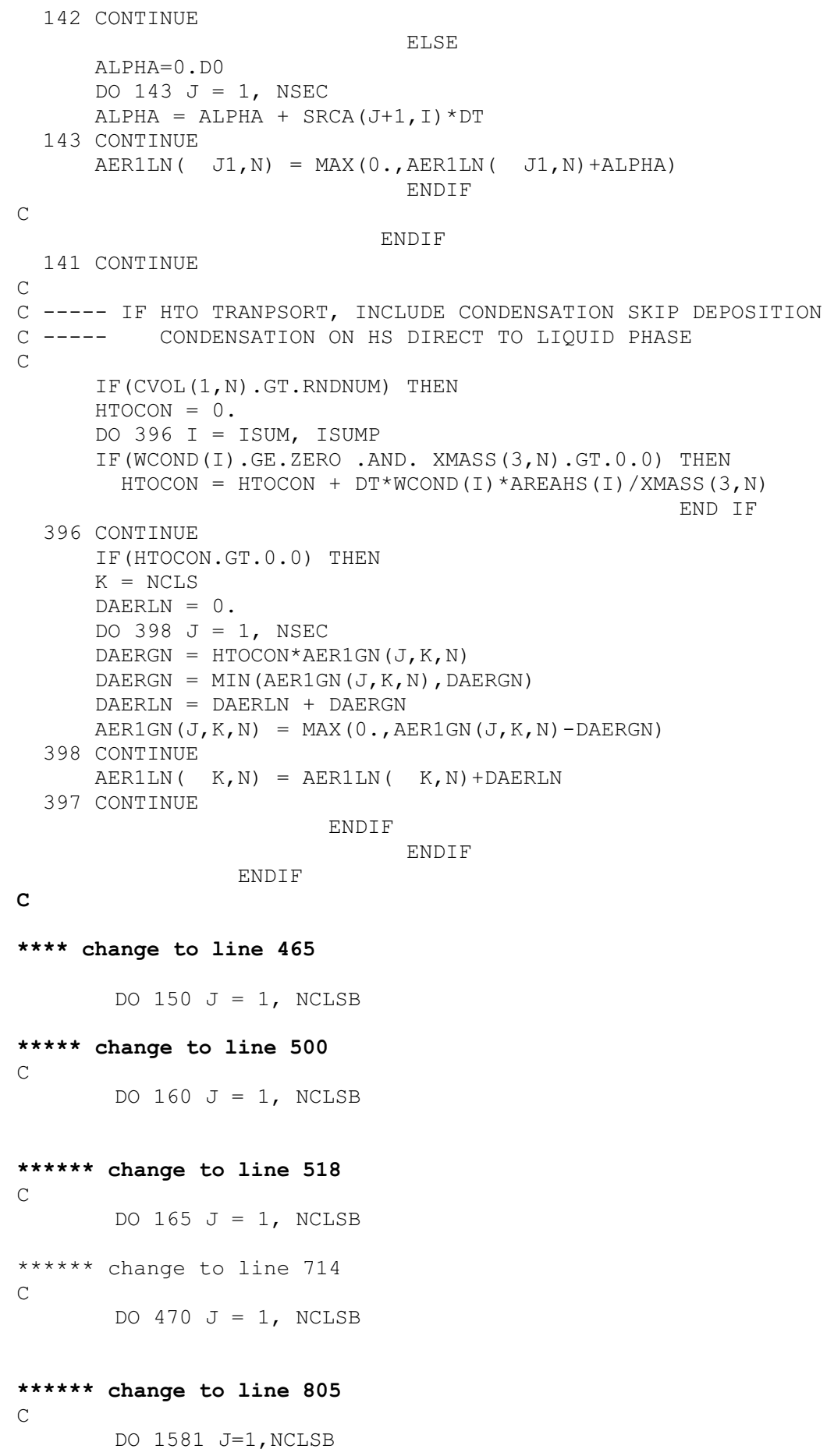

END OF CHANGES TO RN1RN4 


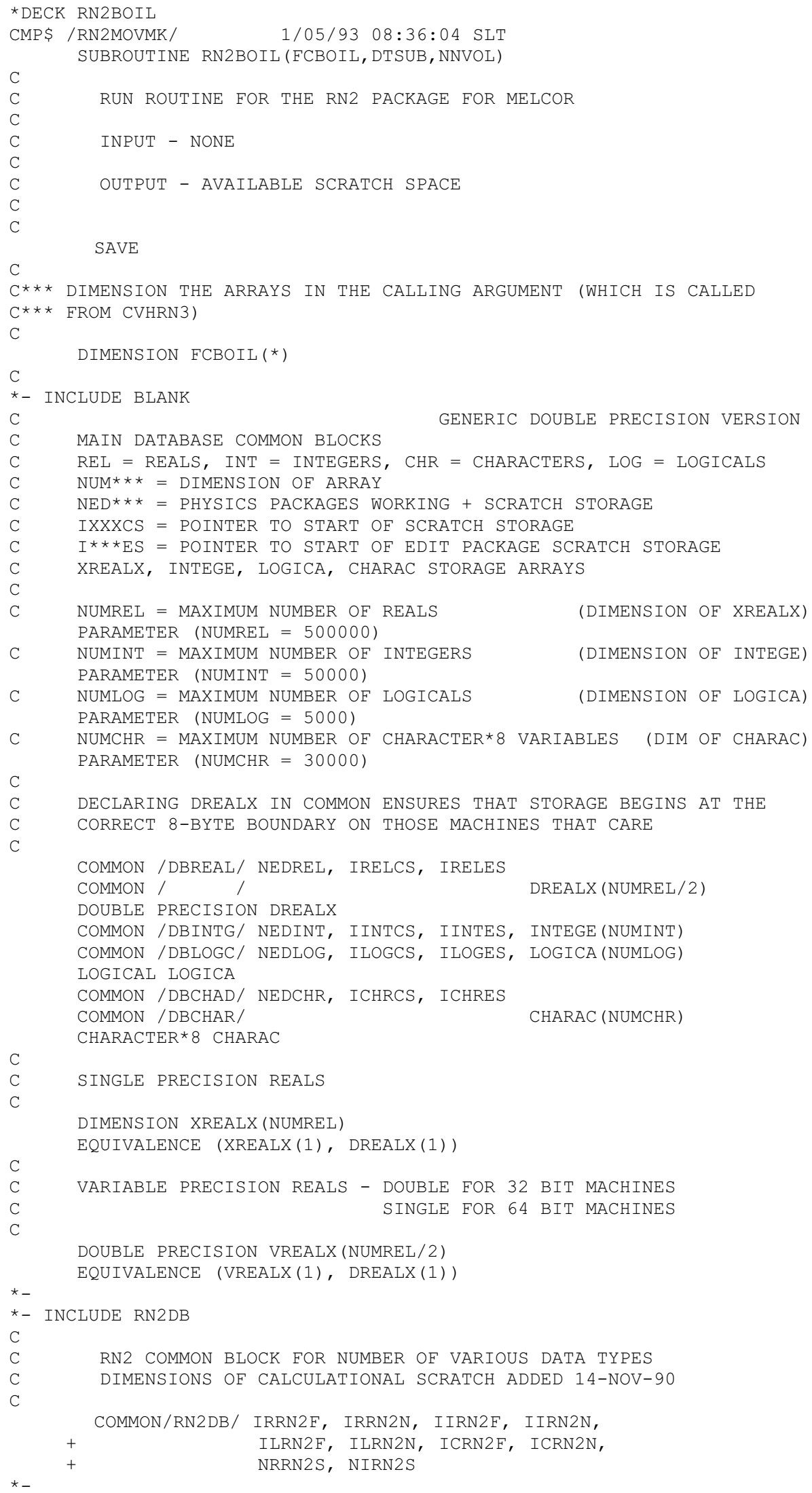




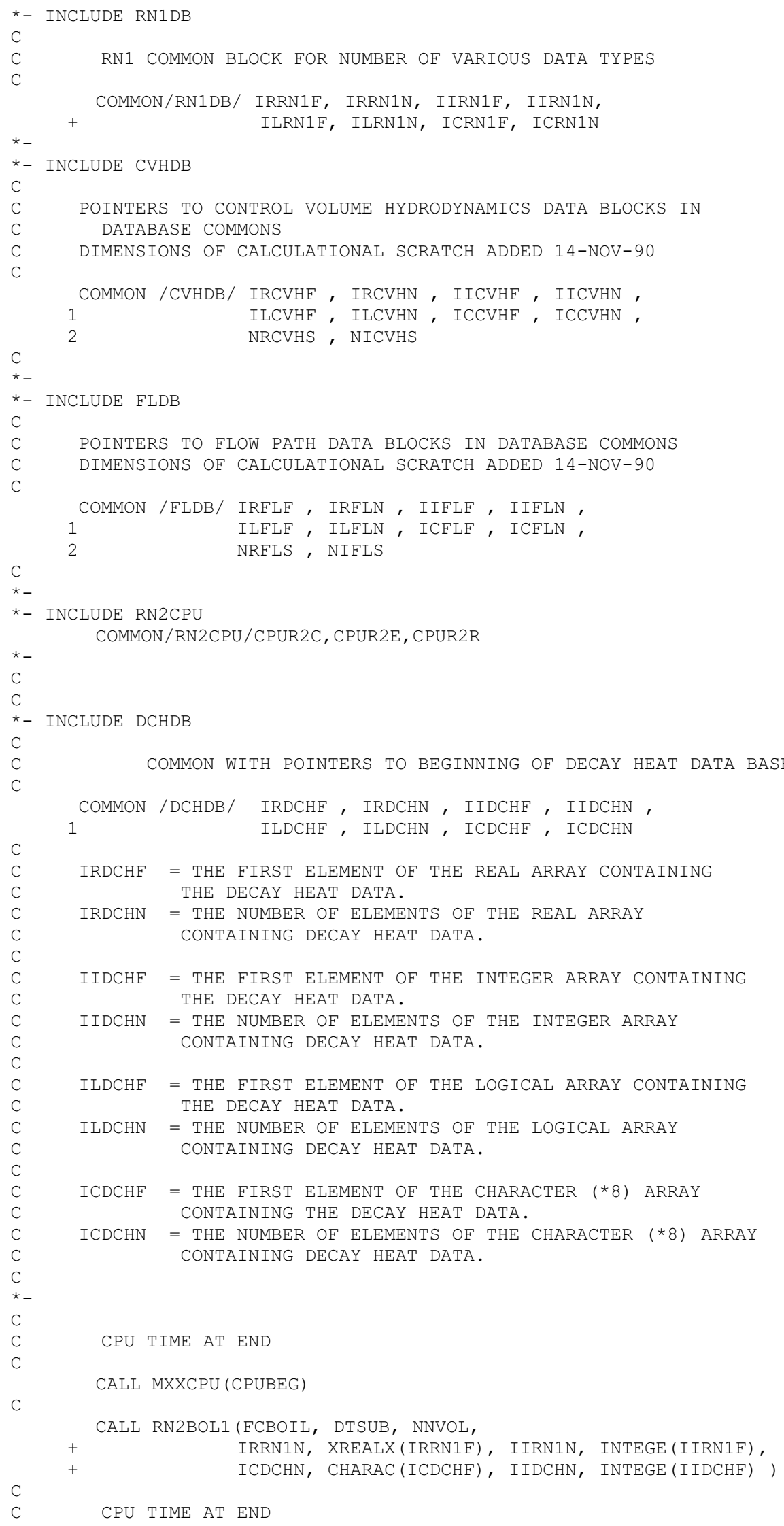


C

CALL MXXCPU (CPUEND)

C

CPUR2C $=$ CPUR2 C + CPUEND - CPUBEG

RETURN

END

*DECK RN2BOL1

SUBROUTINE RN2BOL1 (FCBOIL, DTSUB, NNVOL,

C

$+\quad$ NRRN1, XRN1, NIRN1, IRN1, NDCHC, $\mathrm{CDCH}, \mathrm{IIDCH}, \mathrm{IDCH})$

C

CHARACTER * $8 \mathrm{CDCH}(\mathrm{NDCHC})$

DIMENSION IDCH (IIDCH)

C

* INCLUDE DCHPNT

$\mathrm{C}$

C

$\mathrm{C}$

C

COMMON /DCHPNT/

COMMON BLOCK WITH DECAY HEAT DATABASE POINTERS

SET UP BY JOHN ORMAN

VERSION $1.06 \quad 12 / 1 / 86$

$\star * \star *$ CLASS POINTERS $* \star \star *$

MFPCNM, MFPCID, MCLSMS, MCLSEL, MCLEPT, MCLELM,

MDCHET, MDCTIM, MTIMDH, MTMDHL, MTDALL,

MCLSPB, MCLSPE, MCLSPO, MCLSPN,

NDFPCL, NDELEM, NDDCTM, NDTDAL,

NFPCLS, NELEMS, NDCTIM, NTDALL,

$\mathrm{IOSDCH}$

C

$\mathrm{C}$

C

C

SECOND LEVEL DATA BASE MANAGER ROUTINE

CALLED BY RN2MOV SUBROUTINE

INPUT

NRRN2 - NUMBER OF REALS IN RN2 DATABASE

XRN2 - REAL ARRAY OF RN2 DATABASE VARIABLES

NRRN1 - NUMBER OF REALS IN RN1 DATABASE

XRN1 - REAL ARRAY OF RN1 DATABASE VARIABLES

NIRN1 - NUMBER OF INTEGERS IN RN1 DATABASE

IRN1 - INTEGER ARRAY OF RN1 DATABASE VARIABLES

NISC - NUMBER OF INTEGERS IN SCRATCH DATABASE

ISC - INTEGER ARRAY OF SCRATCH DATABASE

OUTPUT

NONE

EXTERNAL CALLS - RN2MOX

MELCOR/SR MOD-1

MODIFICATION FOR RN FILTER MODEL

MELCOR REFERENCE VERSION: MELCOR V1.80 (SNL)

MELCOR/SR CYCLE: MELCOR/SR MOD-1 CYCLE B

UPDATE SEQUENCE IDENTIFIER: SRMOD1B

DIMENSION XRN1 (NRRN1), IRN1 (NIRN1), FCBOIL ( *)

C

SAVE 


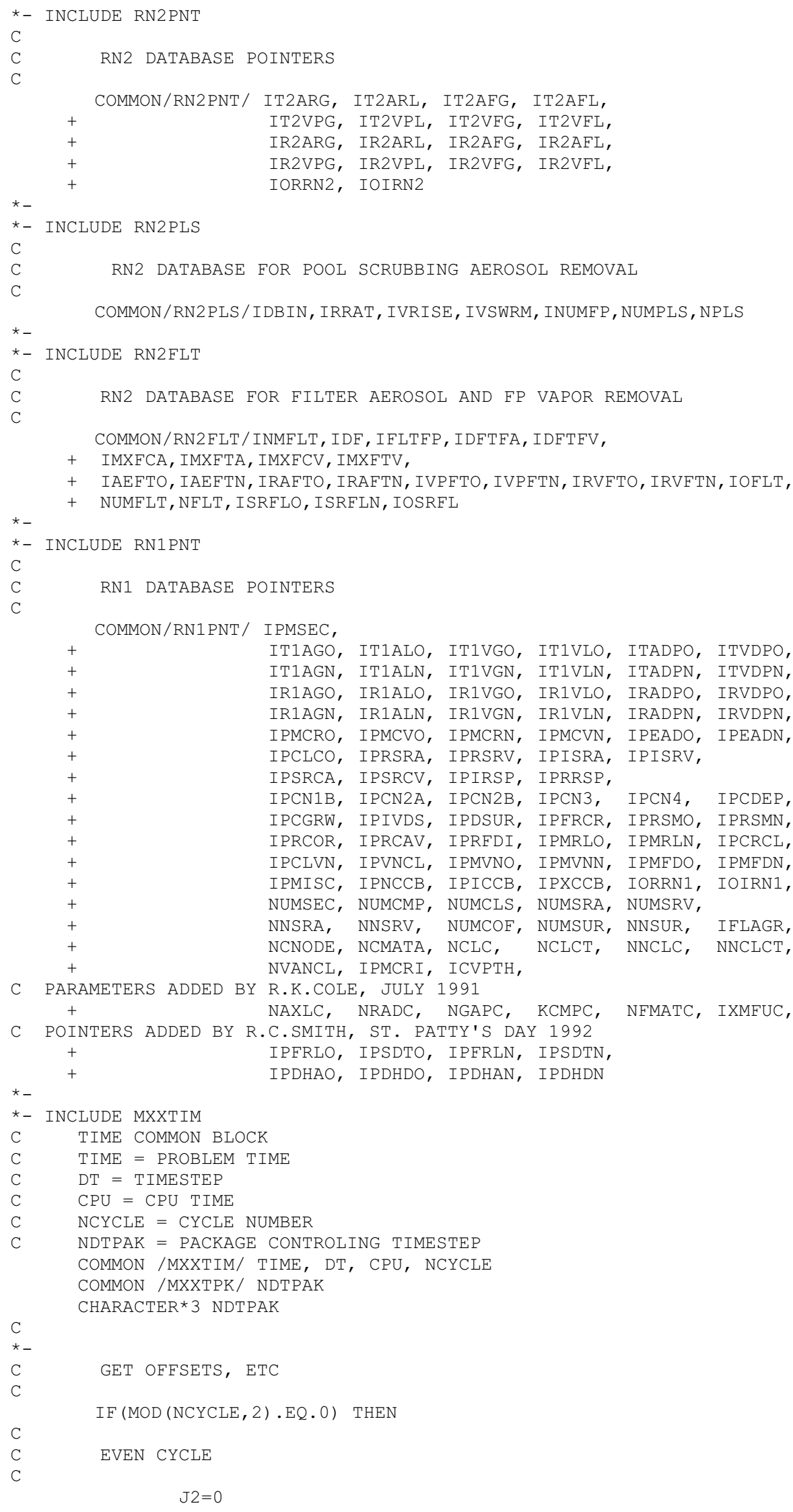




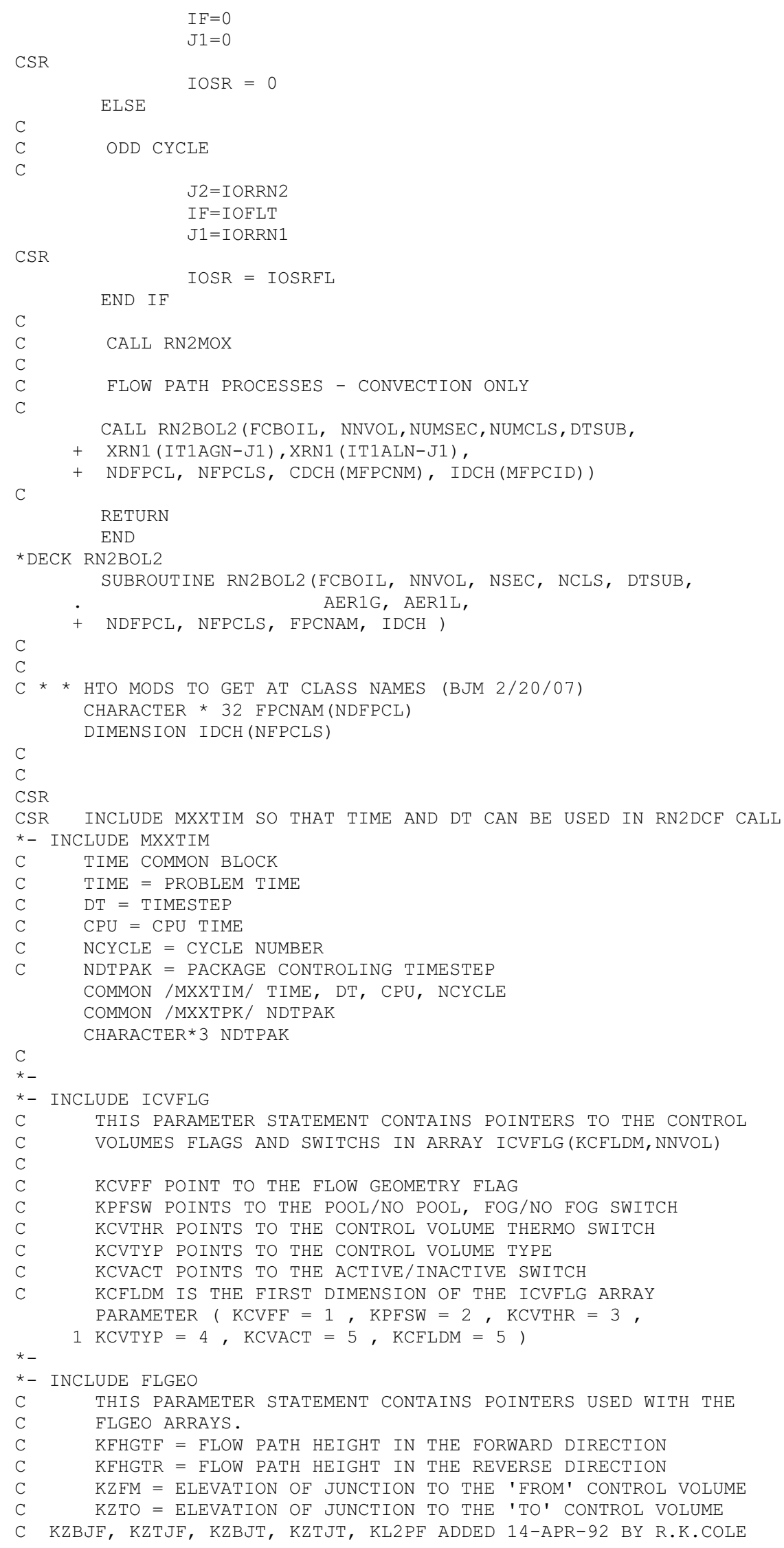




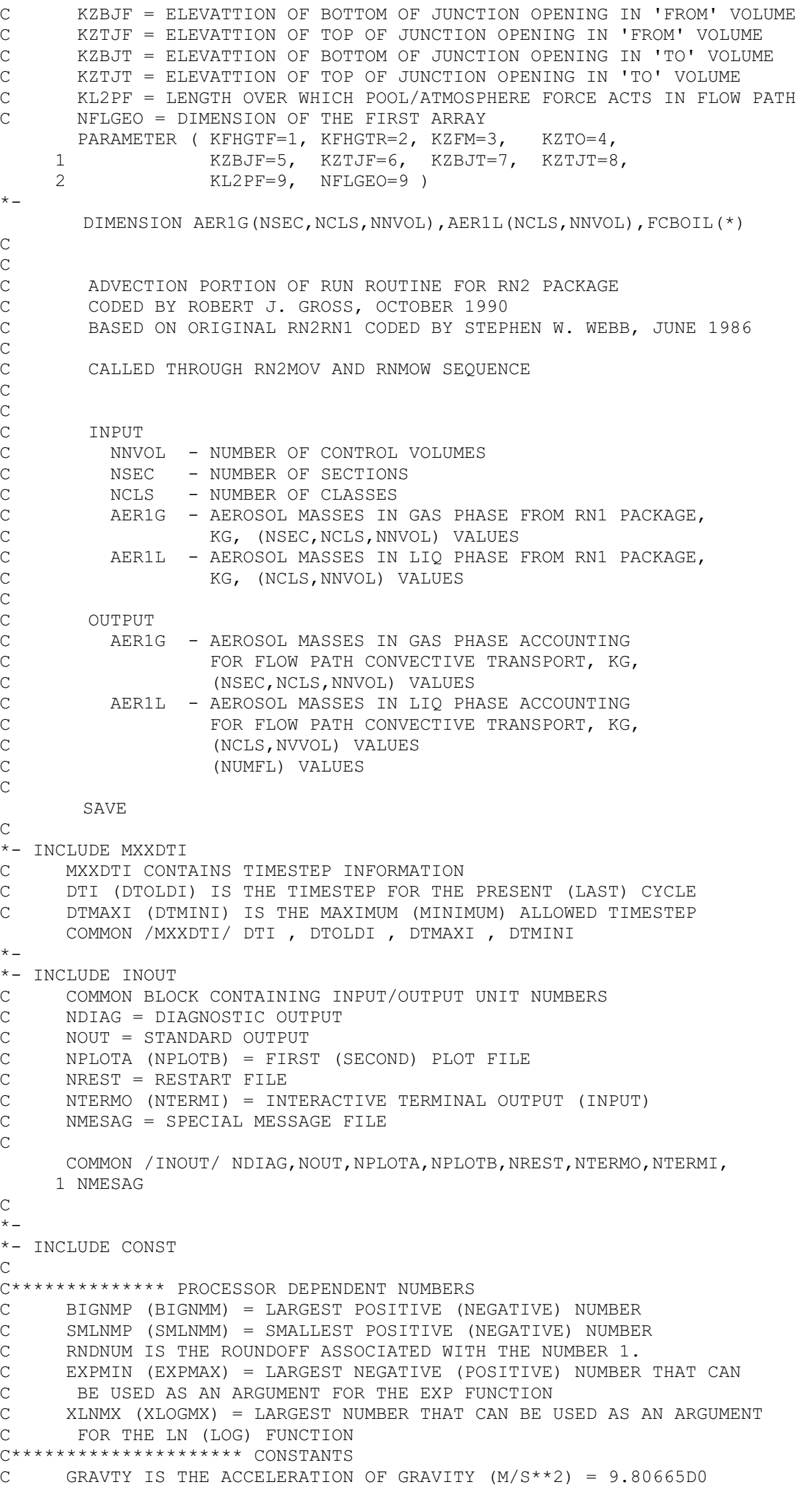




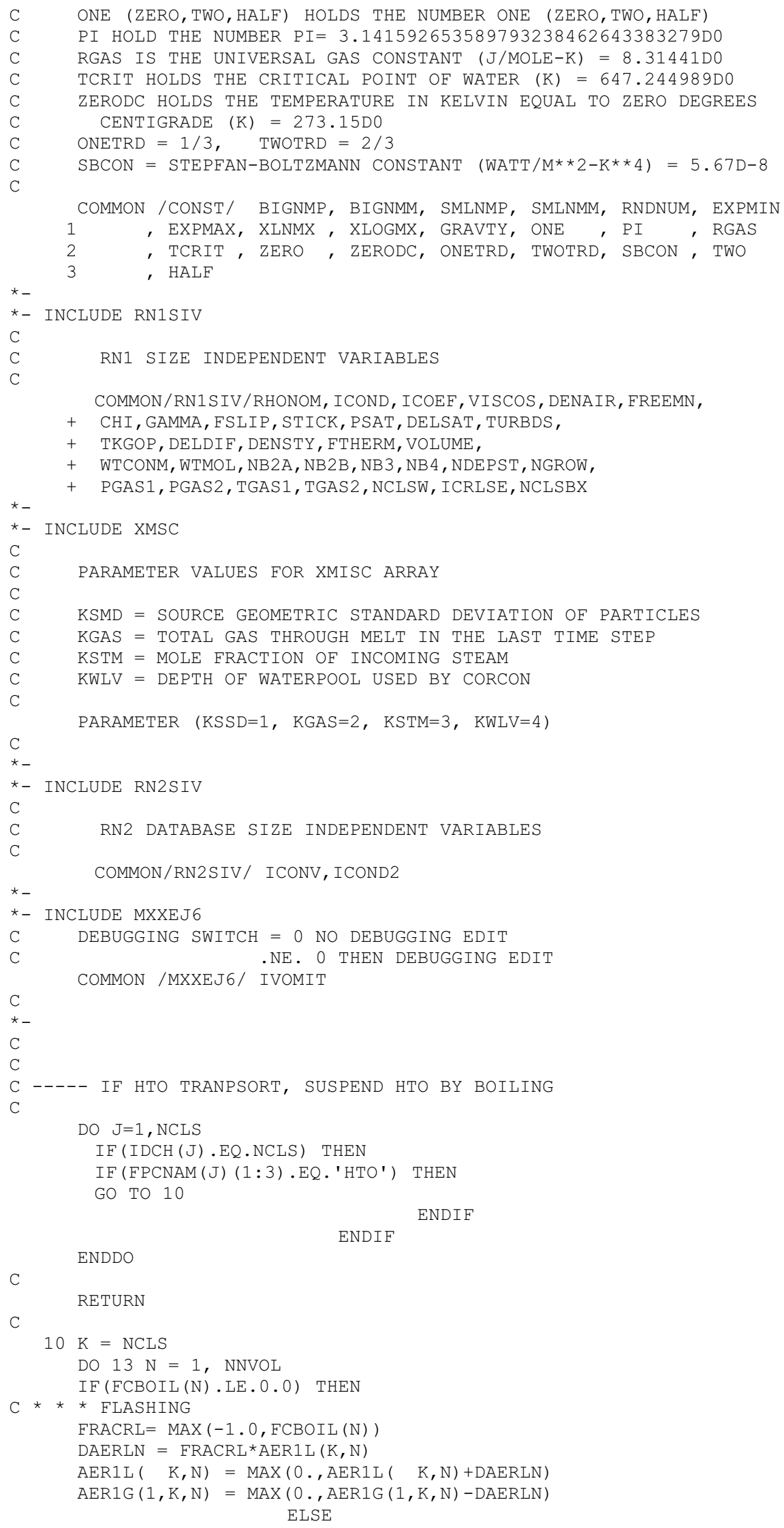




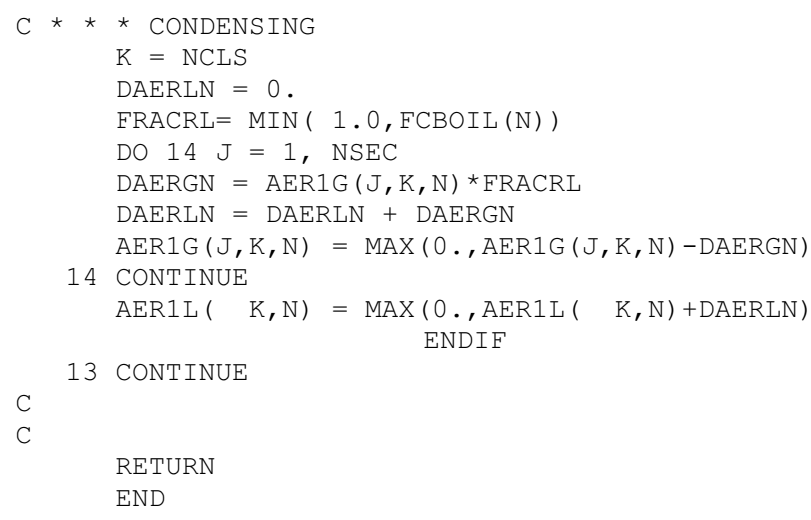




\section{Appendix B}

Code Listing for Oxidation Modifications 


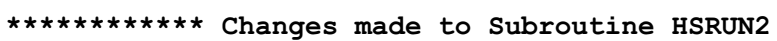

C

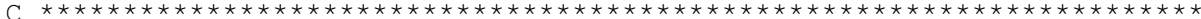

C OXIDIZE SURFACES

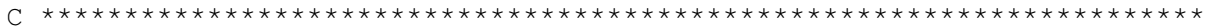

$C * *$ WATER

CALL OXIDIZW (NUMHS , NPTOT , NPMAX , NLOC , IGEOM , HSMULT,

$1 \quad X I$, IMAT, IBVL , ASURFL, BNDZL, IBVR ,

2 ASURFR, BNDZR, HSL , HVL , HSR , HVR ,

4 TEMPN, DELM, DELE , SPOW , MATNMS, NUMNAM,

$5 \quad$ ENINP )

C

IF (KO2.GE. 0) THEN

C

$C * * A I R$

CALL OXIDIZA (NUMHS, NPTOT, NPMAX, NLOC, IGEOM, HSMUlt,

1 XI , IMAT , IBVL , ASURFL, BNDZL , IBVR ,

2 ASURFR, BNDZR, HSL , HVL , HSR , HVR ,

4 TEMPN , DELM , DELE , SPOW , MATNMS, NUMNAM,

5 ENINP )

ENDIF

ENDIF

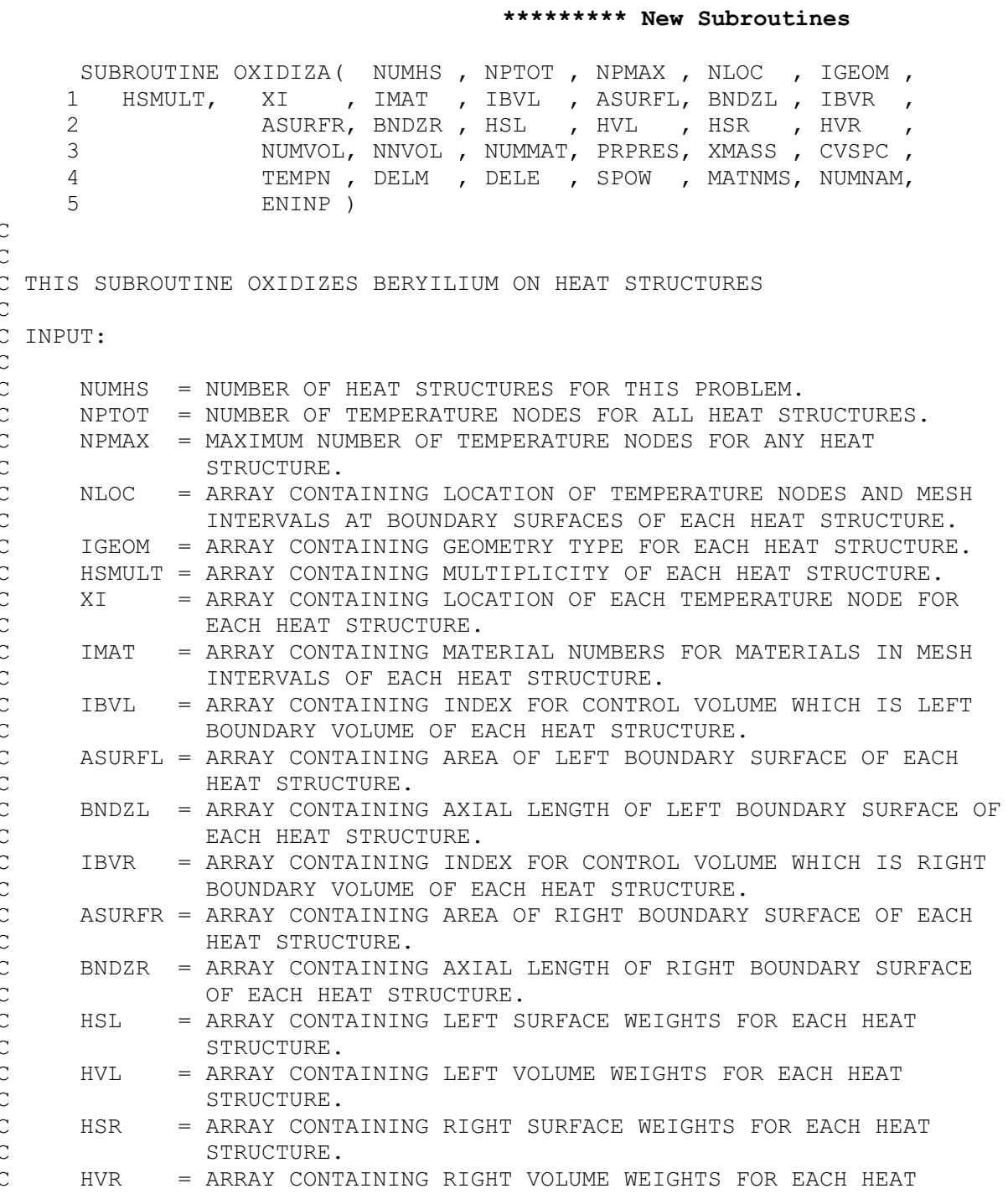

$\star \star \star \star \star \star \star \star \star$ New Subroutines 


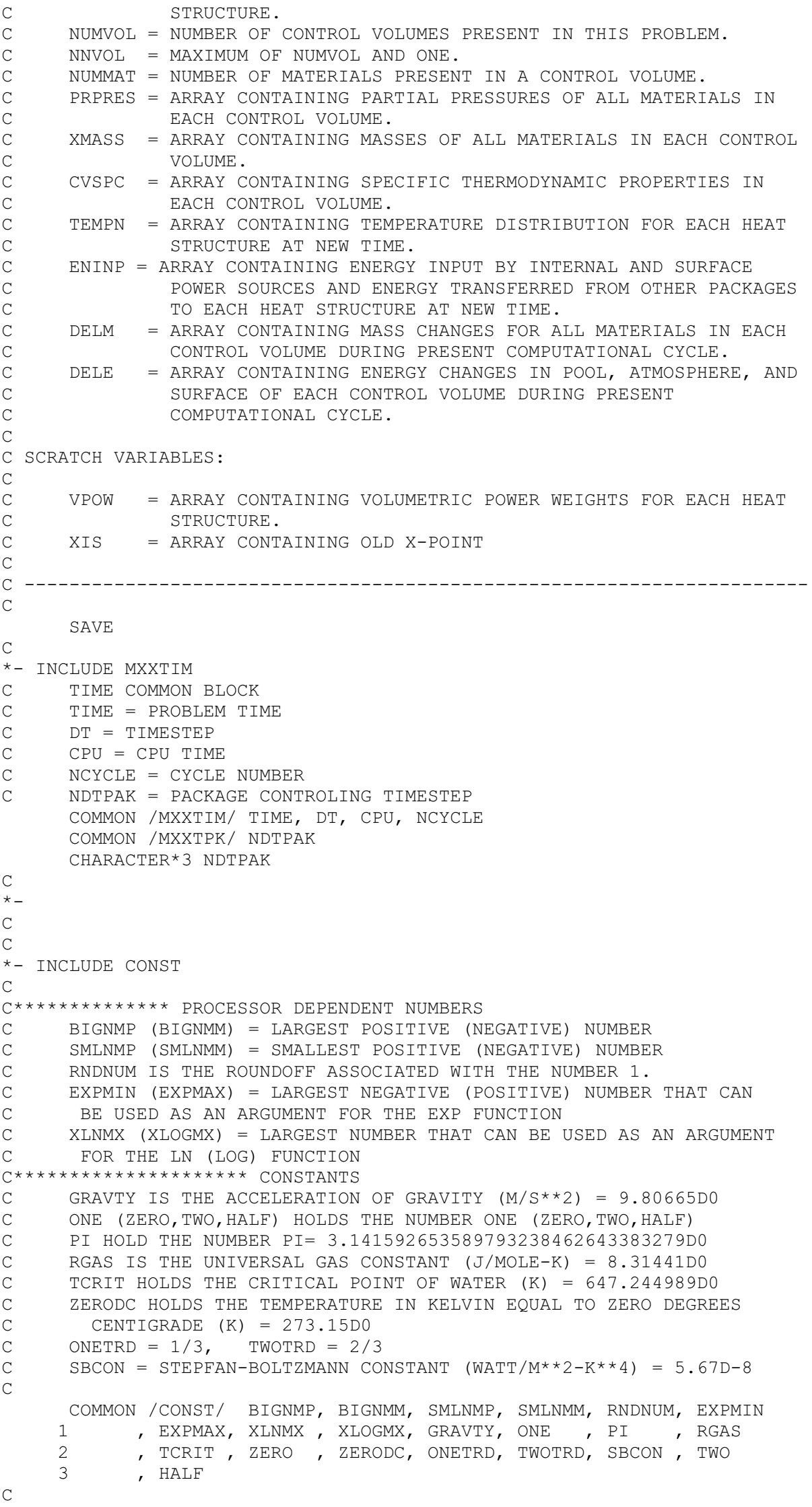




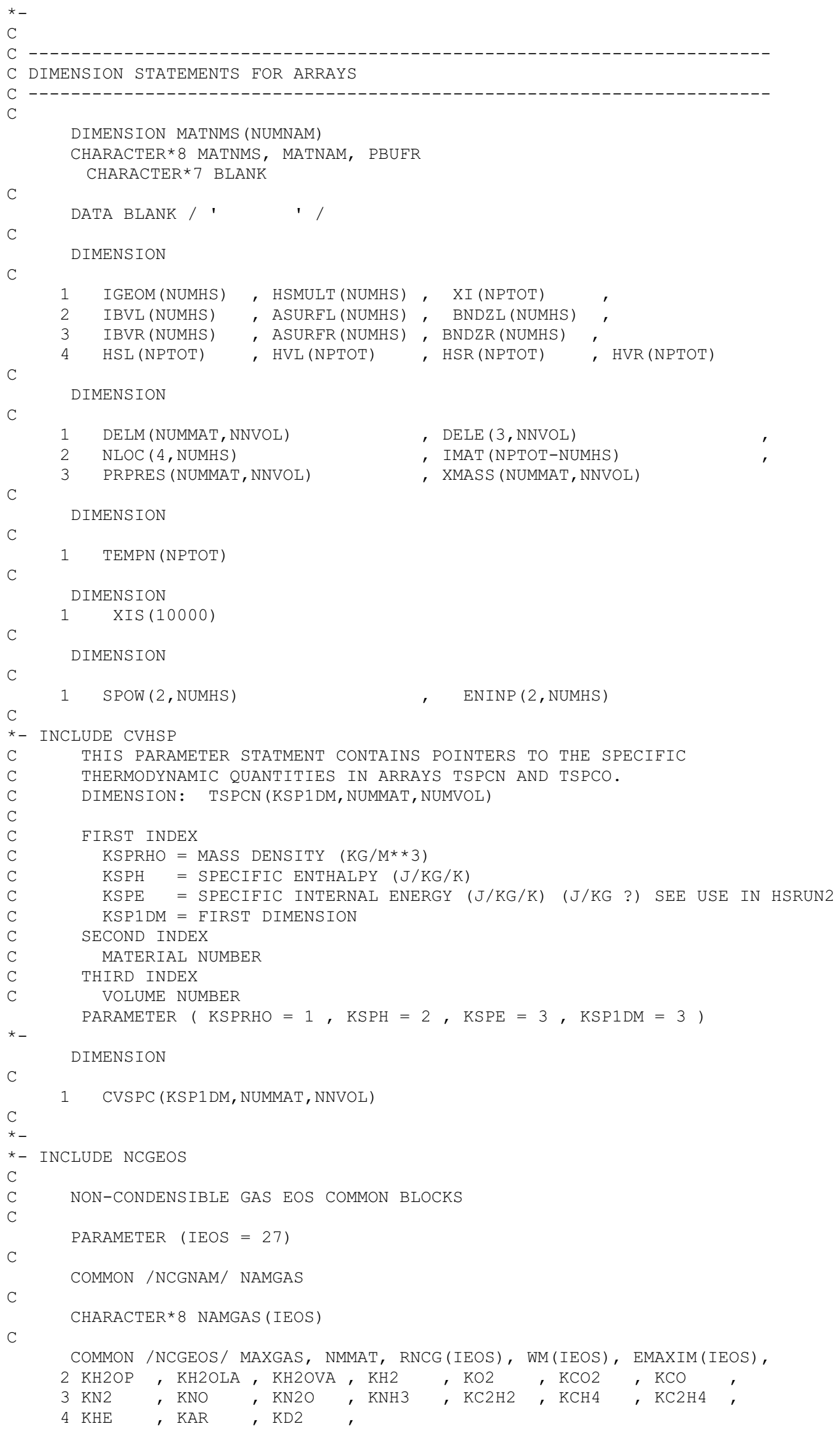




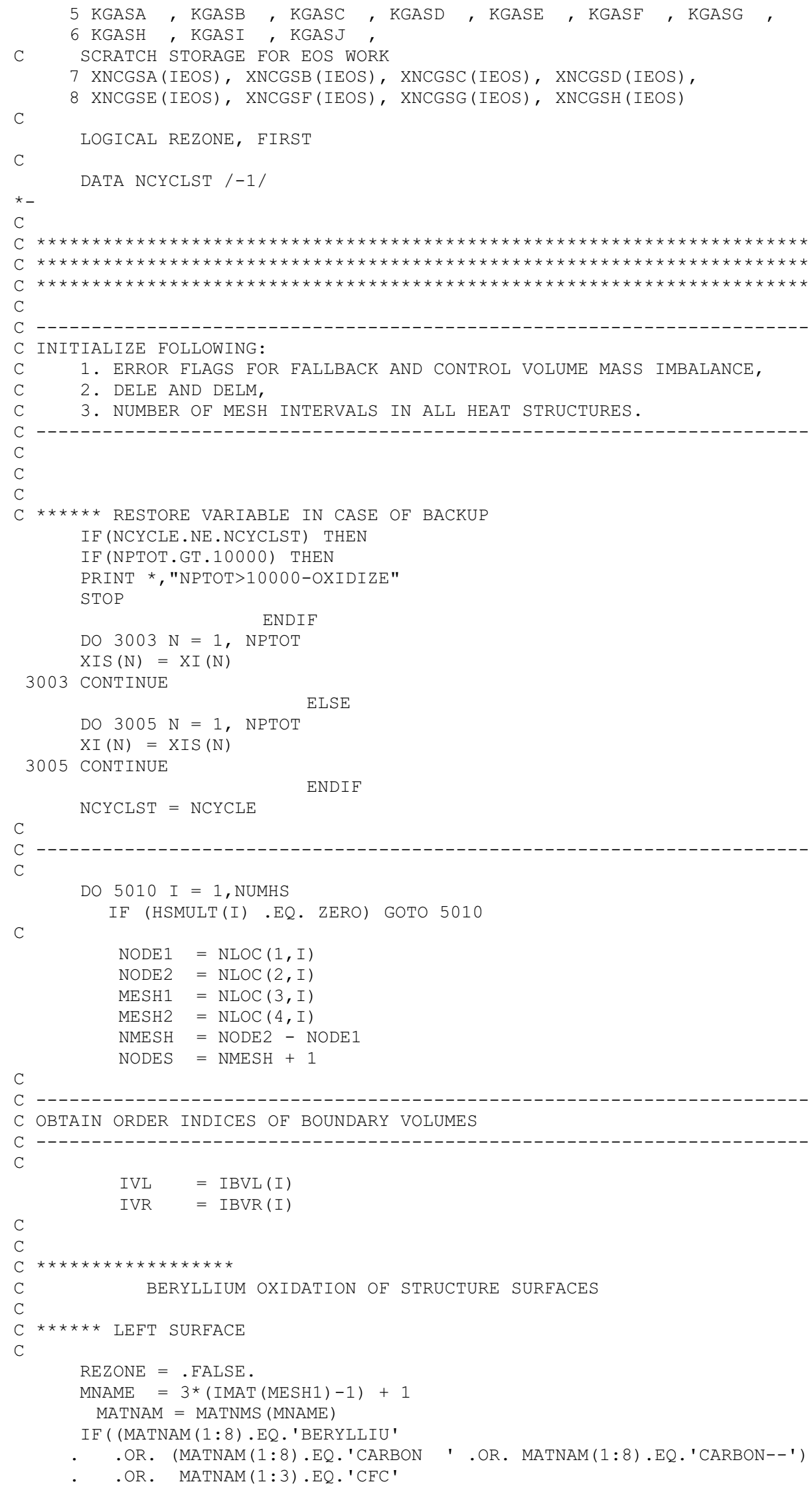




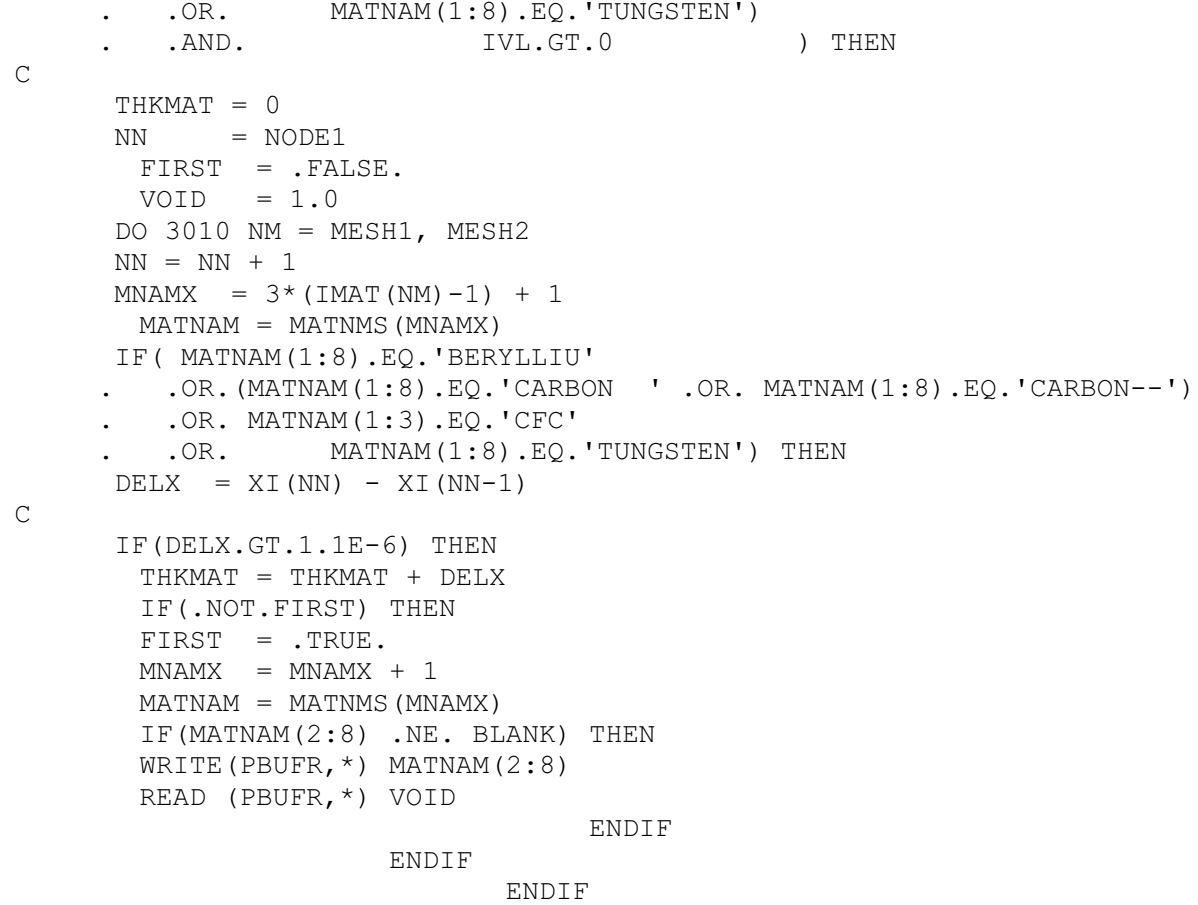

ENDIF

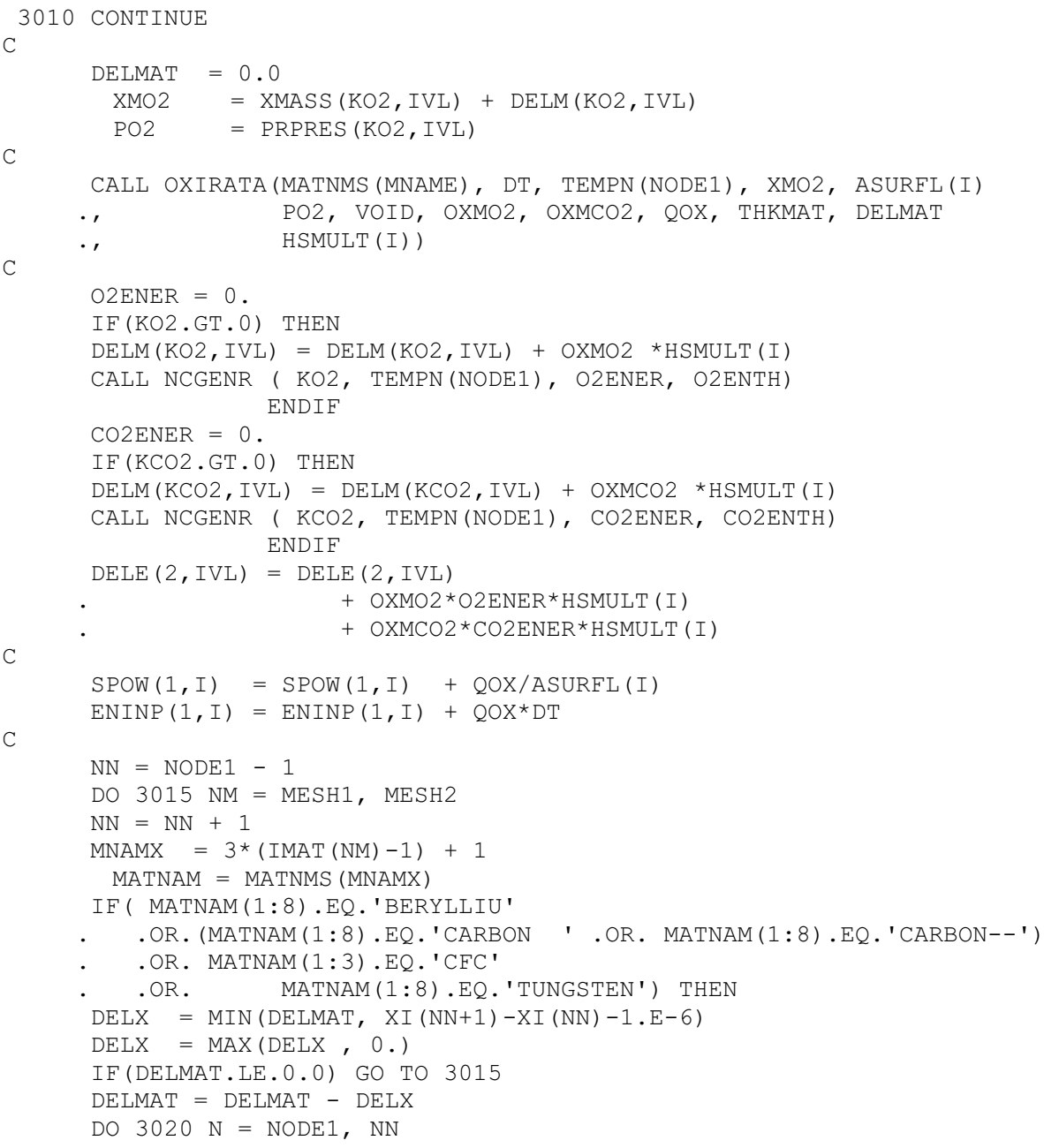




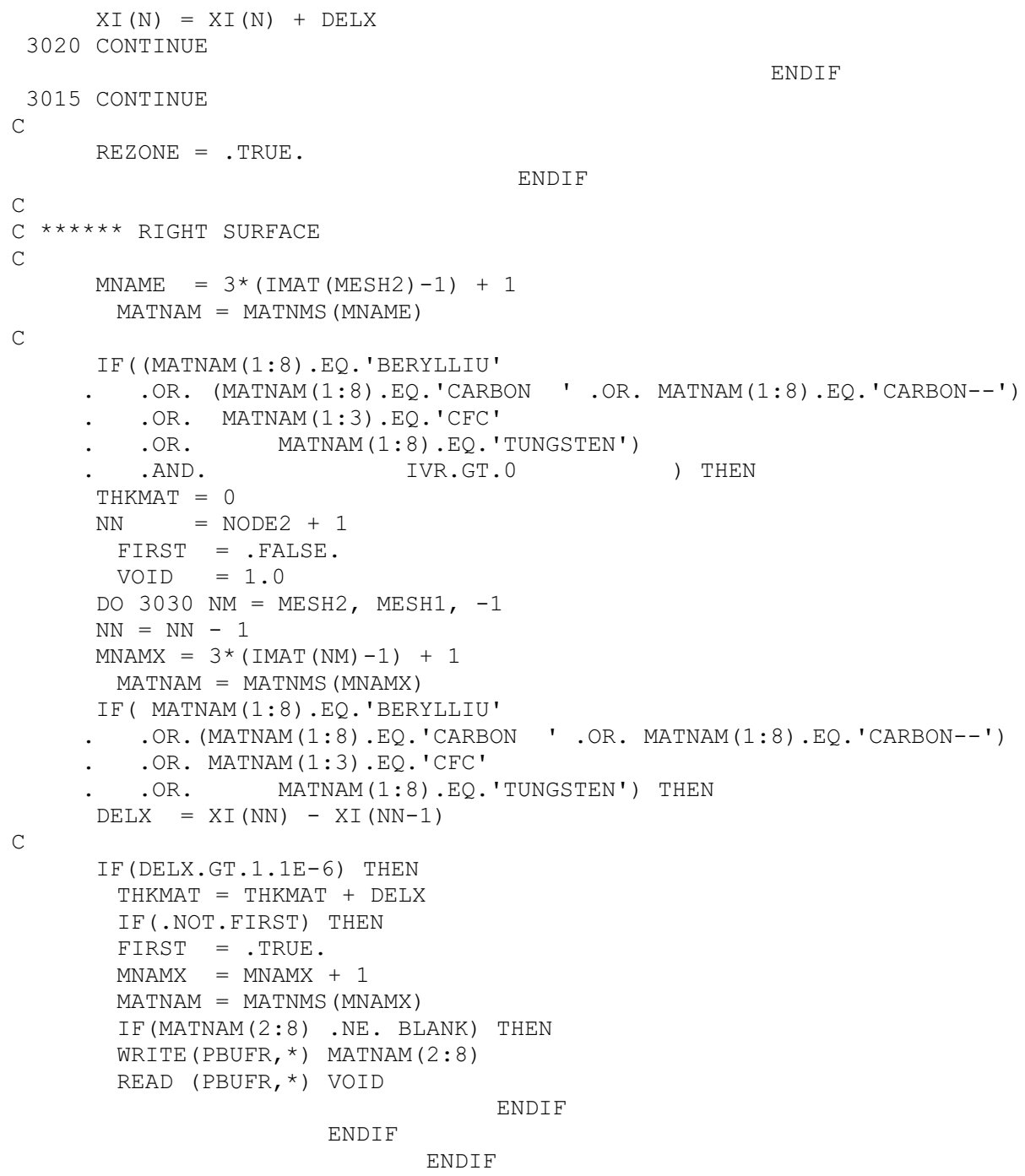




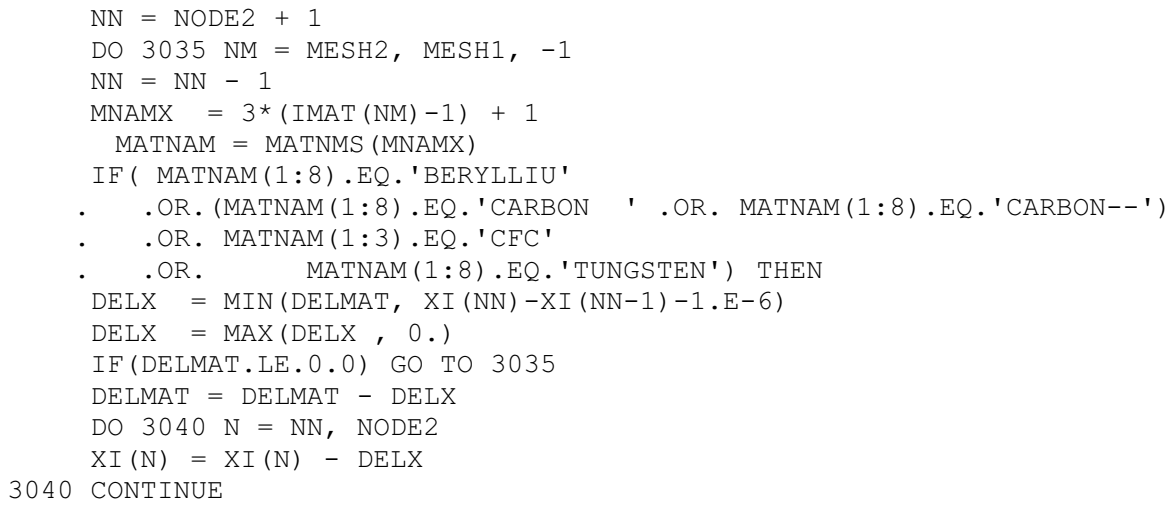


C 3060 CONTINUE

5010 CONTINUE

ENDIF

C

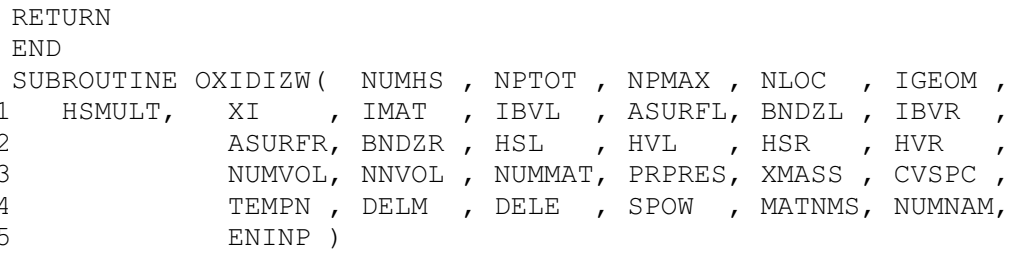

IBVR = ARRAY CONTAINING INDEX FOR CONTROL VOLUME WHICH IS RIGHT BOUNDARY VOLUME OF EACH HEAT STRUCTURE.

ASURFR = ARRAY CONTAINING AREA OF RIGHT BOUNDARY SURFACE OF EACH HEAT STRUCTURE.

BNDZR = ARRAY CONTAINING AXIAL LENGTH OF RIGHT BOUNDARY SURFACE OF EACH HEAT STRUCTURE.

HSL = ARRAY CONTAINING LEFT SURFACE WEIGHTS FOR EACH HEAT STRUCTURE.

HVL = ARRAY CONTAINING LEFT VOLUME WEIGHTS FOR EACH HEAT STRUCTURE.

HSR = ARRAY CONTAINING RIGHT SURFACE WEIGHTS FOR EACH HEAT STRUCTURE.

HVR = ARRAY CONTAINING RIGHT VOLUME WEIGHTS FOR EACH HEAT STRUCTURE.

NUMVOL = NUMBER OF CONTROL VOLUMES PRESENT IN THIS PROBLEM.

NNVOL = MAXIMUM OF NUMVOL AND ONE

NUMMAT = NUMBER OF MATERIALS PRESENT IN A CONTROL VOLUME.

PRPRES = ARRAY CONTAINING PARTIAL PRESSURES OF ALL MATERIALS IN EACH CONTROL VOLUME.

XMASS = ARRAY CONTAINING MASSES OF ALL MATERIALS IN EACH CONTROI VOLUME .

CVSPC = ARRAY CONTAINING SPECIFIC THERMODYNAMIC PROPERTIES IN EACH CONTROL VOLUME.

TEMPN = ARRAY CONTAINING TEMPERATURE DISTRIBUTION FOR EACH HEAT STRUCTURE AT NEW TIME.

ENINP = ARRAY CONTAINING ENERGY INPUT BY INTERNAL AND SURFACE POWER SOURCES AND ENERGY TRANSFERRED FROM OTHER PACKAGES TO EACH HEAT STRUCTURE AT NEW TIME.

DELM = ARRAY CONTAINING MASS CHANGES FOR ALL MATERIALS IN EACH CONTROL VOLUME DURING PRESENT COMPUTATIONAL CYCLE.

DELE = ARRAY CONTAINING ENERGY CHANGES IN POOL, ATMOSPHERE, AND SURFACE OF EACH CONTROL VOLUME DURING PRESENT COMPUTATIONAL CYCLE. 


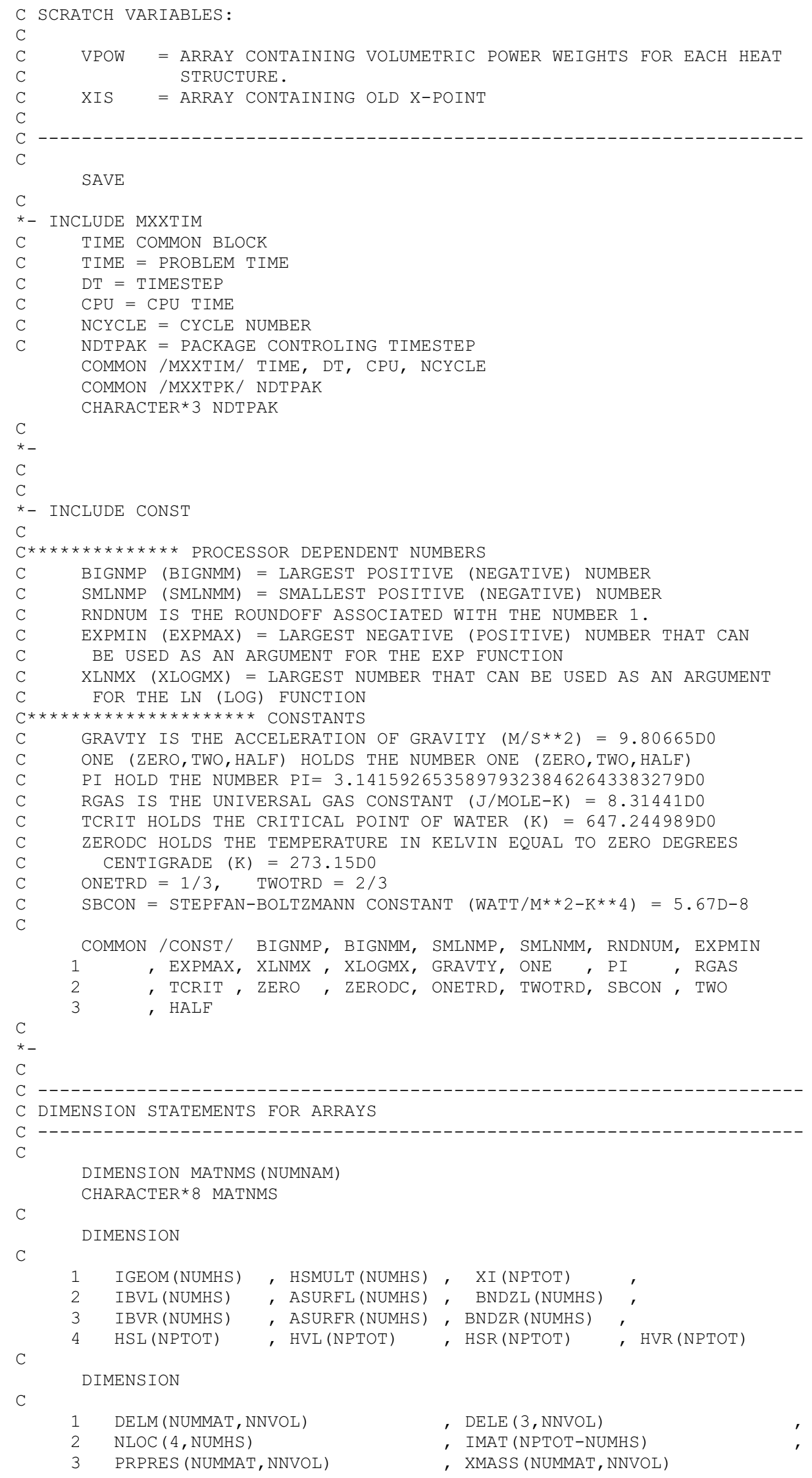


C

$\mathrm{C}$

* INCLUDE CVHSP

C THIS PARAMETER STATMENT CONTAINS POINTERS TO THE SPECIFIC

CHERMODYNAMIC QUANTITIES IN ARRAYS TSPCN AND TSPCO.

C DIMENSION: TSPCN (KSPIDM, NUMMAT, NUMVOL)

C FIRST INDEX

KSPRHO $=$ MASS DENSITY $(\mathrm{KG} / \mathrm{M} * * 3)$

$\mathrm{C} \quad \mathrm{KSPH}=\mathrm{SPECIFIC}$ ENTHALPY $(\mathrm{J} / \mathrm{KG} / \mathrm{K})$

C KSPE = SPECIFIC INTERNAL ENERGY (J/KG/K) (J/KG ?) SEE USE IN HSRUN2

C KSPIDM = FIRST DIMENSION

C SECOND INDEX

MATERIAL NUMBER

THIRD INDEX

VOLUME NUMBER

PARAMETER ( $\operatorname{KSPRHO}=1, \mathrm{KSPH}=2, \operatorname{KSPE}=3, \operatorname{KSP} 1 \mathrm{DM}=3$ )

DIMENSION

C

* INCLUDE NCGEOS

$\mathrm{C}$

C

C

COMMON /NCGEOS/ MAXGAS, NMMAT, RNCG(IEOS), WM(IEOS), EMAXIM(IEOS),
2 KH2OP, KH2OLA, KH2OVA, KH2

$3 \mathrm{KN2}, \mathrm{KNO}, \mathrm{KN} 2 \mathrm{O}, \mathrm{KNH} 3$

$4 \mathrm{KHE}, \mathrm{KAR}, \mathrm{KD} 2$

$5 \mathrm{KGASA}, \mathrm{KGASB}, \mathrm{KGASC}$,

$6 \mathrm{KGASH}$, KGASI, KGASJ,

C

SCRATCH STORAGE FOR EOS WORK

$7 \mathrm{XNCGSA}(\mathrm{IEOS}), \mathrm{XNCGSB}(\mathrm{IEOS}), \mathrm{XNCGSC}(\mathrm{IEOS}), \mathrm{XNCGSD}(\mathrm{IEOS})$,

8 XNCGSE(IEOS), XNCGSF(IEOS), XNCGSG(IEOS), XNCGSH (IEOS)

$\mathrm{C}$

C

LOGICAL REZONE

DATA NCYCLST /-1/

$\mathrm{C}$

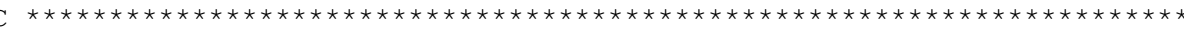

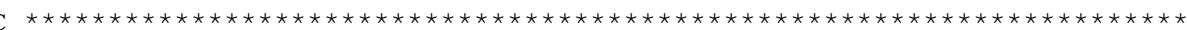

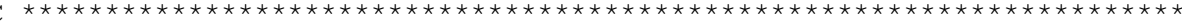

$\mathrm{C}$

C -

INITIALIZE FOLLOWING:

1. ERROR FLAGS FOR FALLBACK AND CONTROL VOLUME MASS IMBALANCE,

2. DELE AND DELM,

3. NUMBER OF MESH INTERVALS IN ALL HEAT STRUCTURES. 


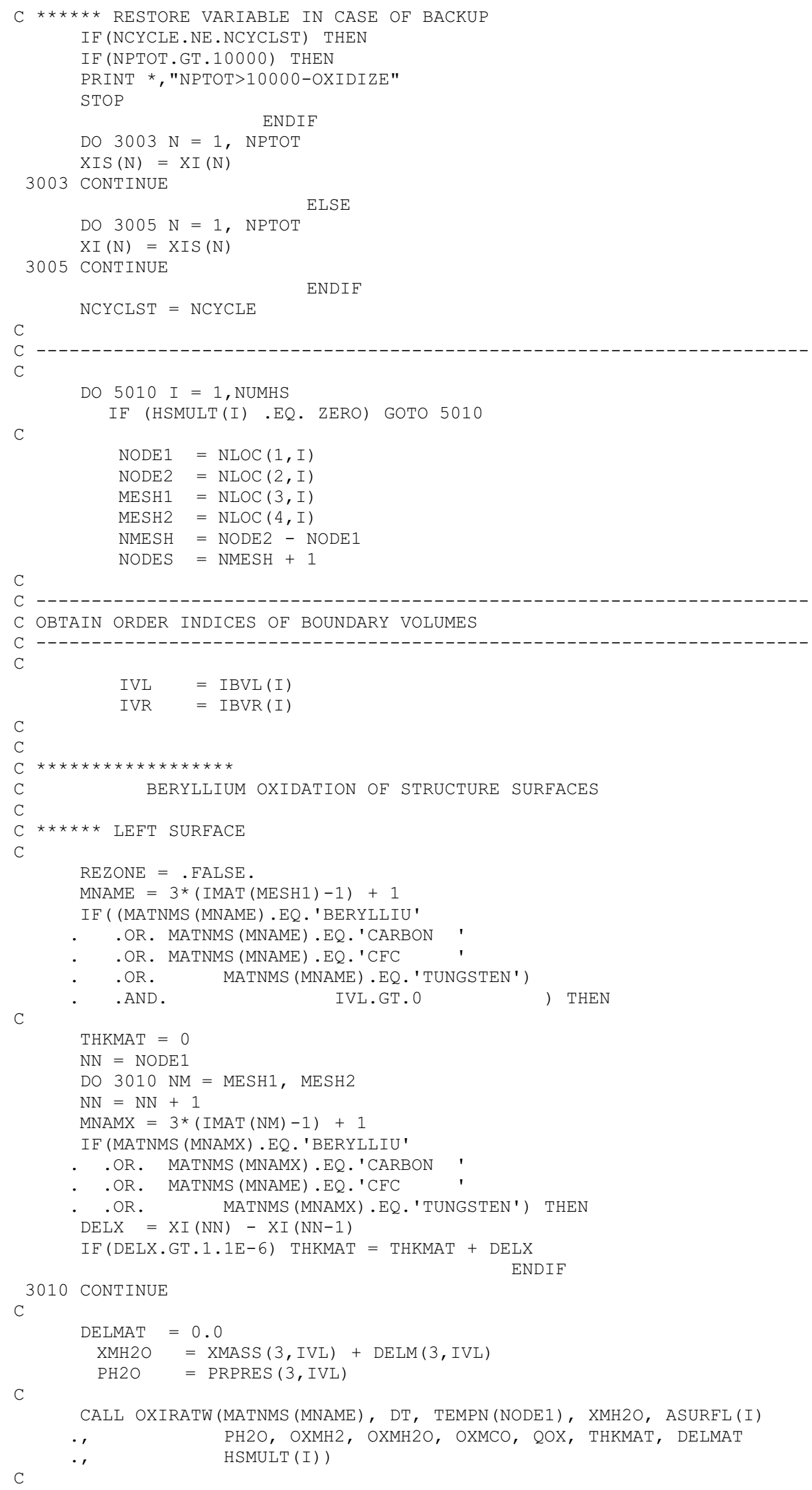




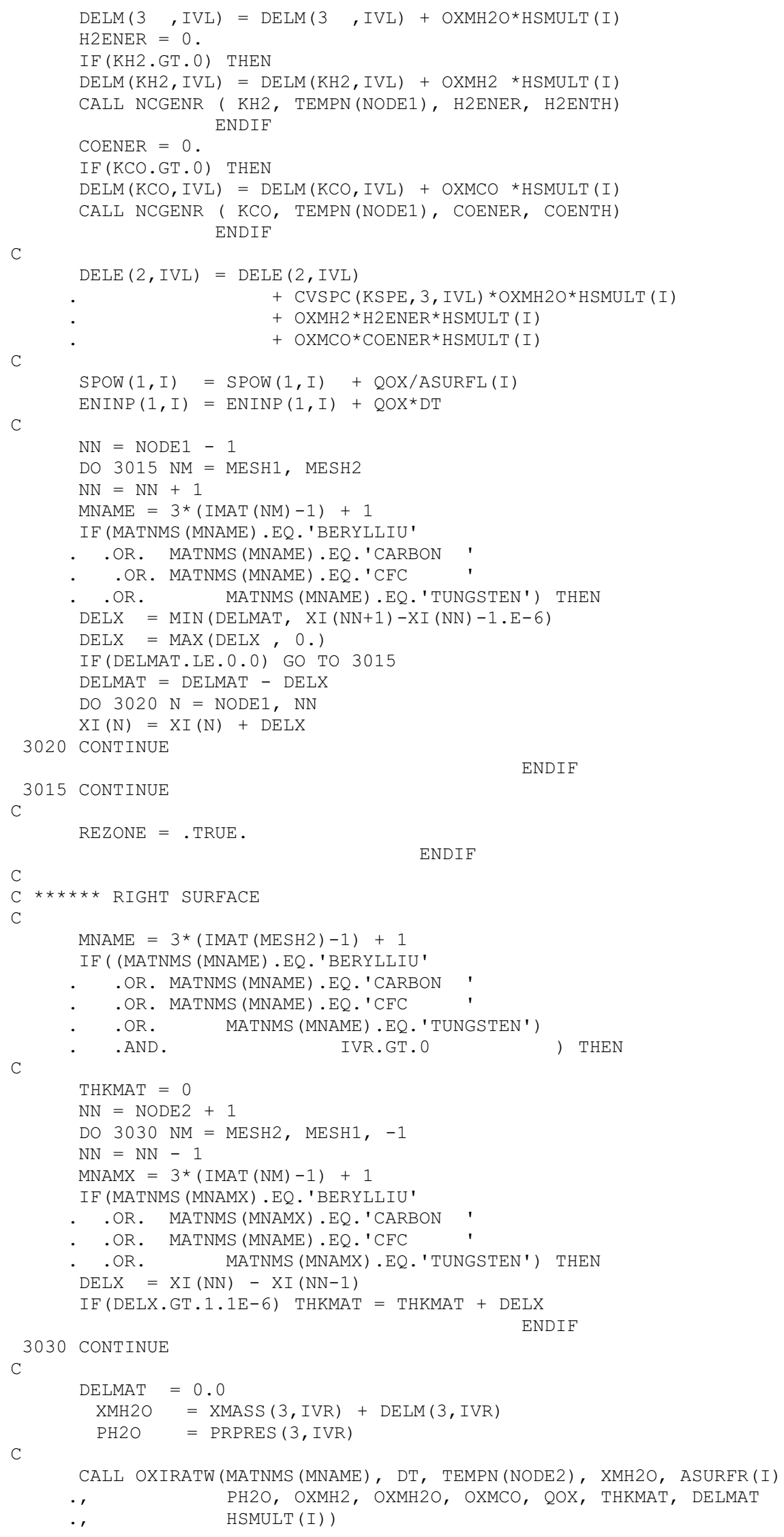


$\operatorname{DELM}(3, \operatorname{IVR})=\operatorname{DELM}(3$, IVR $)+\operatorname{OXMH} 20 * \operatorname{HSMULT}(\mathrm{I})$

$\mathrm{H} 2 \mathrm{ENER}=0$.

IF (KH2.GT.0) THEN

$\operatorname{DELM}(\mathrm{KH} 2, \mathrm{IVR})=\operatorname{DELM}(\mathrm{KH} 2, \mathrm{IVR})+\mathrm{OXMH} 2{ }^{*} \operatorname{HSMULT}(\mathrm{I})$

CALL NCGENR ( KH2, TEMPN (NODE2), H2ENER, H2ENTH) ENDIF

COENER $=0$.

IF (KCO.GT.0) THEN

$\operatorname{DELM}(\mathrm{KCO}, \mathrm{IVR})=\operatorname{DELM}(\mathrm{KCO}, \mathrm{IVR})+\mathrm{OXMCO} * \mathrm{HSMULT}(\mathrm{I})$

CALL NCGENR ( KCO, TEMPN (NODE2), COENER, COENTH) ENDIF

C

$\operatorname{DELE}(2, \operatorname{IVR})=\operatorname{DELE}(2, \operatorname{IVR})$

- $\quad+\operatorname{CVSPC}(\mathrm{KSPE}, 3, \mathrm{IVR})$ *OXMH2O*HSMULT (I)

. + OXMH $2 *$ H2ENER*HSMULT (I)

C

$\operatorname{SPOW}(2, I) \quad=\operatorname{SPOW}(2, I)+\operatorname{QOX} / \operatorname{ASURFR}(I)$

$\operatorname{ENINP}(1, I)=\operatorname{ENINP}(1, I)+Q O X * D T$

C

$\mathrm{NN}=\mathrm{NODE} 2+1$

DO $3035 \mathrm{NM}=\mathrm{MESH} 2, \mathrm{MESH} 1,-1$

$\mathrm{NN}=\mathrm{NN}-1$

$\operatorname{MNAME}=3 *(\operatorname{IMAT}(\mathrm{NM})-1)+1$

IF (MATNMS (MNAME) .EQ. 'BERYLLIU'

- . OR. MATNMS (MNAME) EQ. 'CARBON '

. .OR. MATNMS (MNAME) .EQ.' CFC

. .OR. MATNMS (MNAME) .EQ.'TUNGSTEN') THEN

$\operatorname{DELX}=\operatorname{MIN}(\mathrm{DELMAT}, \mathrm{XI}(\mathrm{NN})-\mathrm{XI}(\mathrm{NN}-1)-1 . \mathrm{E}-6)$

$\operatorname{DELX}=\operatorname{MAX}(\mathrm{DELX}, 0$.

IF (DELMAT.LE.0.0) GO TO 3035

DELMAT = DELMAT - DELX

DO $3040 \mathrm{~N}=\mathrm{NN}, \mathrm{NODE} 2$

$\mathrm{XI}(\mathrm{N})=\mathrm{XI}(\mathrm{N})-\mathrm{DELX}$

3040 CONTINUE

3035 CONTINUE

ENDIF

C

REZONE $=$.TRUE.

C

ENDIF

IF (REZONE) THEN

DO $3050 \mathrm{~N}=\mathrm{NODE} 1, \mathrm{NODE} 2$

IF (N.GT.NODE1) THEN

$\mathrm{DELXM}=\mathrm{XI}(\mathrm{N})-\mathrm{XI}(\mathrm{N}-1)$

$\mathrm{DELXM}=1$.

ELSE

IE (N.LT.NODE2) THEN

$\mathrm{DELXP}=\mathrm{XI}(\mathrm{N}+1)-\mathrm{XI}(\mathrm{N})$

DELXP $=1$.

ELSE

ENDIF

GO TO $(3051,3052,3053,3054,3054)$, IGEOM(I)

$3051 \operatorname{HSL}(\mathrm{N})=1 . / \mathrm{DELXM}$

$\operatorname{HVL}(\mathrm{N})=\mathrm{DELXM} / 2$

$\operatorname{HSR}(N)=1 . / \mathrm{DELXP}$

$\operatorname{HVR}(\mathrm{N})=\mathrm{DELXP} / 2$.

GO TO 3050

$3052 \operatorname{HSL}(\mathrm{N})=2 . * \mathrm{PI} *(\mathrm{XI}(\mathrm{N})-\mathrm{DELXM} / 2.) / \mathrm{DELXM}$

$\operatorname{HVL}(\mathrm{N})=\mathrm{PI} *(\mathrm{XI}(\mathrm{N}) \star * 2-(\mathrm{XI}(\mathrm{N})-\mathrm{DELXM} / 2). * \star 2)$

$\operatorname{HSR}(\mathrm{N})=2 \cdot{ }^{*} \mathrm{PI} *(\mathrm{XI}(\mathrm{N})+\mathrm{DELXP} / 2.) / \mathrm{DELXP}$

$\operatorname{HVR}(\mathrm{N})=\mathrm{PI} *((\mathrm{XI}(\mathrm{N})+\mathrm{DELXP} / 2). * \star 2-\mathrm{XI}(\mathrm{N}) * \star 2)$

GO TO 3050

$3053 \operatorname{HSL}(\mathrm{N})=4 . * \mathrm{PI} *(\mathrm{XI}(\mathrm{N})-\mathrm{DELXM} / 2) * * .2 / \mathrm{DELXM}$

$\operatorname{HVL}(\mathrm{N})=4 \cdot{ }^{*} \mathrm{PI} *(\mathrm{XI}(\mathrm{N}) * \star 3-(\mathrm{XI}(\mathrm{N})-\mathrm{DELXM} / 2). * \star 3) / 3$.

$\operatorname{HSR}(\mathrm{N})=4 . * \mathrm{PI} *(\mathrm{XI}(\mathrm{N})+\mathrm{DELXP} / 2). * \star 2 / \mathrm{DELXP}$

$\operatorname{HVR}(N)=4 . * P I *((X I(N)+D E L X P / 2). * \star 3-X I(N) * \star 3) / 3$.

GO TO 3050

$3054 \operatorname{HSL}(\mathrm{N})=2 . * \mathrm{PI} *(\mathrm{XI}(\mathrm{N})-\mathrm{DELXM} / 2) * * .2 / \mathrm{DELXM}$ 


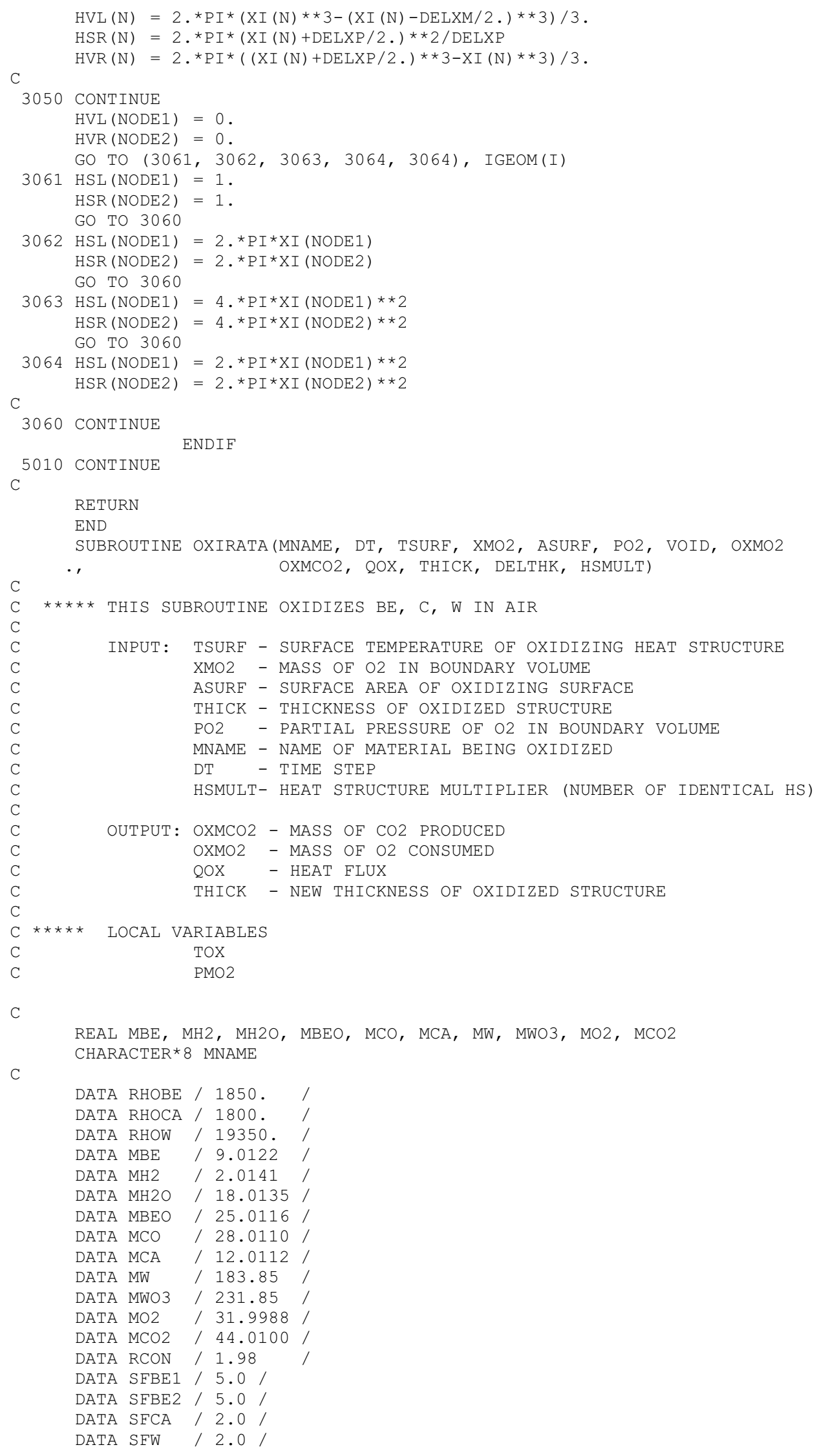


C

$\mathrm{OXMO} 2=0$.

$\mathrm{OXMCO} 2=0$.

$\mathrm{QOX}=0$.

C

IF (XMO2.EQ.0.) RETURN

IF (MNAME.EQ. 'BERYLLIU') THEN

C

C

C

C

C

C

C

C

C

TOX $=$ TSURF

C

TOX $=\operatorname{MIN}(2000.0$, TOX $)$

$\mathrm{ROX}=\mathrm{SFBE} 1 * 4.833 \mathrm{E} 5 * \operatorname{EXP}(-26200.0 / \mathrm{TOX})$

IF (TOX.GT.1073.0) ROX $=\operatorname{SFBE} 2 * 34.83 * \operatorname{EXP}(-15900.0 / \mathrm{TOX})$

$\mathrm{ROX}=\mathrm{VOID} * \mathrm{PMO} 2{ }^{*} \mathrm{ROX}$

$\mathrm{HFBEO}=(-144220 \cdot \mathrm{D} 0+0.83 \mathrm{D} 0 * \mathrm{TOX}$

C

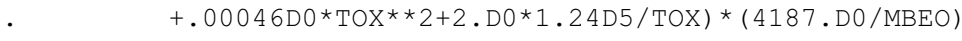

$\operatorname{DELTHK}=\operatorname{MAX}(0.0, \mathrm{DT} * \mathrm{ROX} /(\mathrm{VOID} * \mathrm{RHOBE}))$

IF (DELTHK. GT.THICK) ROX $=$ ROX *THICK/DELTHK

OXMO2 $=-\mathrm{DT} * \mathrm{ROX} *(0.5 * \mathrm{MO} 2 / \mathrm{MBE}) * \mathrm{HSMULT} * \mathrm{ASURF}$

IF (ABS (OXMO2) . GT.0.5*XMO2) ROX $=0.5 * \mathrm{ROX} * \mathrm{XMO} 2 / \mathrm{ABS}(\mathrm{OXMO} 2)$

$\mathrm{DELTHK}=\operatorname{MAX}(0.0, \mathrm{DT} * \mathrm{ROX} /(\mathrm{VOID} * \mathrm{RHOBE}))$

OXMO2 $=-D T * R_{0 X} *(0.5 * \mathrm{MO} 2 / \mathrm{MBE}) * \mathrm{ASURF}$

$\mathrm{QOX}=-\mathrm{HFBEO} * \mathrm{ROX} *(\mathrm{MBEO} / \mathrm{MBE}) * \mathrm{ASURF}$

C

C

IF (MNAME.EQ.'CARBON ' .OR. MNAME.EQ.'CFC ' ) THEN

$\mathrm{C}$

C

C

C

C

C

C

C

C

C

CARBON \& OXYGEN

$\mathrm{C}+\mathrm{O} 2->\mathrm{CO} 2$

$\star \star \star H H=F+T * S$ (PAGE D-45, CRC, 60TH EDITION)

$\mathrm{HFCO} 2$ IN J/(KG-CO2)

ROX IN $(\mathrm{KG}-\mathrm{C}) /(\mathrm{M} 2 * \mathrm{~S}) ; \mathrm{QOX}$ IN W/M2

* * PRESSURE DEPENDENCE

$\mathrm{PMO} 2=\mathrm{PO} 2 / 0.181 \mathrm{E} 5$

TOX $=$ TSURF

TOX $=\operatorname{MIN}(2000.0$, TOX $)$

IF (MNAME.EQ.'CARBON ') THEN

$\mathrm{ROX}=0.2472 \mathrm{D} 0 * \operatorname{EXP}(-5710.0 / \mathrm{TOX})$

IF (TOX . GT. 1273.DO) ROX $=1.56 \mathrm{E}-2 \star \operatorname{EXP}(-2260.0 / \mathrm{TOX})$

$$
\text { ELSE }
$$

$\operatorname{ROX}=1.4754 \mathrm{E}+07 * \operatorname{EXP}(-2.6128 \mathrm{E}+04 / \mathrm{TOX})$

IF (TOX .GT. 983.0 .AND. TOX . LE. 1448.0) THEN

$\mathrm{ROX}=3.6308 \mathrm{E}+01 * \operatorname{EXP}(-1.3475 \mathrm{E}+04 / \mathrm{TOX})$

IF (TOX . GT. 1448.DO) ROX $=1.57 \mathrm{D}-2 \star \mathrm{EXP}(-2260.0 / \mathrm{TOX})$

C ENDIF

$\mathrm{ROX}=\mathrm{VOID} * \mathrm{PMO} 2 * \mathrm{SFCA} * \mathrm{ROX}$

$\mathrm{HFCO} 2=(-93690.0-1.63 * \mathrm{TOX} / 2.303$

C

$$
+.07 \mathrm{E}-3 * \mathrm{TOX} * * 2-2 . * 0.23 \mathrm{E} 5 / \mathrm{TOX}) *(4187 . / \mathrm{MCO} 2)
$$

$\operatorname{DELTHK}=\operatorname{MAX}\left(0.0, \mathrm{DT} * \mathrm{ROX} /\left(\mathrm{VOID}{ }^{\mathrm{RHOCA}}\right)\right)$ 


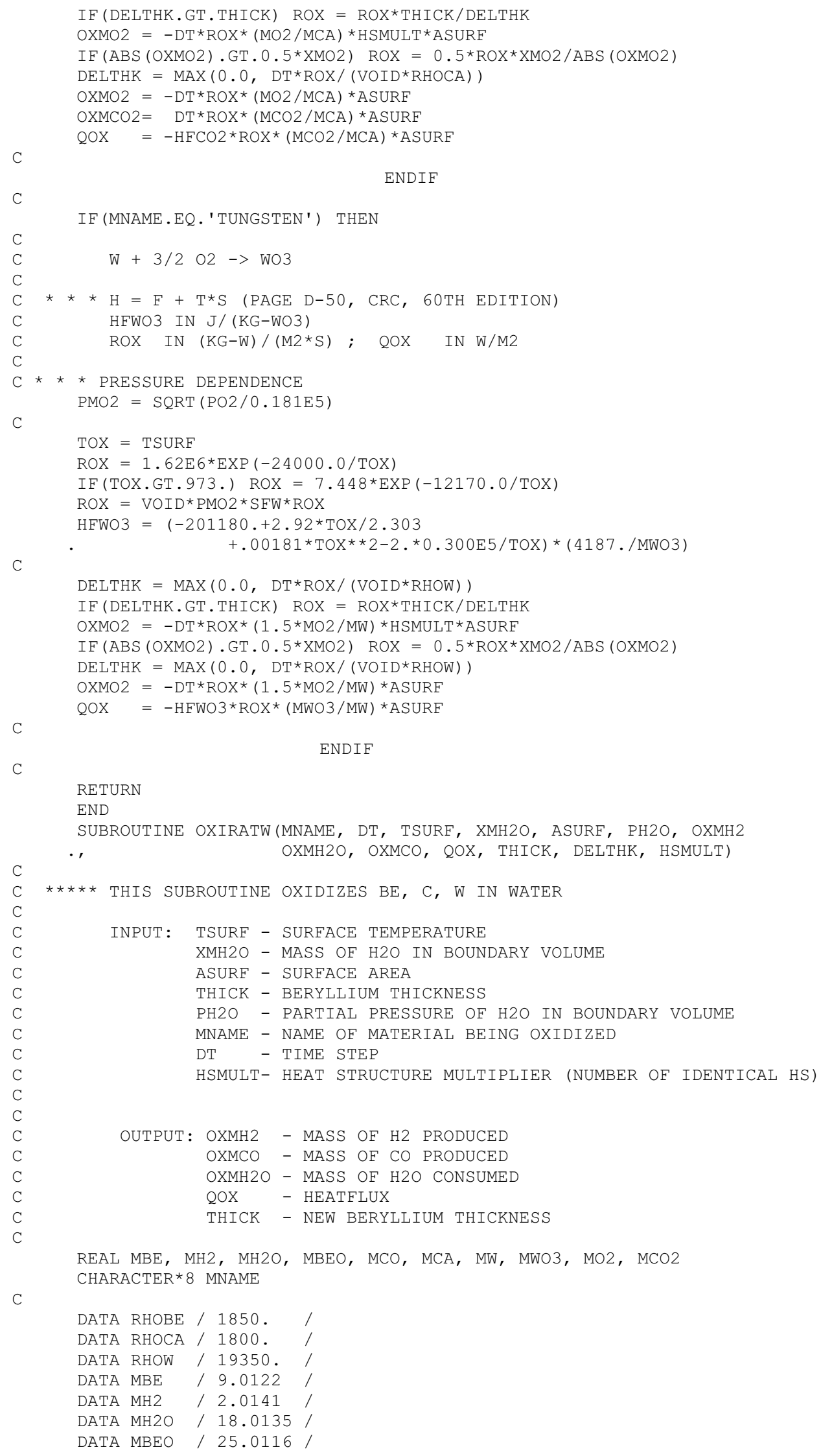




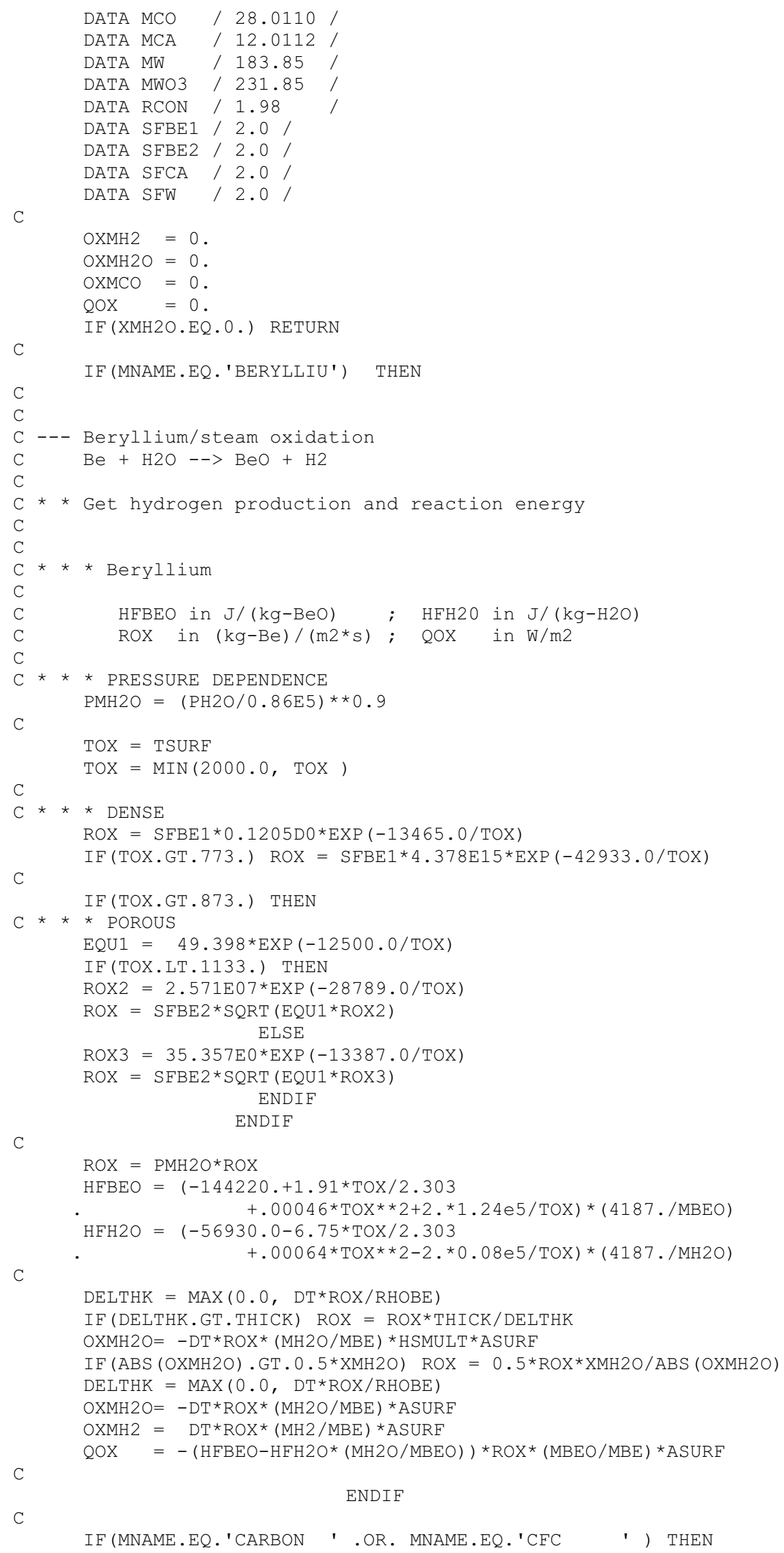




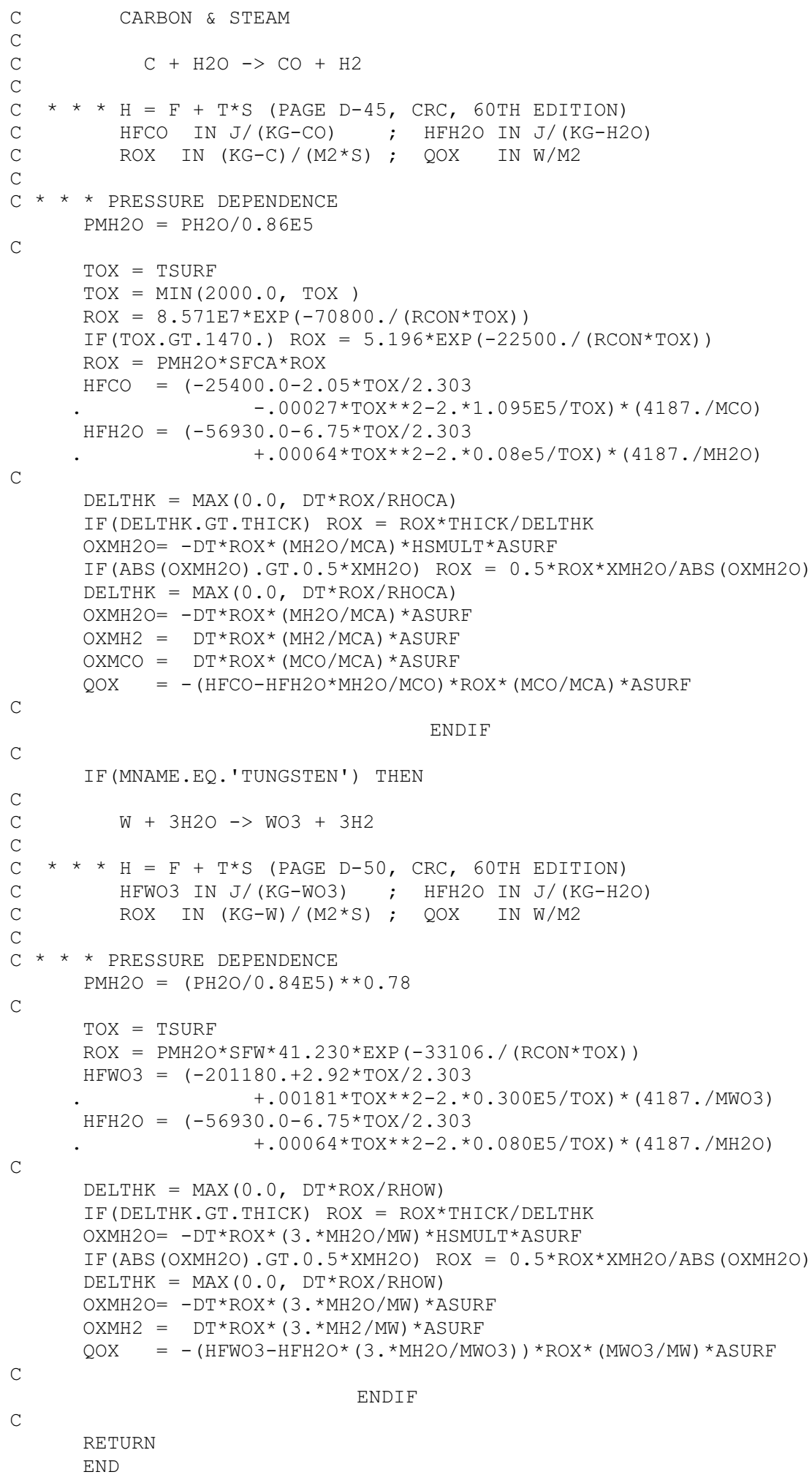




\section{Appendix C}

Code Listing for Aerosol Transport Modifications 


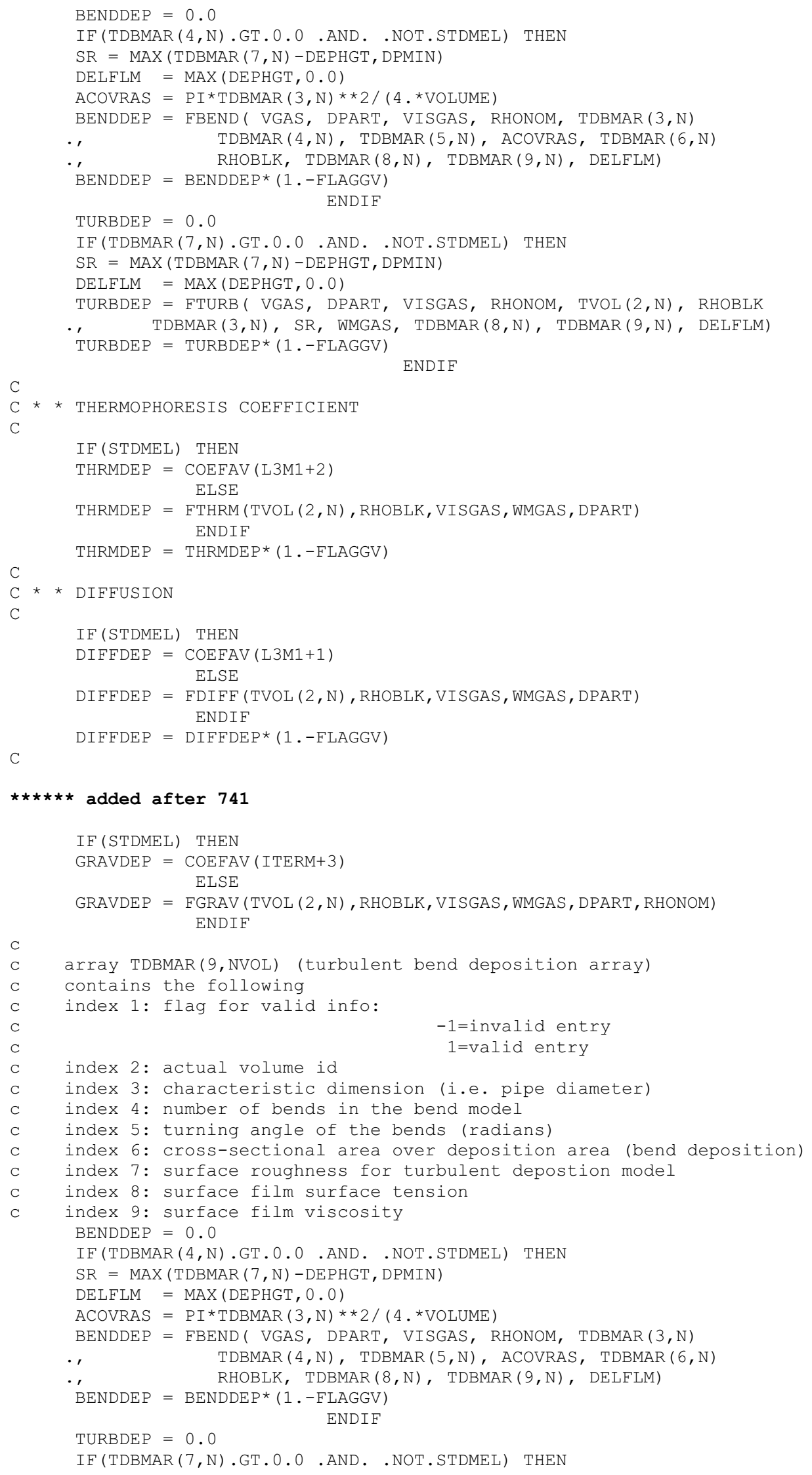

$\star \star \star \star \star \star$ added after 741

IF (STDMEL) THEN

GRAVDEP = COEFAV ( ITERM+3) ELSE

GRAVDEP $=$ FGRAV $($ TVOL $(2, N)$, RHOBLK, VISGAS, WMGAS, DPART, RHONOM $)$ ENDIF

$\mathrm{C}$

C array TDBMAR (9,NVOL) (turbulent bend deposition array)

C contains the following

c index 1: flag for valid info: 


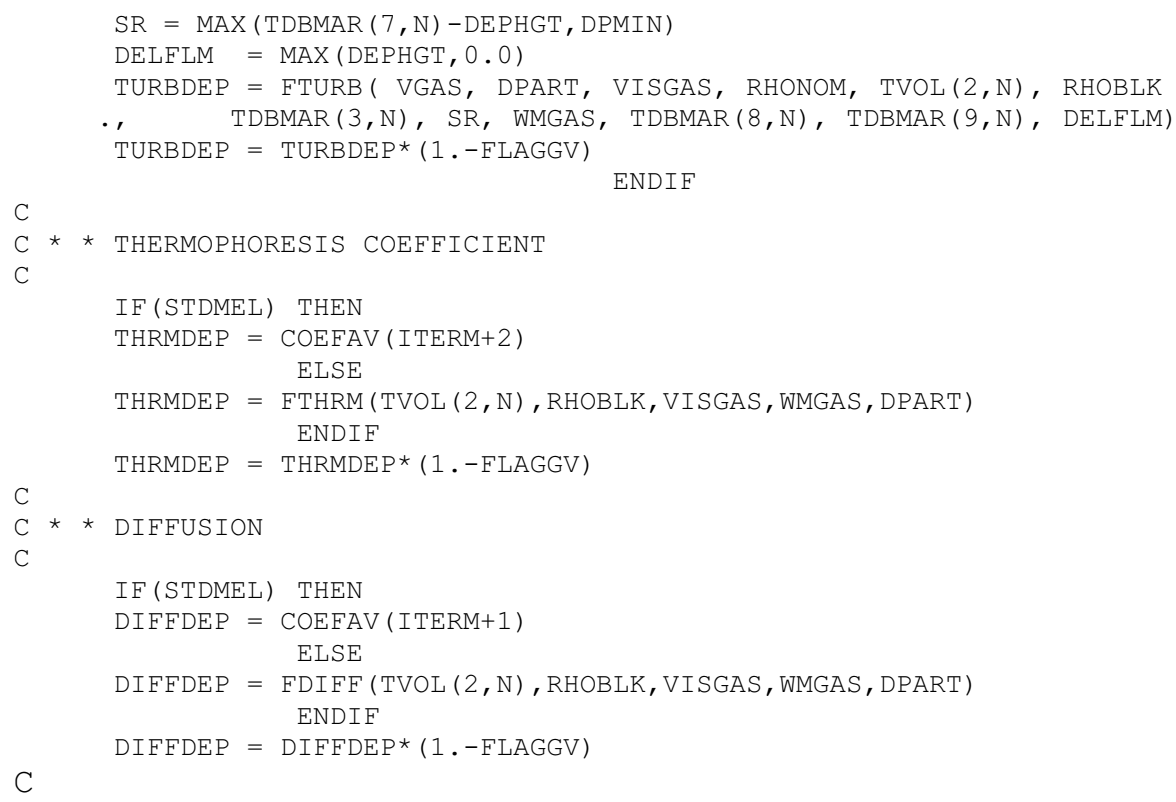




\section{Appendix D}

Code Listing for Air Condensation Model Modifications 


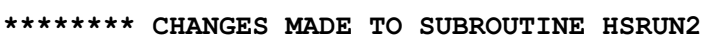

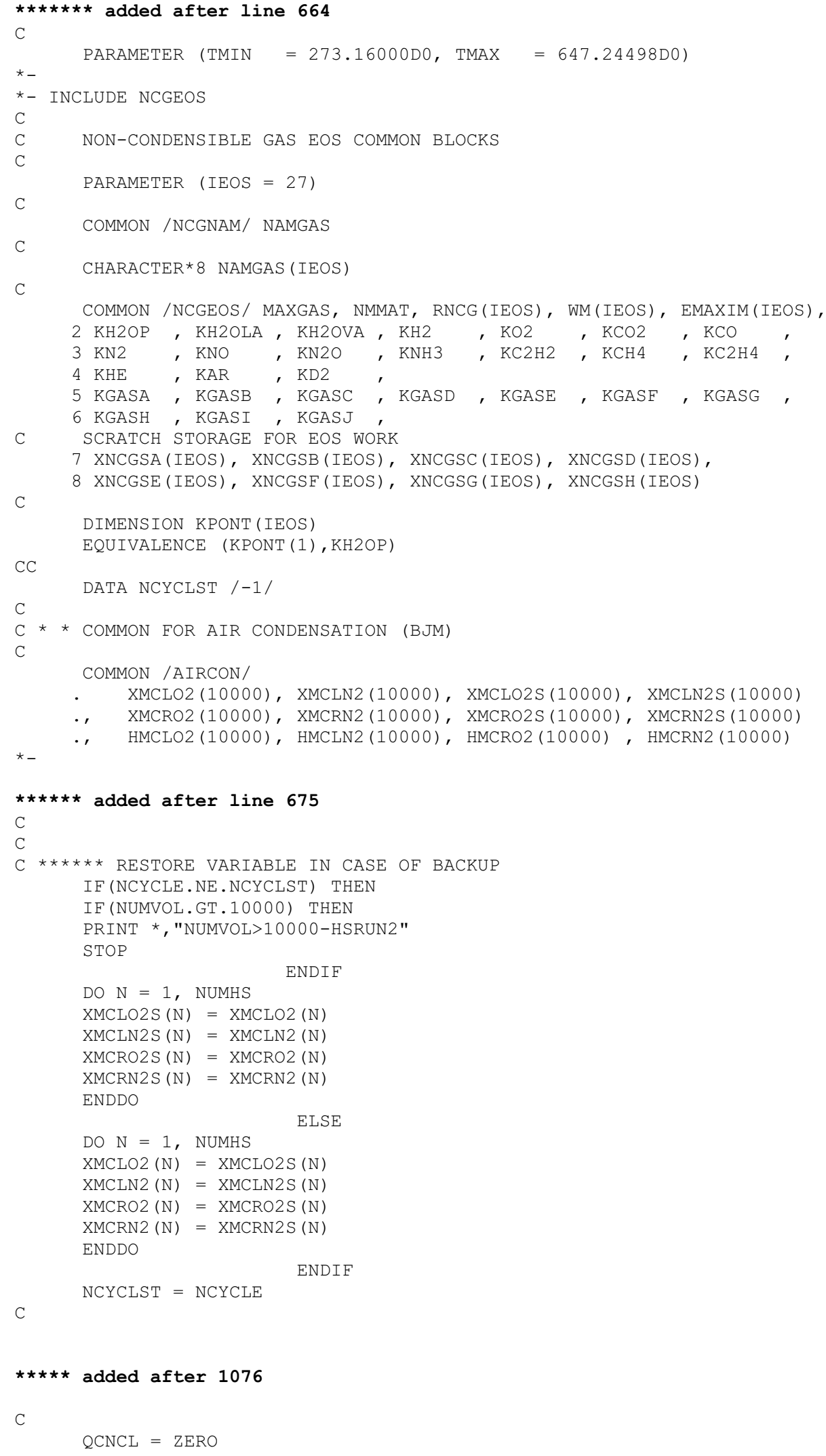


$\star \star \star \star \star$ changes to line 1099

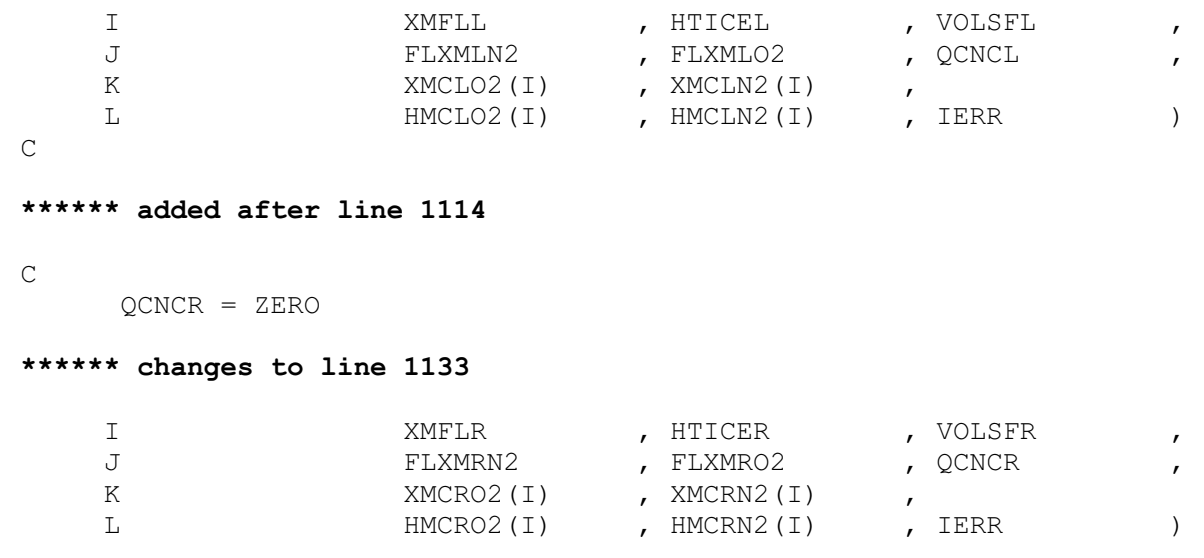

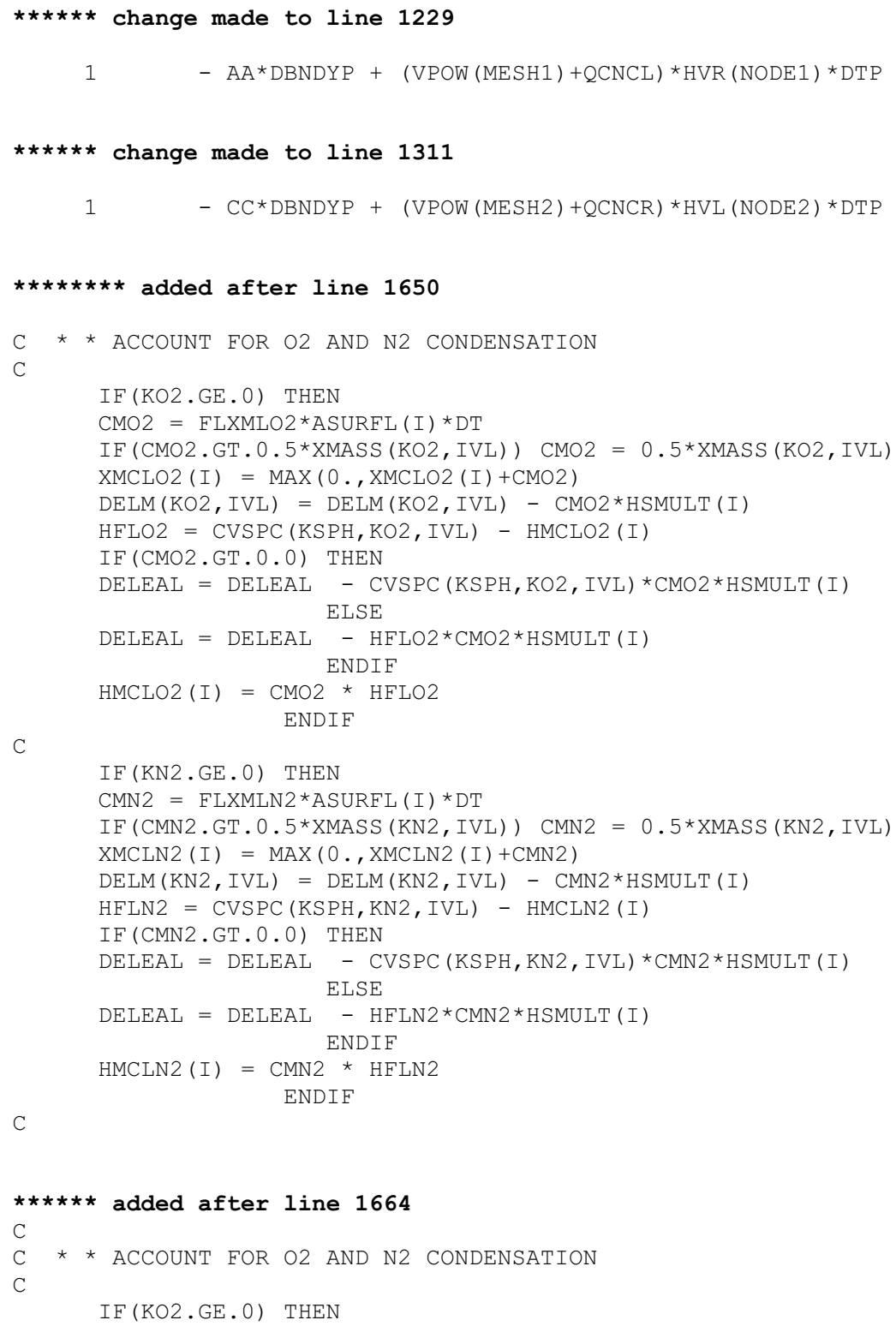




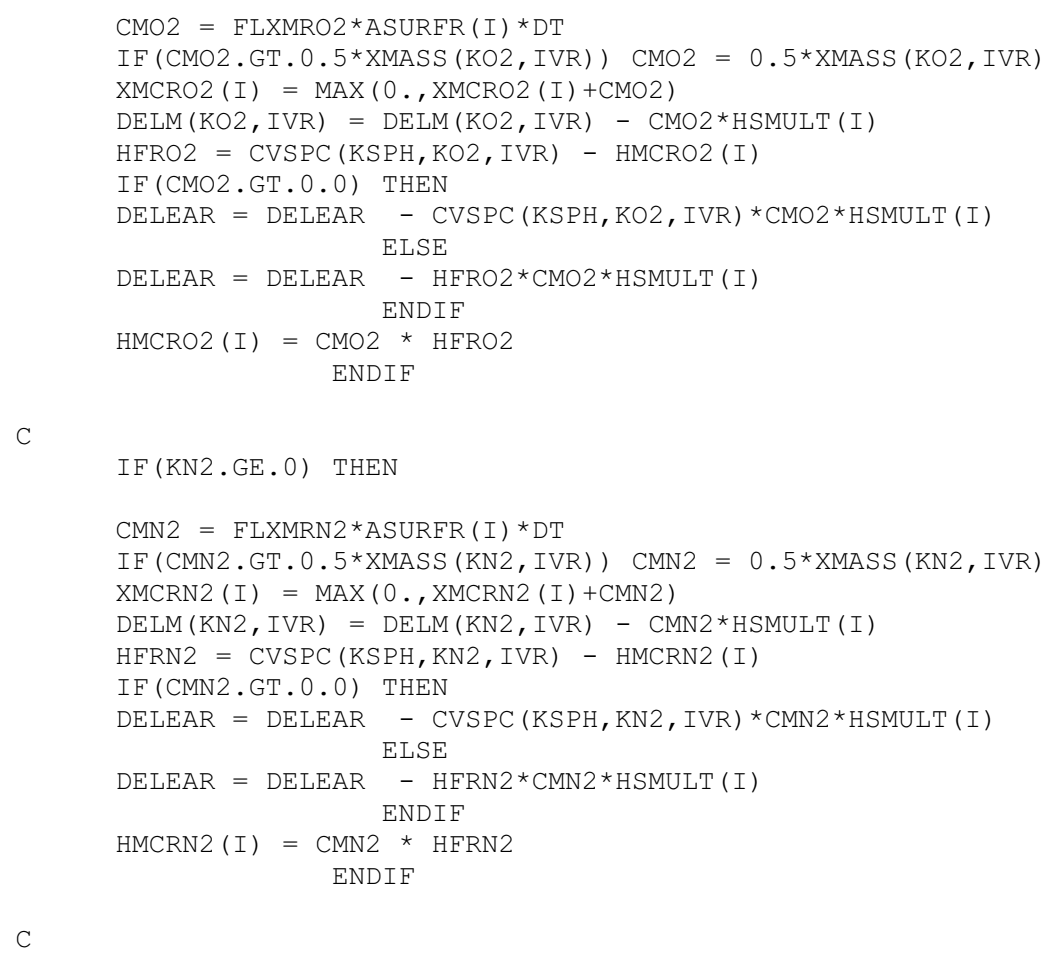

\section{$\star \star \star \star \star \star \star \star \star \star \star \star$ CHANGES TO SUBROUTINE HSTRAN}

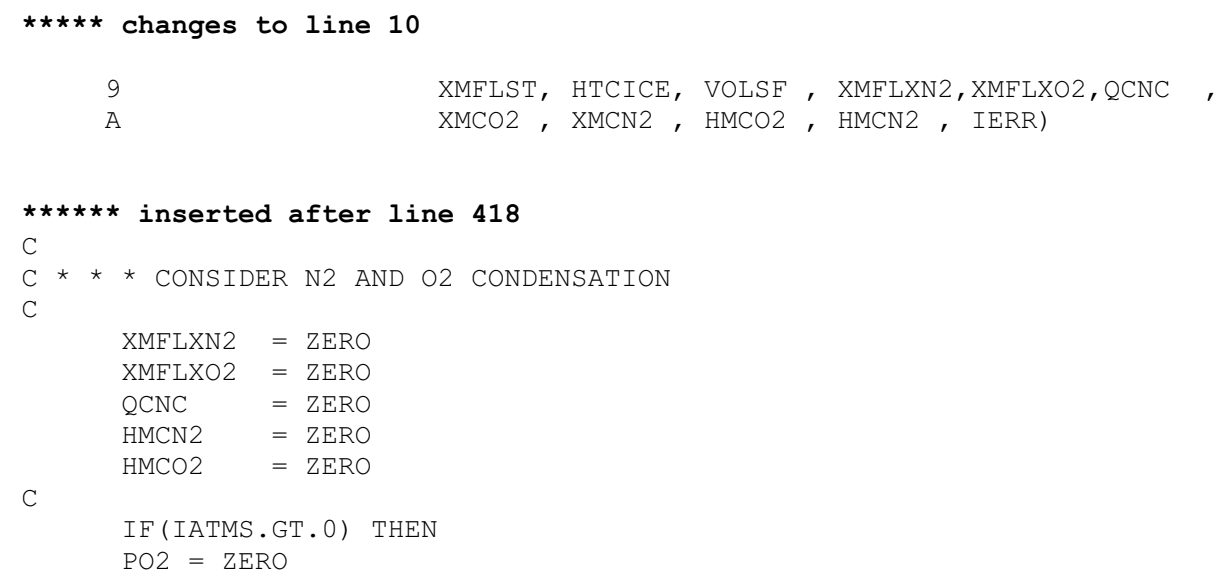




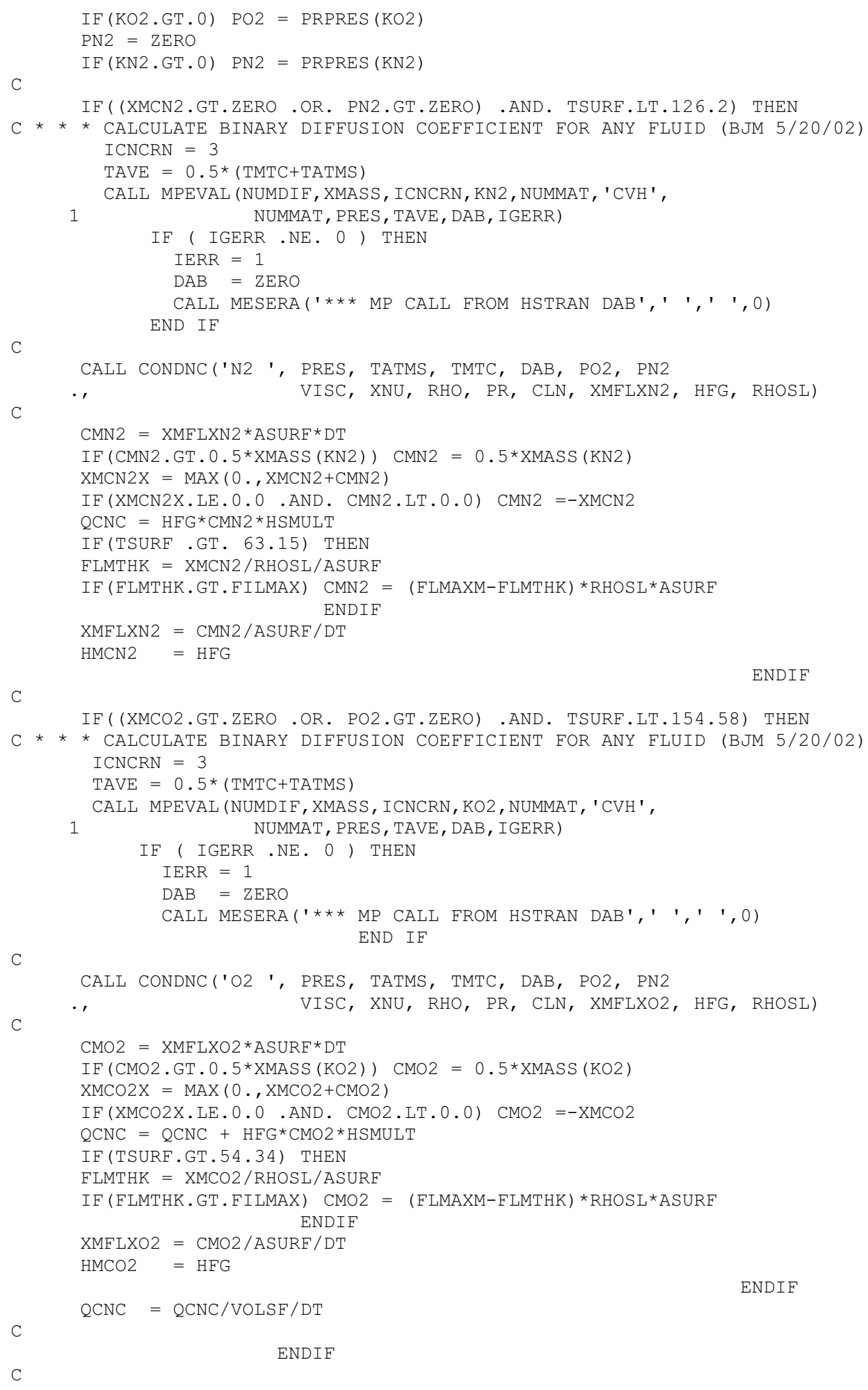




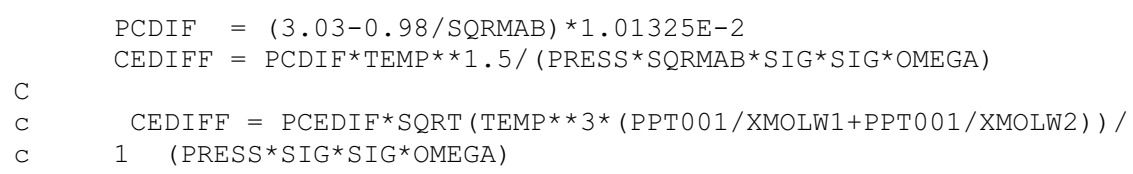

\section{$\star * \star * * * * * *$ CHANGES MADE TO MXXRS}

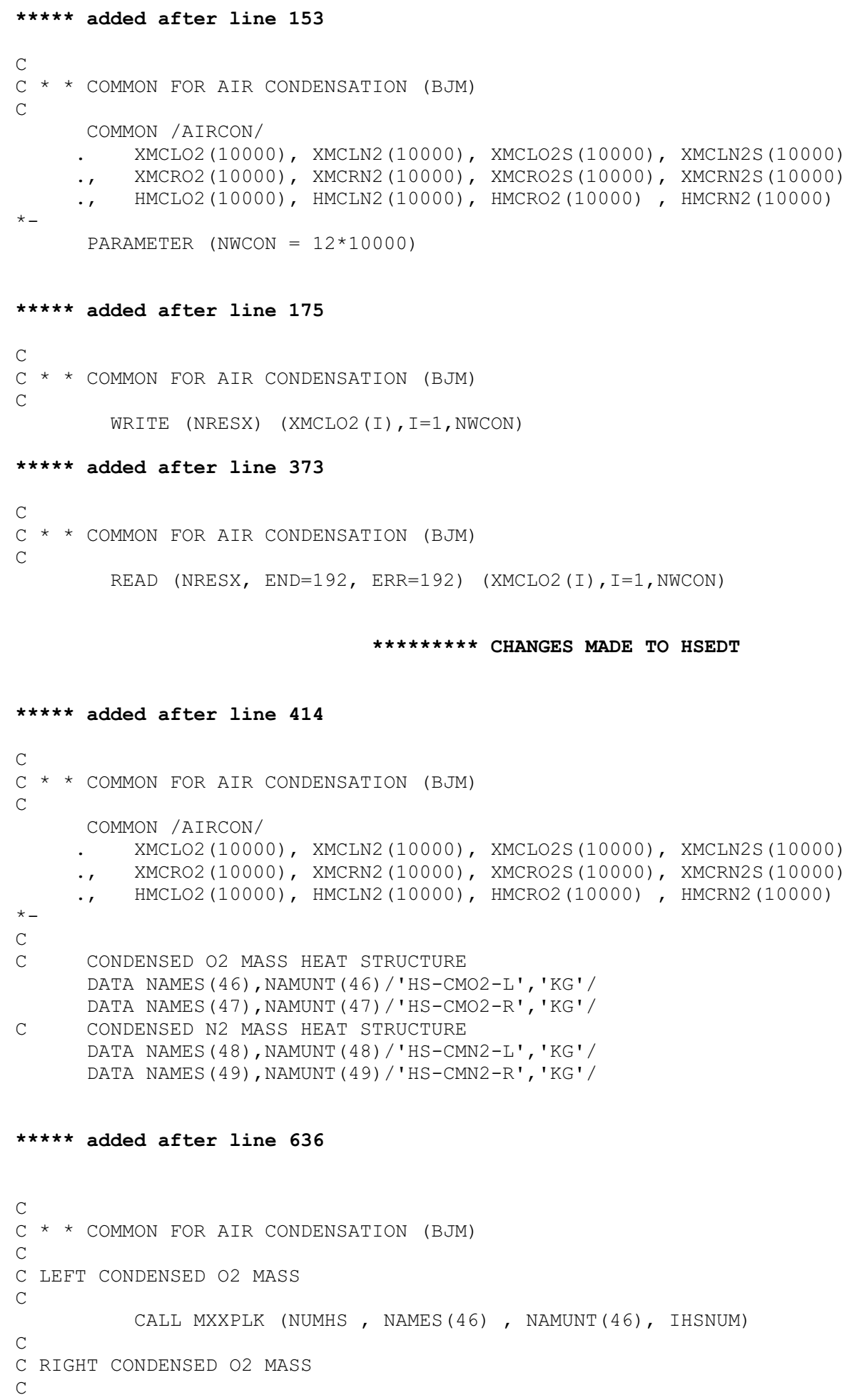


C

C LEFT CONDENSED N2 MASS

C

C

C RIGHT CONDENSED N2 MASS

C

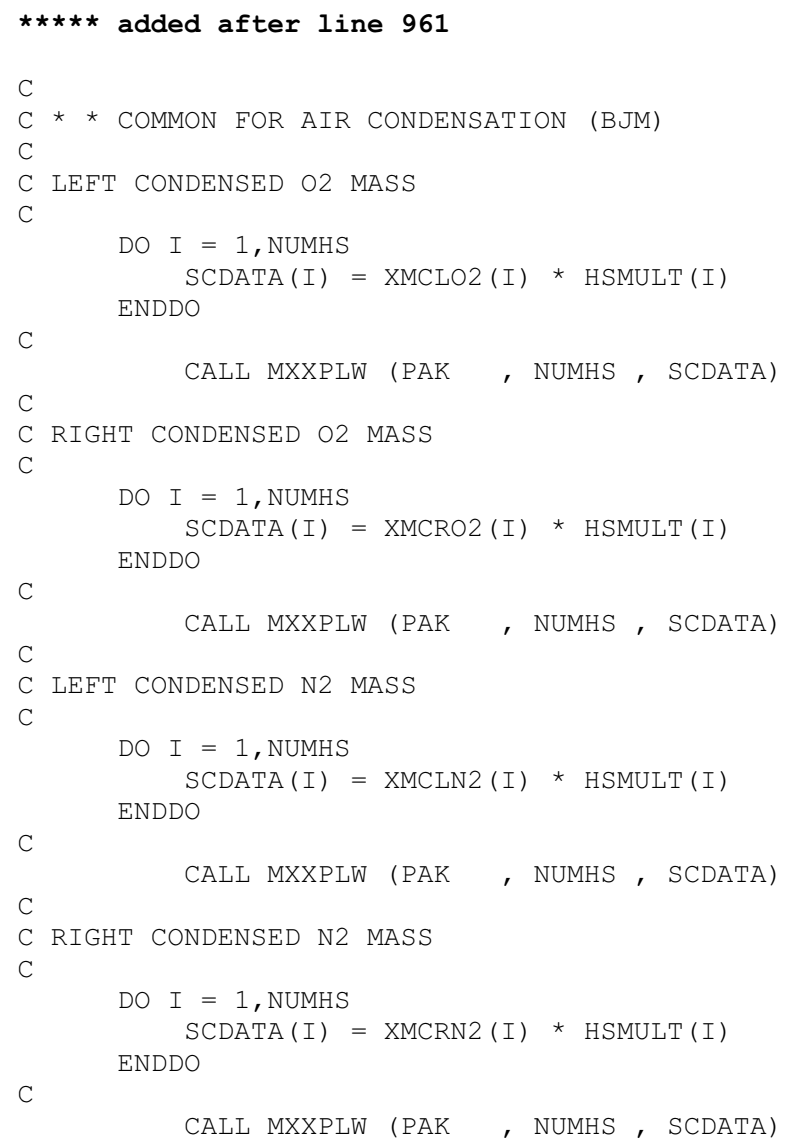




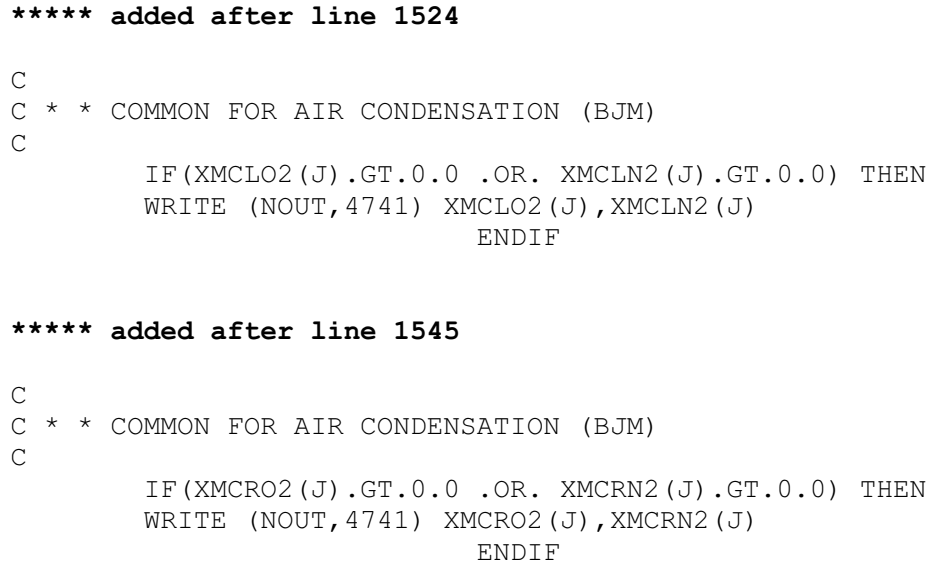

$\mathrm{C}$

C * * COMMON FOR AIR CONDENSATION (BJM)

C

IF (XMCRO2 (J).GT.0.0 .OR. XMCRN2 (J).GT.0.0) THEN

WRITE (NOUT, 4741) XMCRO2 (J), XMCRN2 (J) ENDIF

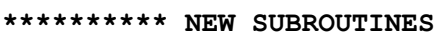

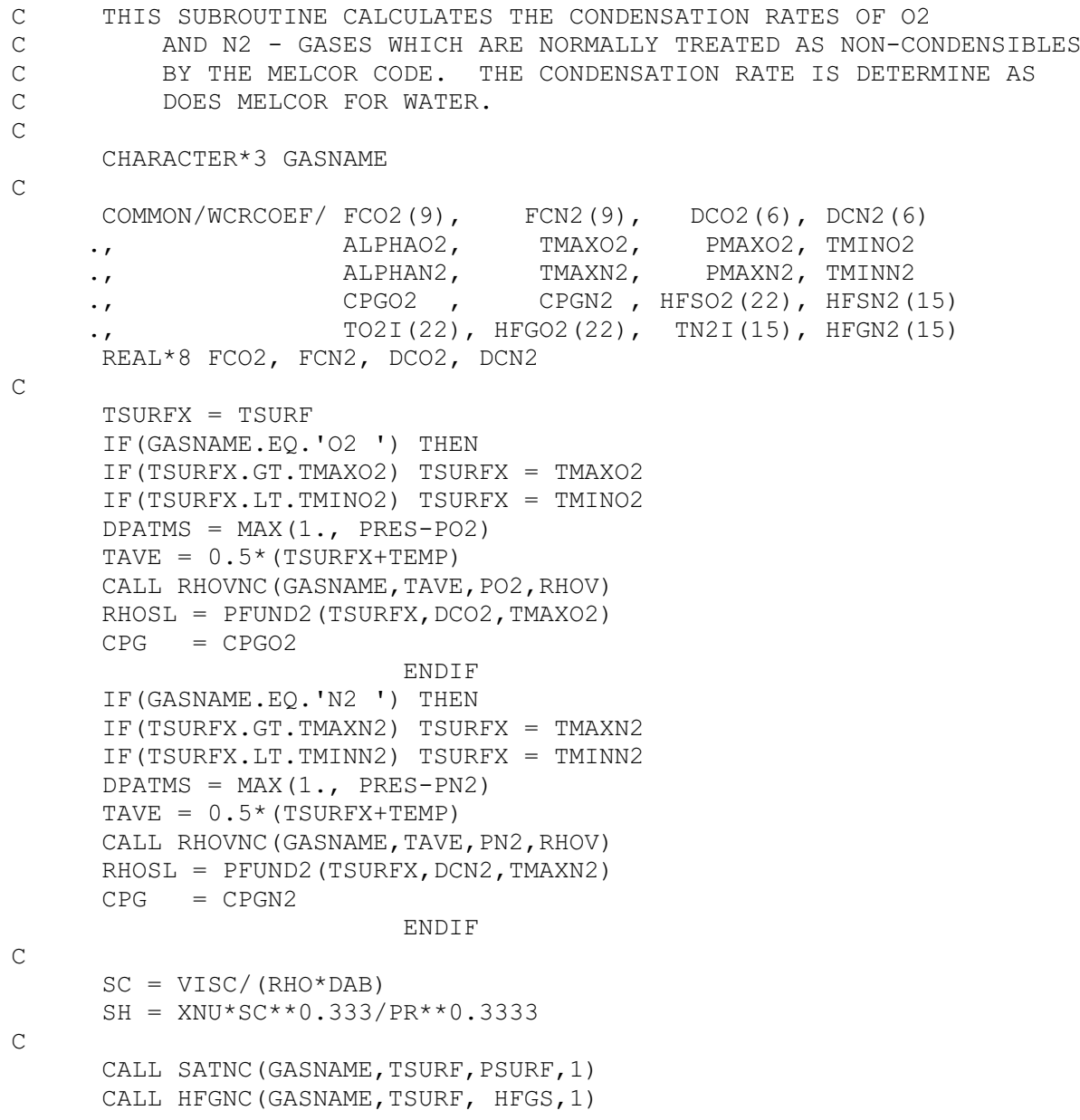


C

C

C

C

C

C

C

\begin{tabular}{|c|c|c|c|c|}
\hline COMMON/WCRCOEF/ & $\mathrm{FCO} 2(9)$, & FCN2 (9), & $\mathrm{DCO} 2(6)$, & $\operatorname{DCN} 2(6)$ \\
\hline . & ALPHAO2, & TMAXO2, & PMAXO2, & TMINO2 \\
\hline . & ALPHAN2, & TMAXN2, & PMAXN2, & TMINN2 \\
\hline . & $\mathrm{CPGO} 2$ & CPGN2 , & $\operatorname{HFSO} 2(22)$, & HFSN2 (15) \\
\hline$\cdot{ }^{\prime} \mathrm{REAL}^{\prime} \times 8 \quad \mathrm{FCO} 2$ & $\begin{array}{l}\text { TO2 I (22) } \\
\mathrm{N} 2, \mathrm{DCO},\end{array}$ & $\begin{array}{l}\text { HFGO2 (22), } \\
\text { DCN2 }\end{array}$ & TN2 I (15), & HFGN2 (15) \\
\hline
\end{tabular}

C

$C \star \star \star I M O D=1$

IF (IMOD.EQ.1) THEN

IF (GASNAME.EQ.'O2 ') THEN

IF(TSAT.LT.TO2I (1)) THEN

$\mathrm{HFG}=\mathrm{HFGO} 2(1) \star 1000$.

DO $I=2,22$

$\mathrm{IM} 1=\mathrm{I}-1$

FRAC $=($ TSAT-TO2I $($ IMI $)) /($ TO2I $(I)-T O 2 I(I M 1))$

IF (FRAC.GE.0.0 .AND. FRAC.LE.1.0) THEN

$\mathrm{HFG}=\left(\operatorname{HFGO} 2(\mathrm{IM} 1)+\operatorname{FRAC}^{*}(\operatorname{HFGO} 2(\mathrm{I})-\mathrm{HFGO} 2(\mathrm{IM} 1))\right) * 1000$.

RETURN

ENDDO

$\mathrm{HFG}=0$.

RETURN

C

IF (GASNAME.EQ.'N2 ') THEN

IF (TSAT.LT.TN2I (1)) THEN

$\mathrm{HFG}=\operatorname{HFGN} 2(1) * 1000$.

DO $I=2,15$

$\mathrm{IM} 1=\mathrm{I}-1$

FRAC $=($ TSAT - TN2I $($ IMI $)) /($ TN2I $(I)-T N 2 I(I M 1))$

IF (FRAC.GE.0.0 .AND. FRAC.LE.1.0) THEN

$\mathrm{HFG}=\left(\operatorname{HFGN} 2(\mathrm{IM} 1)+\mathrm{FRAC}^{*}(\operatorname{HFGN} 2(\mathrm{I})-\mathrm{HFGN} 2(\mathrm{IM} 1))\right) \star 1000$. RETURN

ENDDO

$\mathrm{HFG}=0$.

RETURN

$C * \star \star I M O D=2$

ELSE

$\operatorname{TSATP}=(1 .+\mathrm{BUMP}) *$ TSAT

TSATM $=(1 .-$ BUMP $) *$ TSAT

C

IF (GASNAME.EQ. 'O2' ') THEN

TSATP $=$ MIN $($ TSATP, TMAXO2)

TSATM $=$ MAX (TSATM, TMINO2)

PSATP $=$ PFUNS4 (TSATP, $\mathrm{FCO} 2$, ALPHAO2, TMAXO2)

PSATM $=$ PFUNS4 $($ TSATM, FCO2, ALPHAO2, TMAXO2)

DPDT $=($ PSATP-PSATM $) /($ TSATP-TSATM $)$

ENDIF

ENDIF

ENDIF

ENDIF 
C

RHOSL $=$ PFUND2 (TSAT, DCO2, TMAXO2)

ENDIF

IF (GASNAME.EQ. 'N2') THEN

TSATP $=$ MIN (TSATP, TMAXN2)

TSATM $=$ MAX (TSATM, TMINN2)

PSATP $=$ PFUNS4 (TSATP, FCN2, ALPHAN2, TMAXN2)

PSATM $=$ PFUNS4 (TSATM, FCN2, ALPHAN2, TMAXN2)

$\mathrm{DPDT}=($ PSATP-PSATM $) /($ TSATP-TSATM $)$

RHOSL $=$ PFUND2 (TSAT, DCN2, TMAXN2)

$\mathrm{PSAT}=0.5 *(\mathrm{PSATP}+\mathrm{PSATM})$

CALL RHOVNC (GASNAME, TSAT, PSAT, RHOSV)

$\mathrm{VFG}=\operatorname{MAX}(0 ., 1 . / \mathrm{RHOSV}-1 . / \mathrm{RHOSL})$

$\mathrm{HFG}=\mathrm{TSAT} * \mathrm{VFG} * \mathrm{DPDT}$

C ENDIF

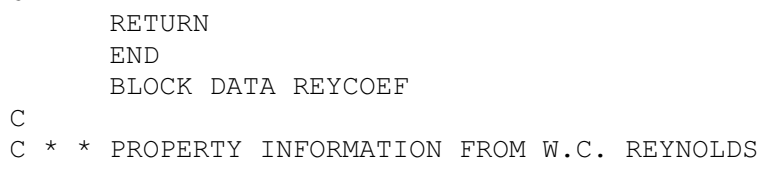


C

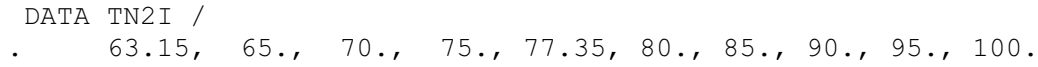


ENDIF

ENDIF

C

C

$\operatorname{EXTRP}=0.5$

DO $10 \mathrm{NLOOP}=1,100$

$\mathrm{TSATB}=1.0001 * \mathrm{TSAT}$

IF (GASNAME.EQ. 'O2') THEN

FNEW = PSAT - PFUNS4 (TSAT, FCO2, ALPHAO2, TMAXO2)

FNEWB $=$ PSAT - PFUNS4 (TSATB, FCO2, ALPHAO2, TMAXO2)

C ENDIF

IF (GASNAME.EQ. 'N2') THEN

FNEW = PSAT - PFUNS4 (TSAT, FCN2, ALPHAN2, TMAXN2)

FNEWB $=$ PSAT - PFUNS4 (TSATB, FCN2, ALPHAN2, TMAXN2) ENDIF

$\mathrm{DFDT}=(\mathrm{FNEWB}-\mathrm{FNEW}) /(\mathrm{TSATB}-\mathrm{TSAT})$

IF (DFDT.EQ.0.0) THEN

WRITE $(6, *)$ 'SATNC HAD ZERO DERATIVE'

STOP

$\mathrm{DELT}=-\mathrm{ENEW} / \mathrm{DFDT}$

$\mathrm{SIGNO}=\mathrm{SIGNN}$

$\operatorname{SIGNN}=\operatorname{SIGN}(1,, \mathrm{DELT})$

IF (NLOOP.GT.2.AND. SIGNO.NE.SIGNN) EXTRP $=0.5 * E X T R P$

IF (ABS (DELT) . GT.EXTRP*TSAT) DELT = EXTRP*TSAT*SIGN $(1 .$, DELT)

$\mathrm{TSAT}=\mathrm{TSAT}+\mathrm{DELT}$

IF (ABS (DELT/TSAT).LT.1.E-6) GO TO 20

10 CONTINUE

WRITE $(6, *)$ 'SATNC DID NOT CONVERGE ON TSAT'

STOP

20 CONTINUE

C

RETURN

END

SUBROUTINE RHOVNC (GASNAME, TEMP, PRES, RHOV)

$\mathrm{C}$

IDEAL GAS LAW ASSUMED FOR NON-CONDENSIBLE VAPOR DENSITIES

$\mathrm{REAL} * 4$ MWN2, MWO2

CHARACTER * 3 GASNAME

C

DATA MWO2 / 31.9994

DATA MWN2 / $28.0134 /$

DATA RGCON / 8314.34/

C

IF (GASNAME . EQ. 'O2' ) THEN

$\mathrm{RHOV}=\mathrm{MWO} 2 * \mathrm{PRES} /(\mathrm{RGCON} * \mathrm{TEMP})$

C

IF (GASNAME . EQ. 'N2') THEN

$\mathrm{RHOV}=\mathrm{MWN} 2{ }^{*} \mathrm{PRES} /\left(\mathrm{RGCON}{ }^{*} \mathrm{TEMP}\right)$

C

ENDIF

RETURN

END

C

FUNCTION PFUND2 (TEMP, DC, TCRIT)

DIMENSION DC $(*)$

$\mathrm{REAL} * 8 \quad \mathrm{DC}$

$\mathrm{RHO}=0$.

$\mathrm{CAPX}=1 .-\mathrm{TEMP} / \mathrm{TCRIT}$

C

DO $I=1,6$

$\mathrm{RHO}=\mathrm{RHO}+\mathrm{DC}(\mathrm{I}){ }^{*} \mathrm{CAPX} * *(\mathrm{FLOAT}(\mathrm{I}-1) / 3$.

ENDDO

C

PFUND2 $=$ RHO 
RETURN

END

DIMENSION FC (*)

$\mathrm{REAL} * 8 \quad \mathrm{FC}$

C

$\mathrm{XLNP}=\mathrm{FC}(1) / \mathrm{TEMP}+\mathrm{FC}(2)+\mathrm{FC}(3) * \mathrm{TEMP}$

$+F C(4) *(\operatorname{MAX}(0,$, TCRIT - TEMP $)) * *$ ALPHA

. $\quad+\mathrm{FC}(5) * \mathrm{TEMP}^{*} * 3+\mathrm{FC}(6) * \mathrm{TEMP}^{*} * 4+\mathrm{FC}(7) * \mathrm{TEMP}^{*} * 5$

C

$+\mathrm{FC}(8) * \mathrm{TEMP} * \star 6+\mathrm{FC}(9) * \mathrm{ALOG}(\mathrm{TEMP})$

C

PFUNS $4=\operatorname{EXP}(\mathrm{XLNP})$

RETURN

END 